\title{
Borehole Tool for the Comprehensive Char- acterization of Hydrate-Bearing Sediments
}

\author{
Final Scientific/ Technical Report
}

Project/ Reporting Period: 10/1/2013 to 9/30/2017

Date of Report Issuance: February 2018

DOE Award Number: DE-FE013961

\section{Principal Investigators / Submitting Organization}

\section{Sheng Dai}

Georgia Institute of Technology

DUNS \#: 097394084

Atlanta, GA 30332

+001-(404) 385 - 4757

sheng.dai@ce.gatech.edu
J. Carlos Santamarina

Formerly at Georgia Institute of Technology Now at King Abdullah University of Science and Technology +966-(0) 12 - 8087262

c a rlos.santa ma rina @ka ust.edu.sa

Prepared for:

United States Department of Energy

National Energy Technology Laboratory

Submission date: 12/30/2017

(2)

ENEDCY NATIONAL ENERGY

TECHNOLOGY LABORATORY

Office of Fossil Energy 


\section{DISCLAIMER:}

This report was prepared as an account of work sponsored by an agency of the United States Government. Neither the United States Government nor any agency thereof, nor any of their employees, makes any warranty, express or implied, or assumes any legal liability or responsibility for the accuracy, completeness, or usefulness of any information, apparatus, product, or process disclosed, or represents that its use would not infringe privately owned rights. Reference herein to any specific commercial product, process, or service by trade name, trademark, manufacturer, or otherwise does not necessarily constitute or imply its endorsement, recommendation, or favoring by the United States Government or any agency thereof. The views and opinions of authors expressed herein do not necessarily state or reflect those of the United States Government or any agency thereof. 


\section{Table of Contents}

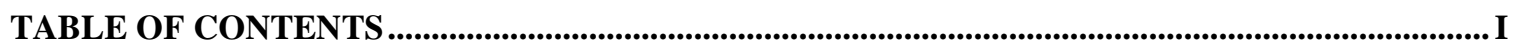

TABLE OF FIGURES ...............................................................................................................

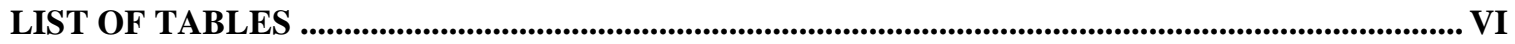

ABSTRACT …...................................................................................................................................................VII

EXECUTIVE SUMMARY ...........................................................................................................

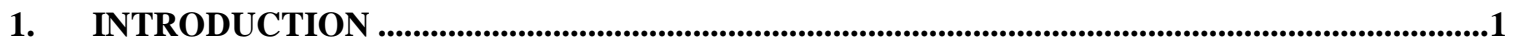

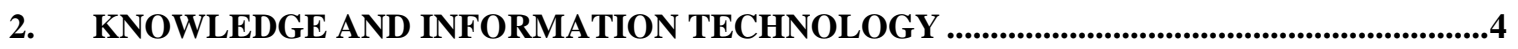

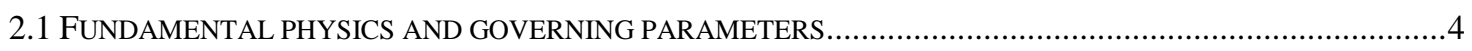

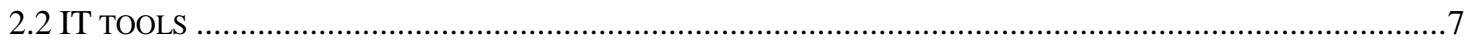

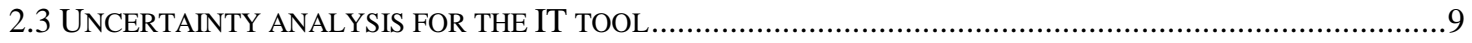

3. BOREHOLE TOOL DESIGN - BODY ..............................................................................................12

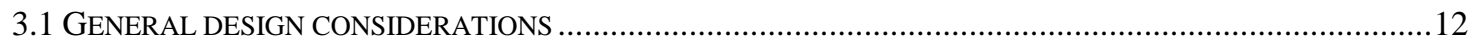

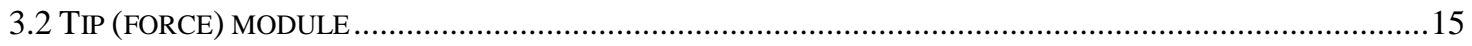

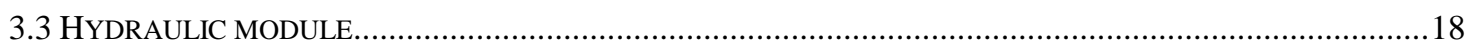

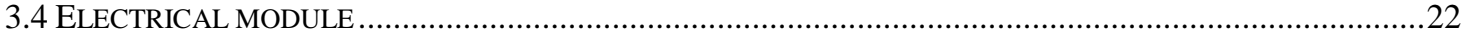

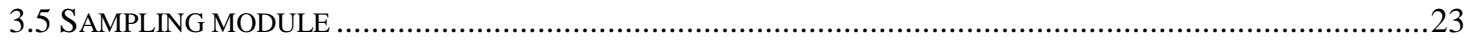

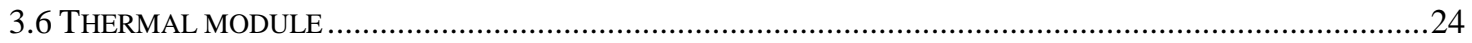

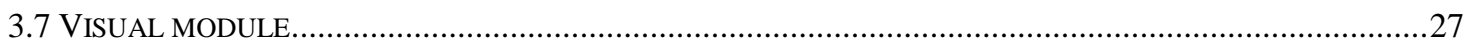

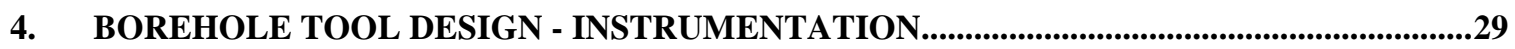

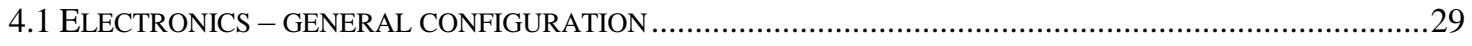

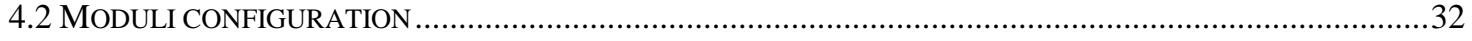

5. LABORATORY FULL-SCALE PROTOTYPE ASSESSMENT ...................................................33

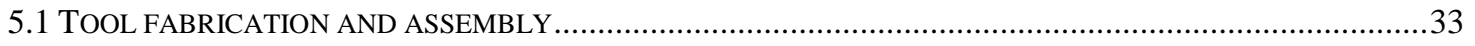

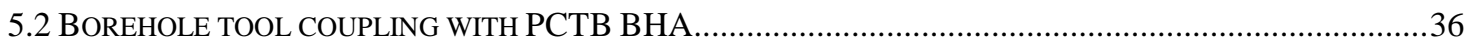

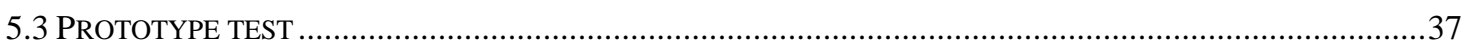

6. FIELD DEPLOYMENT .....................................................................................................................41

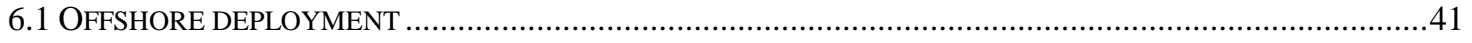

6.2 DEPLOYMENT RESULTS, ANALYSES, AND TOOL IMPROVEMENT ….....................................................

7. SUMMARY AND CONCLUSIONS .....................................................................................................49 


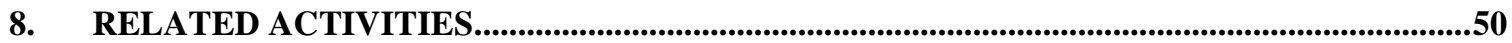

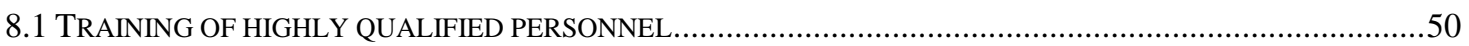

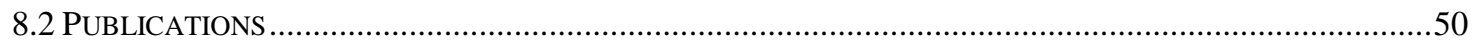

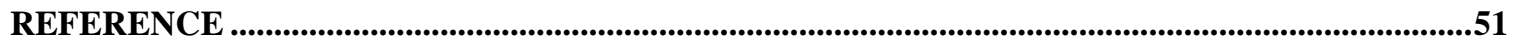




\section{Table of Figures}

Figure 2.1 Illustrations of sampling effects to hydrate-bearing sediments at pore scale [Dai and Santamarina, 2014]..

Figure 2.2 The structure of the IT tool developed to facilitate reliable selection of the physical properties for hydrate reservoir simulators.

Figure 2.3 Relationship among tables for general soil information, large-strain properties, small-strain properties, thermal properties, and hydraulic properties.

Figure 2.4 Predicted using the developed IT Tool versus measured strength of hydrate-bearing sediments. (a) Data from [Santamarina and Ruppel, 2008]; (b) Data from [Miyazaki et al., 2012].

Figure 2.5 Phase boundaries: (a) hydrate phase equilibrium in seawater; (b) freezing point of seawater........9

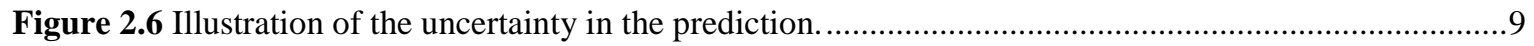

Figure 2.7 Permeability of hydrate-bearing sediments (relative to hydrate-free sediments) versus hydrate saturation. The model used here is $\log _{10} \mathrm{k}_{\mathrm{hbs}}=\operatorname{alog}_{10}\left(1-\mathrm{S}_{\mathrm{h}}\right)$........ . .10

Figure 2.8 Examples of uncertainty analysis for shear wave velocity. The error bar in this plot represents one standard error of the prediction. The model used here is from [Santamarina and Ruppel, 2008] and the data are from [Priest et al., 2009].

Figure 2.9 Examples of uncertainty analysis for shear strength. The model used here is from [Miyazaki et al., 2012] and data are from [Miyazaki et al., 2011].

Figure 2.10 Summary of uncertainty analysis for shear strength of hydrate-bearing sediments. The error bar in this plot represents one standard error of the prediction. The model used here is from [Miyazaki et al., 2012].

Figure 3.1 In-situ characterization tool: General view.

Figure 3.2 Overall mechanical design. (a) Maximum needed force. (b) Maximum tool length to satisfy buckling restrictions. (c) Tool longitudinal stress dependence between water pressure and undrained shear strength.

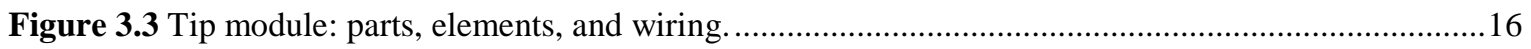

Figure 3.4 Tip module mechanical verification: Yield stress for SS316 is 200MPa...............................16

Figure 3.5 Tip module calibration. Measured pressure using strain gauges vs. chamber water pressure. .....17

Figure 3.6 Hydraulic dual-system components: (a) Hydraulic conductivity measurement system. (b) Miniproduction test...

Figure 3.7 Hydraulic conductivity measurement system. (a) Pressure and volume versus time. (b) Shape factor from numerical simulations. Note: $u_{o}$ is the reservoir water pressure and $p_{o}$ the initial water pressure in the container.

Figure 3.8 Hydraulic conductivity system verification. (a) Numerical model in COMSOL. (b) Comparison of the numerical model and the ideal spherical case. (c) Solution chart for a measured flow rate and water pressure change. 
Figure 3.9 Porous filter calibration: (a) Setup of the two types of control tests: flow control and pressure control-based test. (b) Results for the different porous filter. Lines represent results from numerical simulations and discrete points show measured values.

Figure 3.10 Complete hydraulic/fluid sampling test: (a) Setup. (b) Results for different porous filters. .......21

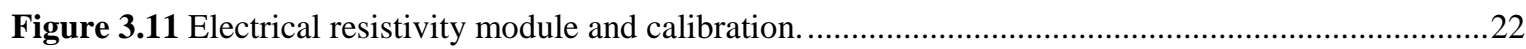

Figure 3.12 Impedance analyzer comparison test: Error respect to measured resistance..............................23

Figure 3.13 Sediment piston sampler. (a) Position in the tool. (b) Drawings. (c) Photographs. (d) Field test.

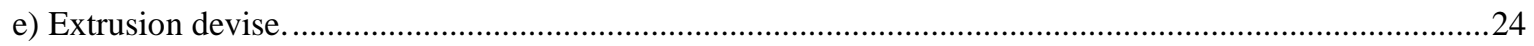

Figure 3.14 Strain gauge installation and configuration.............................................................................25

Figure 3.15 Tip module: temperature effect. (a) Thermocouples response time. (b) Strain gage response to

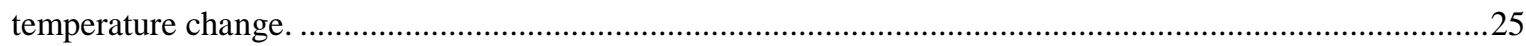

Figure 3.16 Left: Sensor calibration. Right: Impacts of the S-TPS probe configuration on measured thermal properties of the specimens. The $\mathrm{x}$-axis reflects the effusivity (density $\mathrm{x}$ thermal conductivity $\mathrm{x}$ thermal diffusivity) ratio between the thermal probe and the tested specimen; the y-axis reflects the thermal flux ratio between the probe and the tested specimen. Scenarios of different duration of current injection have also been considered (from 10s to 200s) in order to identify optimum measurement duration..............................26

Figure 3.17 Video module. The visor consists of a high-pressure window...............................................27

Figure 3.18 Video capability prototype test. Image analysis of typical grain compares well with sieving analysis in coarse grains. Sphericity = area of particle projection/area of the circle with diameter equal to the longest length of the projection. Roundness= average radius of curvature of surface features/radius of the

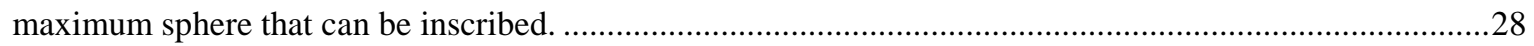

Figure 4.1 Data storage unit: Arduino UNO (arduino.cc)............................................................................29

Figure 4.2 Data storage unit: Resolution (a) Thermocouples. (b) Strain gauge. (c) Standard load cell. (d)

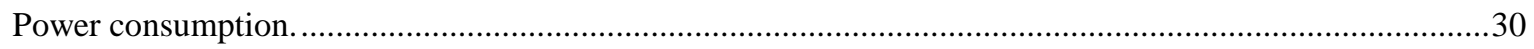

Figure 4.3 Electronics: Enhanced resolution attained with the new board, microprocessor and circuitry.....30

Figure 4.4 Electronics: new PCB configuration. . .31

Figure 4.5 Latest version of electronics configuration (updated after field deployment). Arduino Mega with peripheral data amplifiers. .31

Figure 4.6 Details of the components and circuitry design of each testing module. 32

Figure 5.1 The detailed dimension of the tool body (to house electronics, valves, cables, and memory disks).

Figure 5.2 The detailed dimension of the testing module. The length of each testing module varies from $0.15 \mathrm{~m}$ to $1 \mathrm{~m}$ depending on the nature of the measurement properties and methods.

Figure 5.3 The detailed dimension of the tip (force) module. (a) The inner stem of the force module to house strain-gauges for strength measurement and two thermocouples for temperature measurement. (b) The tip of the force module for penetrating into hydrate formations and pore water sampling. Note that the force module has identical end connection as that in the testing modules. ............................................................34

Figure 5.4 The detailed dimension of the bottom cap to couple the testing modules with the main body.....35 
Figure 5.5 Major machined pieces of the borehole tool.

Figure 5.6 Sensors and peripheral components housed within the tool body..........................................35

Figure 5.7 Overall dimension of the assembly borehole tool...............................................................36

Figure 5.8 Left: machined testing modules and the tip module. Right: assembled borehole tool. The body houses the peripheral components of the tool including the piping, pressure transducers, fluid samplers,

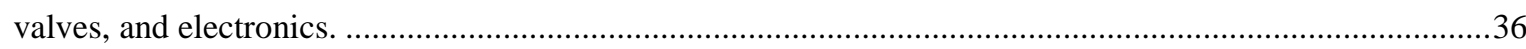

Figure 5.9 Coupler design. (a) Illustration of the borehole tool in run in and collet release status with PCTB BHA. (b) Major parts and assembly the CDS-type coupler of the tool with PCTB BHA. .37

Figure 5.10 Core recovery with small sampler - Field study: (a) Continuous push schematics. (b) Dynamic driving. (c) The picture at the site. (d) Samplers dimensions.

Figure 5.11 Core recovery with the small sampler. (a) Sampled length (distance measured before removing the sampler from the ground). (b) Penetration force vs. depth. There is no clear evidence of significant differences between the two samplers. .39

Figure 5.12 High pressure vessel and pressure test. 40

Figure 5.13 High-pressure vessel testing - sensor readings. (a) Pressure transducers location. (b) Pressure transducers readings showing the three tool insertions. (c) Temperature readings at the tip. (d) Accelerations for the three principal directions. (e) Assembly of electronics in the rack ready to be connected and inserted into the tool body.

Figure 6.1 Test site of the tool field deployment: $12 \mathrm{~km}$ offshore KAUST.

Figure 6.2 General schematics of the tool assembly and the dimensions.

Figure 6.3 Key steps of the tool deployment. Left $-1^{\text {st }}$ tool deployment: (a) Tool waiting to be coupled. (b) Lifting and approach to the water. (c) Decoupling to the hoist. (d) Lowering the tool to start the test. (e) Retrieving the tool. Right $-2^{\text {nd }}$ tool deployment: (a) Research Vessel Thuwal R/V. (b) Departing from KAUST. (c) Tool ready to be lowered. (d) Tool recovery. . .42

Figure 6.4 Measured water pressure and the 3-axis accelerator data during the two deployments. 43

Figure 6.5 Penetration resistance obtained from the tool deployment.

Figure 6.6 COMSOL numerical simulation of inverse sediments thermal properties. Dimensions of this model are shown here along with the initial conditions (i.e., tool at $33.75^{\circ} \mathrm{C}$ and sediment temperature at $30.5^{\circ} \mathrm{C}$ ) and the thermocouple location. .45

Figure 6.7 Thermal diffusivity of the Red Sea sediments on the selected test site. Blue and green dots represent the measured values, while the continuous lines are results of COMSOL simulations for this particular case with differently assumed diffusivities.

Figure 6.8 Hydraulic conductivity test. (a) Water volume in the container during sampling. (b) Numerical simulation on COMSOL. (c) Data interpretation. . .47

Figure 6.9 Soil samplers and soil catchers tested during the offshore field deployments. . .48

Figure 6.10 Grain size distribution of collected soil samples. The inset image shows the microscopic photo of collected sandy sediments. The particles are angular with mean grain size $\mathrm{d}_{50}=\sim 0.15 \mathrm{~mm}$ in accordance with the grain size distribution. .48 


\section{List of Tables}

Table 2.1 Critical parameters for hydrate-bearing sediments characterization and gas production simulation. .5

Table 2.2 Fundamental physical processes in hydrate-bearing sediments......................................................6

Table 3.1 Key physical properties of hydrate-bearing sediments and the corresponding capabilities of the

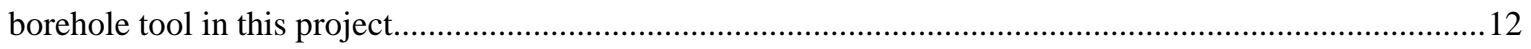

Table 3.2 Offshore CPT development (updated from [Lunne, 2012])........................................................13 


\begin{abstract}
Reservoir characterization and simulation require reliable parameters to anticipate hydrate deposits responses and production rates. The acquisition of the required fundamental properties currently relies on wireline logging, pressure core testing, and/or laboratory observations of synthesized specimens, which are challenged by testing capabilities and innate sampling disturbances. The project reviews hydrate-bearing sediments, properties, and inherent sampling effects, albeit lessen with the developments in pressure core technology, in order to develop robust correlations with index parameters. The resulting information is incorporated into a tool for optimal field characterization and parameter selection with uncertainty analyses. Ultimately, the project develops a borehole tool for the comprehensive characterization of hydrate-bearing sediments at in situ, with the design recognizing past developments and characterization experience and benefited from the inspiration of nature and sensor miniaturization.
\end{abstract}




\section{Executive Summary}

The project goal is to conduct a review of hydrate-bearing sediment properties and the inherent effects of in situ sampling for the purpose of designing, developing and fieldtesting a new borehole tool to comprehensively characterize hydrate-bearing sediment in situ. This project has reviewed and updated the database of the fundamental physical properties of hydrate-bearing sediment in order to develop robust correlations with index parameters. A corresponding IT tool has been developed with incorporated information from the database to allow parameter optimization with uncertainty analyses for field characterization and simulation. The electronics and instrumentation of the comprehensive borehole tool developed in this project have acknowledged the above information and previous designs and characterization experience. The tool can acquire multiple fundamental properties of hydrate-bearing sediments at in situ while avoiding the inherent difficulties and biases in sampling the sediments. The prototype of the tool has been constructed in full-scale and tested in both laboratory and the field.

The project reflects a convergence of multiple favorable conditions including sensor miniaturization, the availability of extensive data gathered from multiple laboratory and field studies, and past experience in characterizing hydrate-bearing sediments. The project has profound impacts in many fields including direct measurement of sediment properties in situ to avoid sampling disturbance, the most comprehensive site characterization tool for characterizing hydrate-bearing sediments, the ability to robustly and reliably determine sample characteristics in situ complemented with pre-existing knowledge and postsampling laboratory characterization, and a characterization tool and approach designed to provide information needed for reservoir simulations and analysis tools used for resource recovery, seafloor stability studies, and environmental evaluations. Such information plays a critical role in the design of strategies for resource recovery, seafloor instability analyses, and environmental studies. 


\section{Introduction}

Earlier research on gas hydrate focused on the properties of the hydrate crystals [Sloan and Koh, 2008], studies during the last decade have increasingly explored hydrate formation in both marine and permafrost sediments, their properties, and production strategies [Moridis et al., 2011; Waite et al., 2009]. Reservoir simulation requires reliable material parameters to anticipate reservoir responses and production rates. Hydrate saturation governs initial properties and gas recovery; strength and stiffness before and after dissociation determine the deformation field and stability conditions; liquid and gas permeability and their variation with saturation define flow rates, and heat capacity and conduction limit dissociation. This information currently relies on wireline logging, pressure core testing, and/or laboratory observations of synthesized specimens.

Logging while drilling (LWD) and measure while drilling (MWD) provide valuable information, but material properties required for analysis and design are inferred through correlations. Coring permits direct measurement of properties but faces pronounced challenges due to sampling disturbance followed by inherent difficulties with core handling and testing under pressure/temperature stability conditions. Inherent sampling disturbance presents the greatest challenge to geo-analyses and engineering production strategies. Drilling, wall shear, core recovery, specimen extrusion from the sampler, and trimming and insertion into test chambers are destructive to sediment fabric and have a pronounced effect on all types of sediments. The presence of hydrates aggravates sampling effects (even when pressure core technology is used) due to pressure- and temperature-dependent hydrate dissolution and dissociation and time-dependent hydrate relaxation. Synthesized specimens in the laboratory are often not representative as those formed in nature in terms of sediment types and hydrate pore habits, cannot capture the complexities in situ, and often suffers from scales effects. A new borehole tool for characterizing hydrate-bearing sediments in situ will help researchers avoid the inherent difficulties and biases in the abovementioned methods to characterize hydrate-bearing sediments.

The characterization of marine sediments at great depths increased noticeably in the last 50 years [Lunne et al., 2011]. Logging data are used to estimate hydrate saturation and formation characteristics [Sun et al., 2011]. LWD and MWD provide data such as small strain $\mathrm{S}$ and $\mathrm{P}$ velocities, gamma density, resistivity, imaging (acoustic, electrical scanning), nuclear magnetic resonance. Various correlation equations are invoked to infer porosity and hydrate saturation, and even fluid conductivity from these data [Collett et al., 2012; Lee and Collett, 2011]. Large strain mechanical parameters needed for reservoir simulators can be obtained in-situ using penetration testing. Penetrometers are deployed from the seabed or ahead of the borehole. The penetration depth is limited by either me- 
chanical/geometrical factors or by the reaction force that can be mobilized. Seabed operations can involve a submersible rig (e.g., MeBo, IFREMER, PROD, Searobin, Geoceptor, DeepCPT); difficulties associated with automated rod assembly (e.g., Gregg Drilling and Testing device) were addressed using the coiled rod (IFREMER's rig and NeptunDATEM - can be extended 30m or more into the sediment). ROV based operations are typically limited to the upper few centimeters of the sediment column (e.g., Cherokee www.marum.de, Quest and Move - used for fluid sampling, turbidity, net and scoop catcher, temperature monitor, sonar or biochemical processes). Free-fall cones can be used to measure penetration resistance, heat generation and dissipation, and pressure diffusion (e.g., FFCPT or FF-CPTU, www.marum.de;[Steiner et al., 2012]). Data interpretation requires proper integration of depth-dependent insertion conditions, and penetration depth is typically limited to the upper few meters of the sediment column. On-shore and off-shore penetrometers have been instrumented to perform multiple measurements, such as penetration resistance, electrical resistivity, nuclear density, S-wave detection, transverse stress measurement [Jefferies et al., 1987] and visual grain size analysis [Raschke and Hryciw, 1997]. However, the parameters most frequently used are tip resistance, sleeve resistance, and water pressure.

The cone-shaped CPT is the most common tip geometry. Other geometries offer advantages for mechanical analysis and data interpretation. Besides the vane shear (e.g., Halibut - Fugro), the ball and the T-bar are "full flow" penetrometers and can be used to conduct cyclic penetration tests to measure the initial undrained shear strength and the degraded strength in remolded sediment [Lunne et al., 2011; Randolph and Gourvenec, 2011]. Penetrometers involve high shear strain rates and can lead to values significantly higher than strengths that can be mobilized at very small strains. Available sidewall tools are designed to recover specimens from consolidated sediments using either rotary motion or percussion or to conduct fluid sampling.

This research project is founded on three fundamental bases: (1) in-depth understanding of hydrate-bearing sediments and associated characterization challenges, (2) recognition of key properties needed for analyses and reservoir simulation, and (3) an acute awareness that the potential of in situ characterization is maximized when all available information is utilized to constrain the unknowns and to optimize the testing strategy. Detailed research efforts have been placed on:

- fundamental understanding of sampling effects, physical properties, and critical parameters for characterizing hydrate-bearing sediments

- mechanisms of testing including methodologies, sensors, and data reduction and enhanced interpretation 
- tool optimization and miniaturization

- laboratory and field deployment

Salient findings are presented in the following sections. 


\section{Knowledge and information technology}

\subsection{Fundamental physics and governing parameters}

The presence of hydrates aggravates sampling effects (even when pressure core technology is used) due to pressure and temperature dependent hydrate dissolution and dissociation, and time-dependent hydrate relaxation (Figure 1.1).

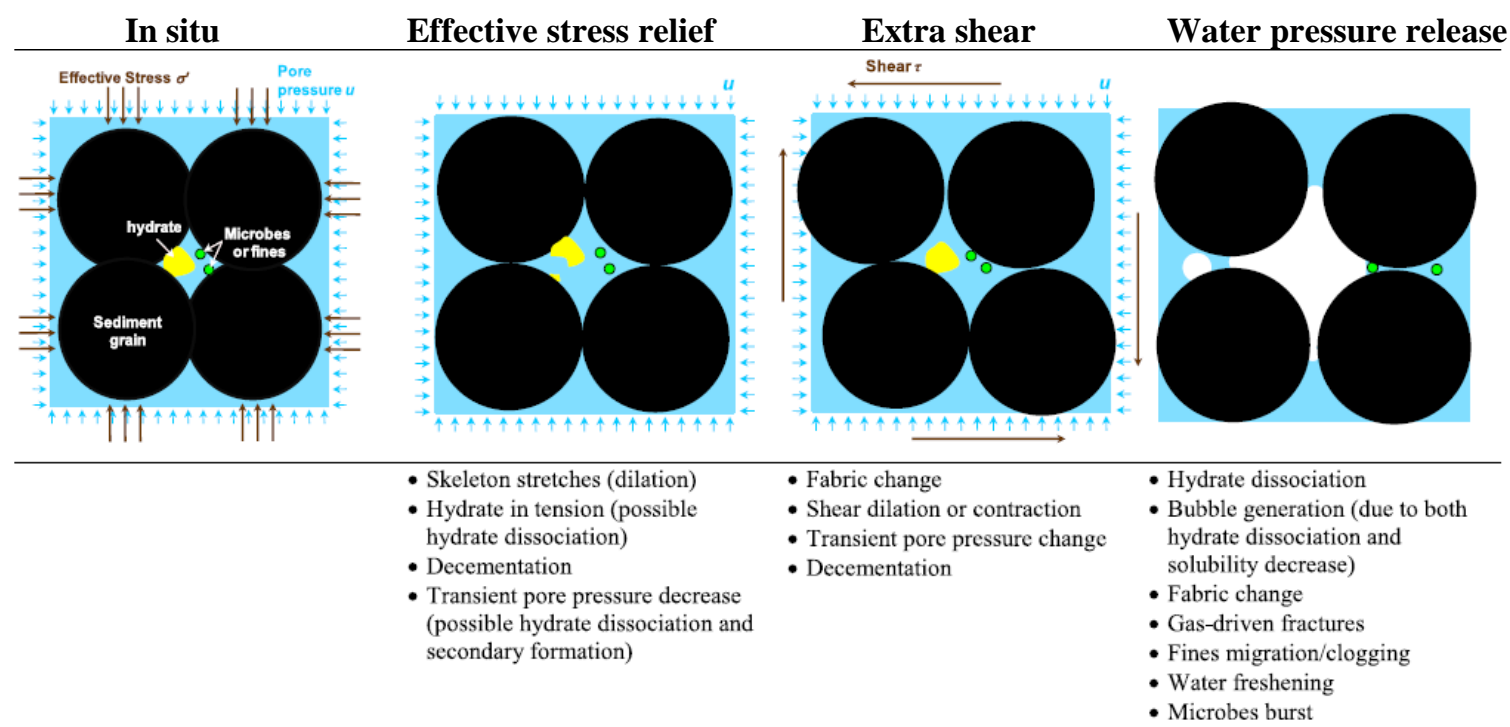

Figure 2.1 Illustrations of sampling effects to hydrate-bearing sediments at pore scale [Dai and Santamarina, 2014].

Compared to the hydrate-bearing sediment in situ, if the effective stress is removed while preserving PT conditions (i.e., pressure coring), the skeleton dilates, the connecting hydrate is placed in tension, there are partial de-cementation and stiffness loss, and the transient pore pressure drop due to skeletal dilation may cause hydrate dissociation followed by secondary formation. Note that this is the particle scale explanation of the equivalent continuum Mandel-Cryer effect. Hydrate creep following stress relaxation affects pressure cores as well. Fast drilling and extraction procedures lead to more intense tensile fractures in hydrate bridges, and thus slow unloading followed by recompression is preferred.

If in addition, the pore fluid pressure is decreased, hydrate dissociates, gas will tend to expand against capillarity ( 170 times the volume of hydrate), capillary forces massively destructure the sediment fabric, gas-driven fractures develop throughout the sediment, fines migrate, and microbes may burst.

Current pressure core technology allows the coring, transfer, subsample, and testing of 
natural hydrate-bearing sediments all under in situ pressure without dissociating the hydrate. Post-sampling characterization is conducted inside pressure chambers using noninvasive methods including gamma density, stiffness, permeability, X-rays and 3D X-ray $\mathrm{CT}$, and destructive methods including strength, stress-strain response, compressibility, biological activity, volumetric changes upon dissociation, and mini-production tests [Dai et al., 2017; Santamarina et al., 2012; Schultheiss et al., 2006; Yoneda et al., 2013].

Table 2.1 identifies the most critical parameters needed to estimate the gas extraction potential [Lee and Collett, 2011; Moridis et al., 2011; Waite et al., 2009].

Table 2.1 Critical parameters for hydrate-bearing sediments characterization and gas production simulation.

\begin{tabular}{l|l}
\hline & In-situ temperature - pressure \\
& In-situ stresses \\
Porosity - Hydrate saturation \\
Index Properties and Reservoir & Grain size distribution - Fines content, mineralogy \\
Characteristics & Stratigraphy / hydrate morphology \\
& Formation history \\
& Salinity \\
& Pore water geochemistry \\
\hline \multirow{2}{*}{ Thermal Properties } & Thermal conductivity \\
& Specific heat and latent heat \\
\hline \multirow{3}{*}{ Hydraulic Properties } & Water retention curve - Relative k \\
& Hydraulic conductivity \\
& Potential migration pathways \\
\hline \multirow{3}{*}{ Mechanical Properties } & Lateral stress coefficient \\
& Soil Stiffness: shear and bulk stiffness \\
& Strength \\
& Stress-dependent dilatancy \\
& Compressibility upon dissociation \\
\hline
\end{tabular}

Most of the fundamental properties of hydrate-bearing sediments are affected by not only the volume fraction (i.e., hydrate saturation) but also the pore habits of hydrate in sediments. The underlying physics of how hydrate affects some of the physical properties are summarized in Table 2.2. 
Table 2.2 Fundamental physical processes in hydrate-bearing sediments

\begin{tabular}{|c|c|c|c|c|c|}
\hline & Stiffness & Strength & Electrical & Hydraulic & Thermal \\
\hline $\begin{array}{l}\text { Particle } \\
\text { properties }\end{array}$ & $\begin{array}{l}\text { Specific surface captures } \\
\text { particle size and shape }\end{array}$ & $\begin{array}{l}\text { Particle shape, friction angle, } \\
\text { and apparent cohesion }\end{array}$ & $\begin{array}{l}\text { High conductivity of clay due } \\
\text { to surface charge and surface } \\
\text { area }\end{array}$ & $\begin{array}{l}\text { Pore size (distribution) de- } \\
\text { termines permeability }\end{array}$ & $\begin{array}{l}\text { High quartz content } \\
\rightarrow \text { high conductivity }\end{array}$ \\
\hline Packing & $\begin{array}{l}\text { Dense packing } \\
\text { higher stiffness }\end{array}$ & $\begin{array}{l}\text { High density } \\
\rightarrow \text { higher strength, dilation }\end{array}$ & $\begin{array}{l}\text { Saturated, high porosity } \\
\rightarrow \text { higher conductivity }\end{array}$ & $\begin{array}{l}\text { Dense packing } \\
\rightarrow \text { lower permeability }\end{array}$ & $\begin{array}{l}\text { High coordination no. } \\
\rightarrow \text { high conductivity }\end{array}$ \\
\hline Pore fluids & $\begin{array}{l}\text { Low saturation affects stiff- } \\
\text { ness; fully water saturation } \\
\text { affects only p-wave. }\end{array}$ & Drained vs. Undrained & $\begin{array}{l}\text { PF dominates bulk property. } \\
\text { Unsaturated: volumetric wa- } \\
\text { ter content }\end{array}$ & & $\begin{array}{l}\text { High water saturation } \\
\rightarrow \text { high conductivity }\end{array}$ \\
\hline Contact & $\begin{array}{l}\text { Cementation increases stiff- } \\
\text { ness }\end{array}$ & Cementation increases strength & & & $\begin{array}{l}\text { Large contact area } \\
\rightarrow \text { high conductivity }\end{array}$ \\
\hline $\begin{array}{l}\text { Hydrate } \\
\text { saturation }\end{array}$ & $\begin{array}{l}\text { High hydrate saturation } \\
\text { Vp, Vs increase } \\
\text { damping increases } \\
\text { Poisson’s ratio de- } \\
\text { creases }\end{array}$ & $\begin{array}{l}\text { High hydrate saturation } \\
\text { strength increases } \\
\text { dilation }\end{array}$ & $\begin{array}{l}\text { High hydrate saturation } \\
\rightarrow \text { conductivity decreases }\end{array}$ & $\begin{array}{l}\text { High hydrate saturation } \\
\rightarrow \text { conductivity decreases }\end{array}$ & $\begin{array}{l}\text { Hydrate has similar con- } \\
\text { ductivity as water }\end{array}$ \\
\hline $\begin{array}{l}\text { Hydrate } \\
\text { pore habits }\end{array}$ & $\begin{array}{l}\text { Cementation habit has more } \\
\text { evident effect on stiffness }\end{array}$ & $\begin{array}{l}\text { Cementation habit tends to in- } \\
\text { crease strength, dilation, and } \\
\text { brittleness }\end{array}$ & & $\begin{array}{l}\text { Pore-filling habit is more } \\
\text { effective in reducing permea- } \\
\text { bility than coating }\end{array}$ & $\begin{array}{l}\text { Hydrate increases conduc- } \\
\text { tive paths. It may also ce- } \\
\text { ment contacts and reduce } \\
\text { contact impedance }\end{array}$ \\
\hline $\begin{array}{l}\text { Effective } \\
\text { stress }\end{array}$ & $\begin{array}{l}\text { Hydrate increases Vp, Vs, } \\
\text { dampling, but decreases } \\
\text { Poisson’s ratio }\end{array}$ & $\begin{array}{l}\text { High hydrate saturation } \\
\text { strength increases } \\
\text { dilation }\end{array}$ & $\begin{array}{l}\text { High hydrate saturation } \\
\rightarrow \text { conductivity decreases }\end{array}$ & $\begin{array}{l}\text { High hydrate saturation } \\
\rightarrow \text { conductivity decreases }\end{array}$ & $\begin{array}{l}\text { Hydrate has similar con- } \\
\text { ductivity as water }\end{array}$ \\
\hline $\begin{array}{l}\text { Tempera- } \\
\text { ture }\end{array}$ & & $\begin{array}{l}\text { Lower temperature } \\
\qquad \begin{array}{l}\text { higher strength } \\
\text { (minor effect) }\end{array}\end{array}$ & $\begin{array}{l}\text { Conductivity increases with } \\
\text { temperature, } \sim 2 \% \text { per } \mathrm{K}\end{array}$ & $\begin{array}{l}\text { Higher temperature } \\
\rightarrow \text { Lower viscosity }\end{array}$ & $\begin{array}{l}\text { Conductivity increases with } \\
\text { temperature }\end{array}$ \\
\hline Pressure & $\begin{array}{l}\text { Vp increases with pressure } \\
\text { particularly for unsaturated } \\
\text { condition }\end{array}$ & & & & $\begin{array}{l}\text { Conductivity increases with } \\
\text { pressure }\end{array}$ \\
\hline
\end{tabular}




\subsection{IT tools}

Based published data from logging, pressure core testing, and laboratory measurements, an IT is designed to help select reliable properties for hydrate-bearing sediments simulators. For most properties, the tool offers various alternative equations obtained from experimental data. A user-friendly interface facilitates its use. This IT tool is Mathcad-based and updated as an E-book form that is readable, editable, and efficient.

Tool Structure. As shown in Figure 2.2, this E-book consists of four Mathcad files: IT_Tool_Code, IT_Tool_Main, IT_Tool_Reference, and Quick_Calculation. The IT_Tool_Code includes most functions for hydrate-bearing sediments properties inference. The IT_Tool_Main is the main interface in which users can enter inputs and calculate sediments physical properties. The IT_Tool_Reference is complementary to the previous and includes methods to estimate inputs values in IT_Tool_Main. The Quick_Calculation is the calculation worksheet.

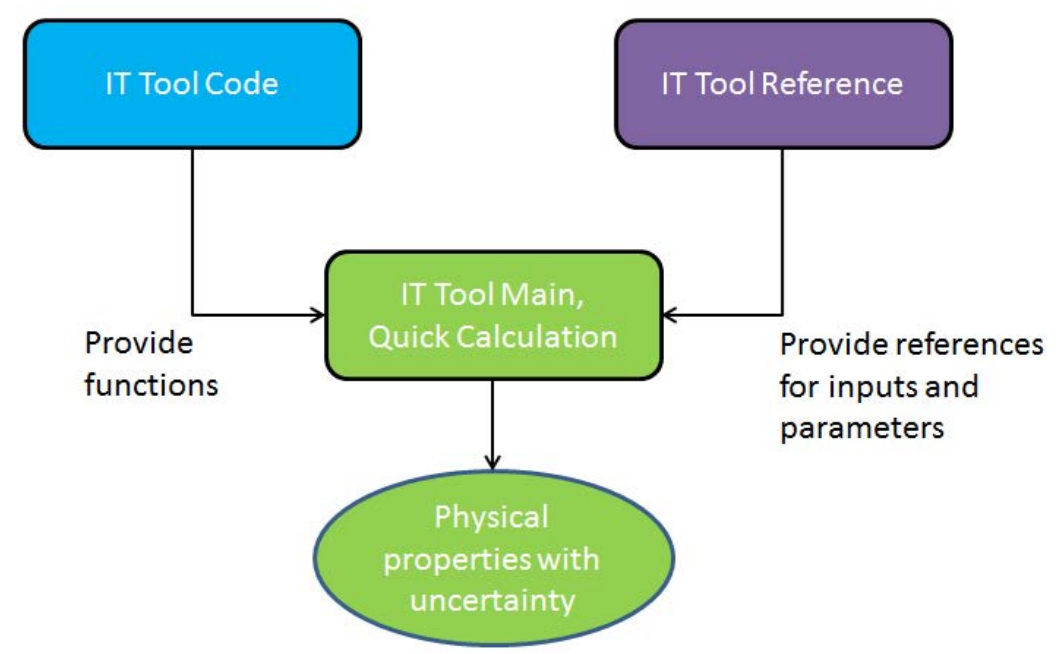

Figure 2.2 The structure of the IT tool developed to facilitate reliable selection of the physical properties for hydrate reservoir simulators.

Database Management System. A database management system for the physical properties of hydrate-bearing sediments is being developed. This system is based on Microsoft Access. This database management system will facilitate the processes to store, organize, retrieve, query, analyze, and report data. Microsoft Access allows to link databases: which helps to store and maintain information more efficiently. Figure 2.3 shows the relationship among five tables in this system. 


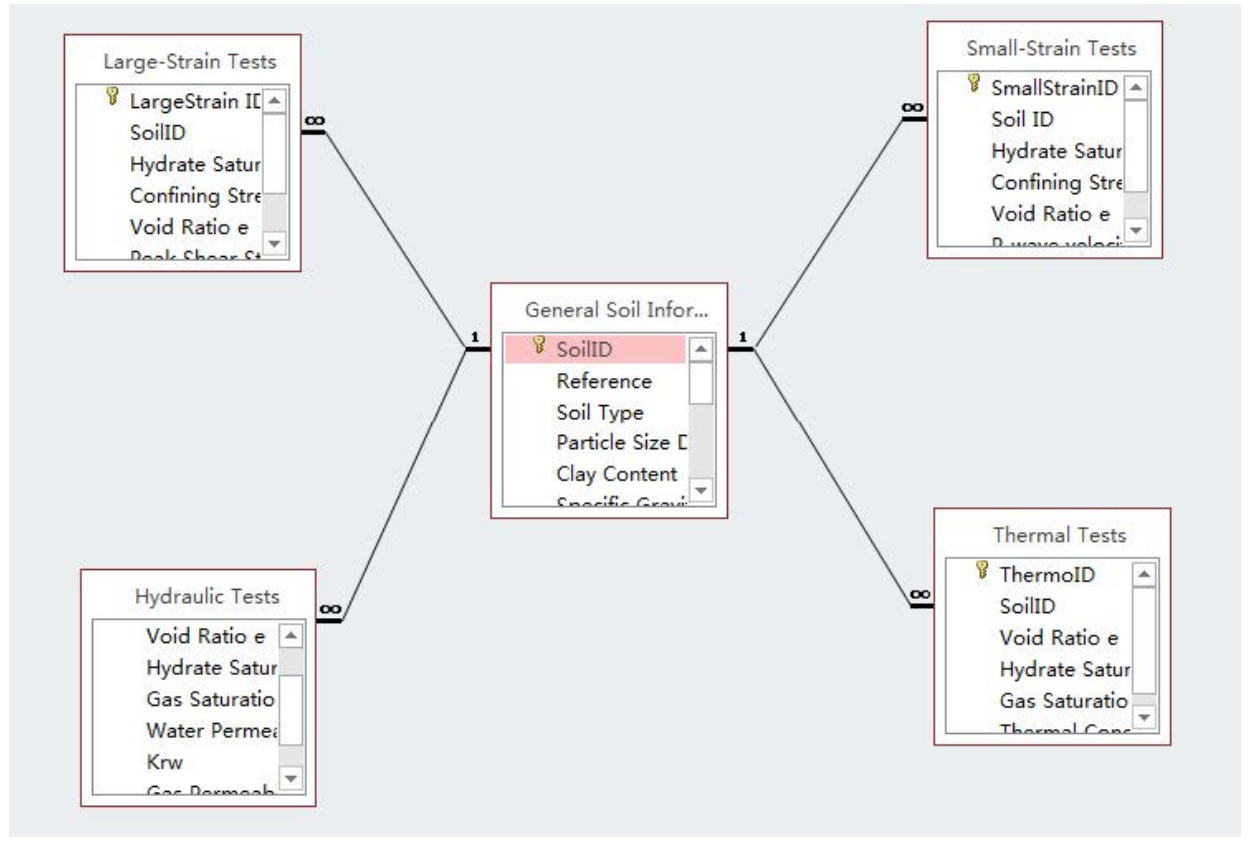

Figure 2.3 Relationship among tables for general soil information, large-strain properties, smallstrain properties, thermal properties, and hydraulic properties.

Figures 2.4 and 2.5 show the examples of comparison between predictive trends and compiled experimental data, in terms of the strength and phase boundary respectively.

(a)

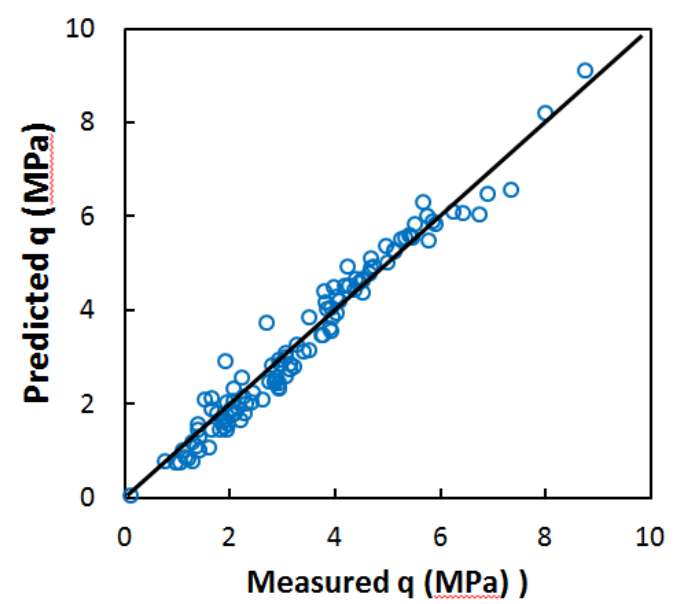

(b)

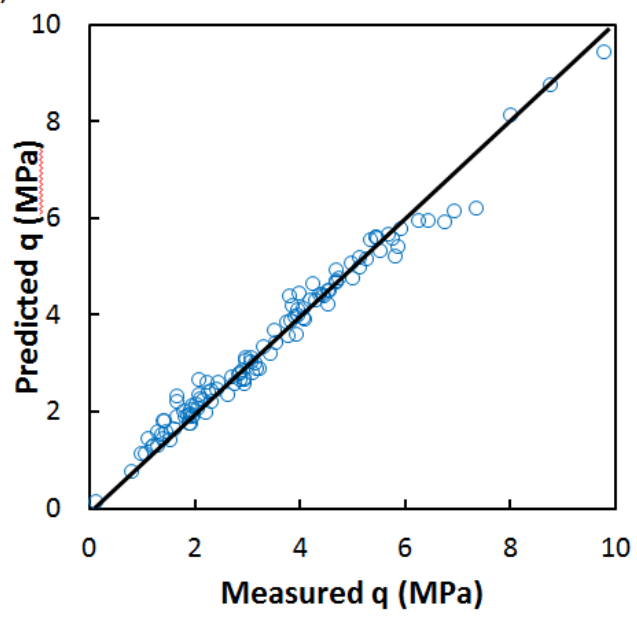

Figure 2.4 Predicted using the developed IT Tool versus measured strength of hydrate-bearing sediments. (a) Data from [Santamarina and Ruppel, 2008]; (b) Data from [Miyazaki et al., 2012]. 
(a)

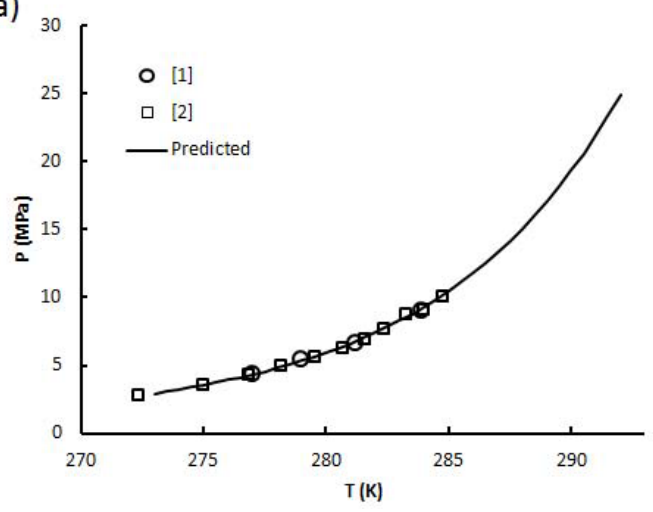

(b)

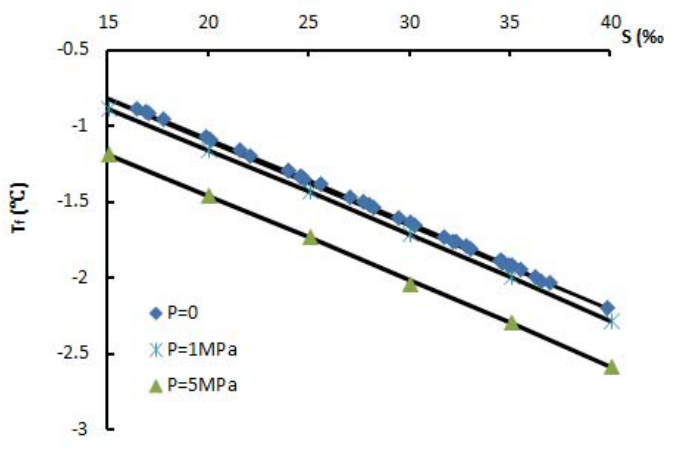

Figure 2.5 Phase boundaries: (a) hydrate phase equilibrium in seawater; (b) freezing point of seawater.

\subsection{Uncertainty analysis for the IT tool}

Most correlations are based on deterministic models. However, all predictions have a certain degree of uncertainty. Uncertainty may be due to the structure of the model, errors in the data set, and/or in the measurements, as illustrated in Figure 2.6. Furthermore, uncertainty in the input is propagated across models. A better prediction can be obtained by comparing uncertainties of alternative models [McBratney et al., 2002]. The framework related to the uncertainty analysis for the IT tool in this project is based on least squares method [Buonaccorsi, 1995; Coleman and Steele, 2009; Cook and Weisberg, 1999; Rawlings and Mayne, 2009].

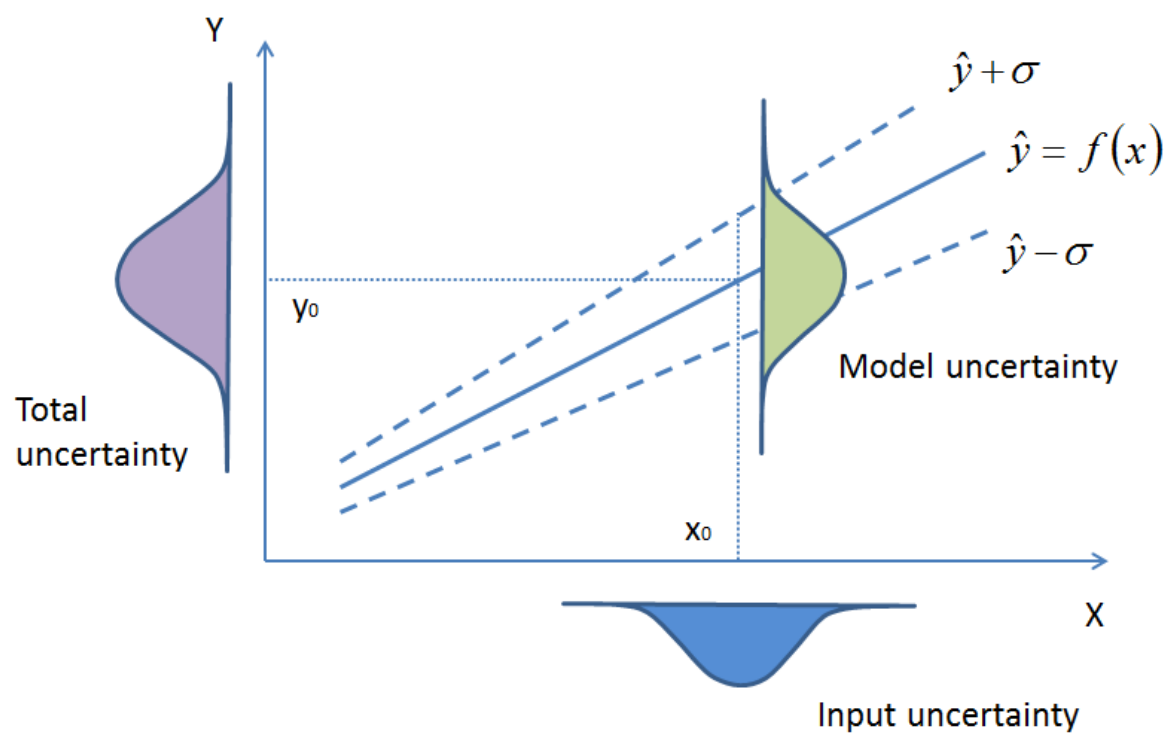

Figure 2.6 Illustration of the uncertainty in the prediction. 
Examples of uncertainty analyses for permeability of hydrate-bearing sediments relative to hydrate-free sediments, shear wave velocity, and shear strength are shown in Figures 2.72.10. In these figures, $\sigma$ is the standard error of the prediction; $s$ is the root mean square error (RMSE) of the prediction, an approximation of $\sigma$.

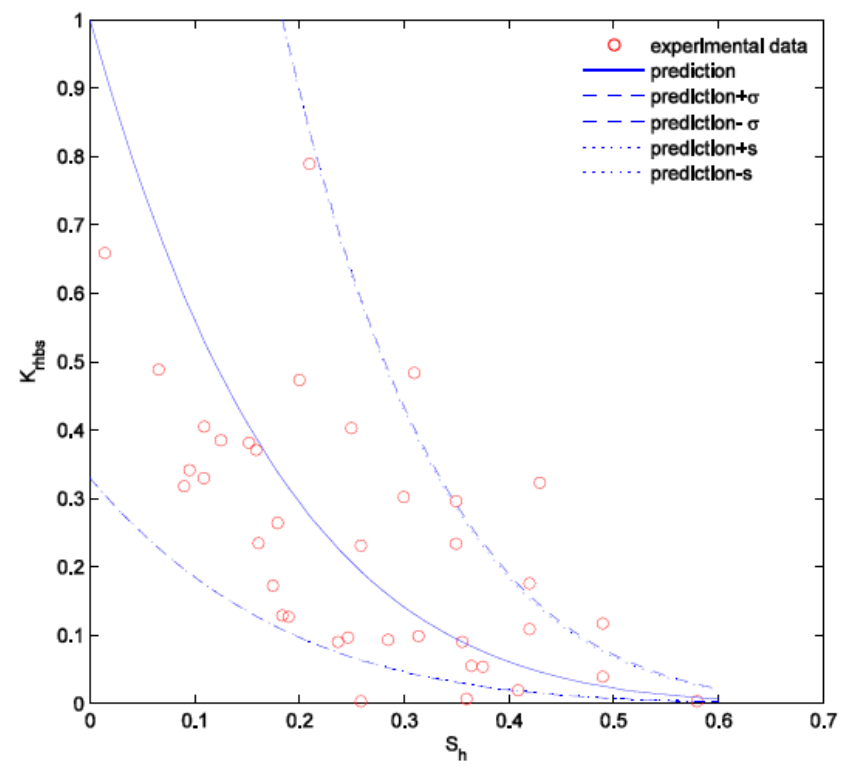

Figure 2.7 Permeability of hydrate-bearing sediments (relative to hydrate-free sediments) versus hydrate saturation. The model used here is $\log _{10} \mathrm{k}_{\mathrm{hbs}}=\mathrm{alog} \log _{10}\left(1-\mathrm{S}_{\mathrm{h}}\right)$.

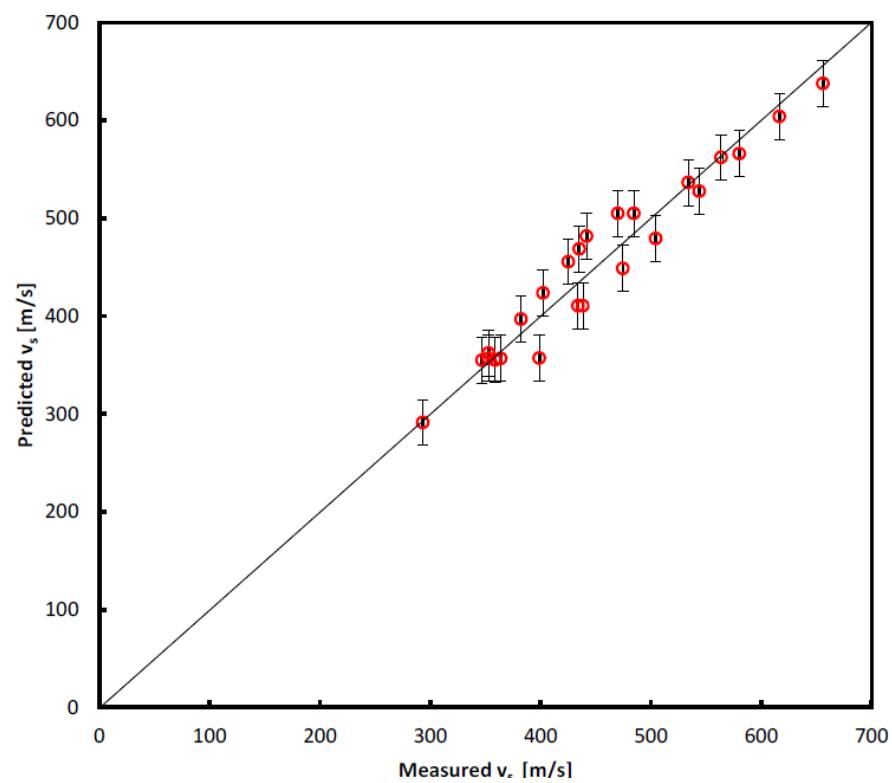

Figure 2.8 Examples of uncertainty analysis for shear wave velocity. The error bar in this plot represents one standard error of the prediction. The model used here is from [Santamarina and Ruppel, 2008] and the data are from [Priest et al., 2009]. 


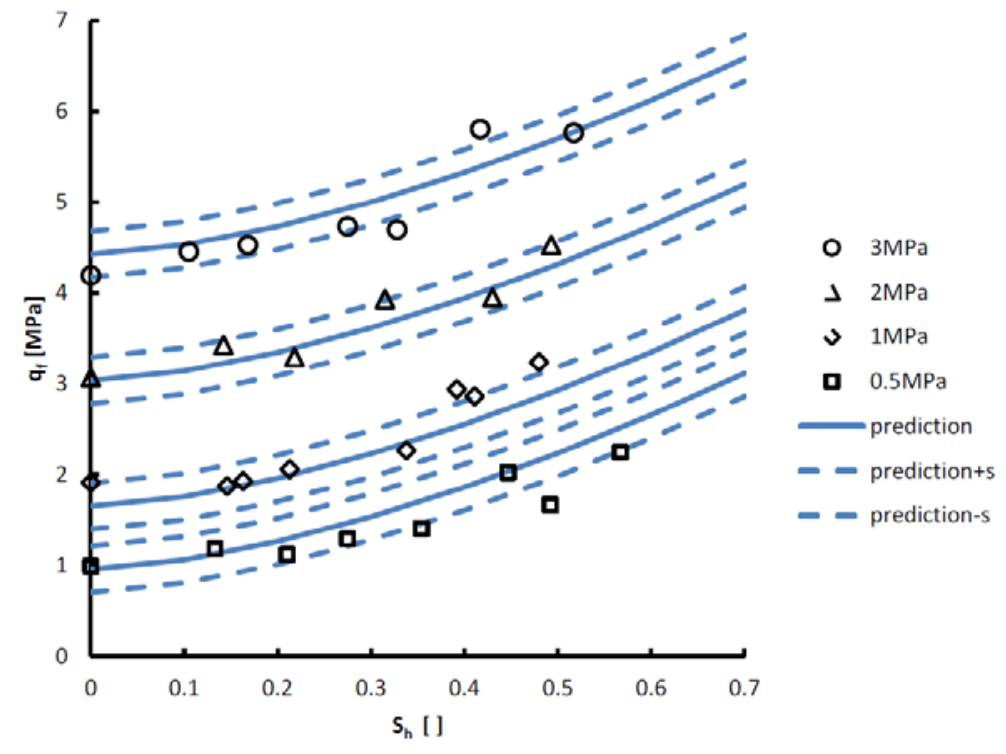

Figure 2.9 Examples of uncertainty analysis for shear strength. The model used here is from [Miyazaki et al., 2012] and data are from [Miyazaki et al., 2011].

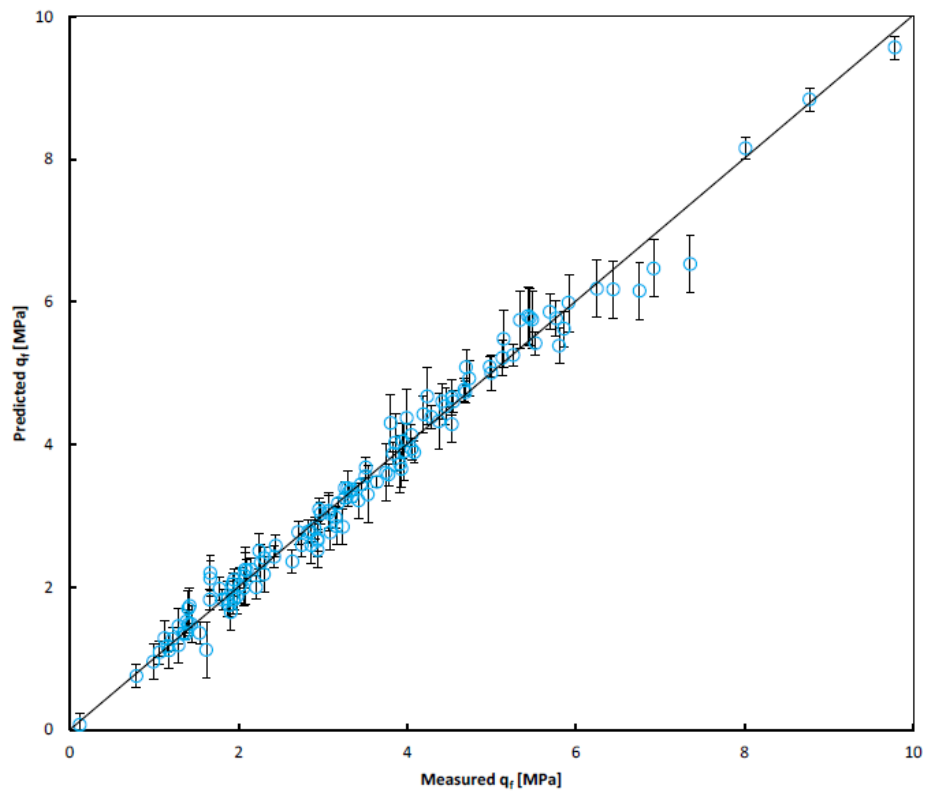

Figure 2.10 Summary of uncertainty analysis for shear strength of hydrate-bearing sediments. The error bar in this plot represents one standard error of the prediction. The model used here is from [Miyazaki et al., 2012]. 


\section{Borehole tool design - Body}

\subsection{General design considerations}

The overall design of a new borehole tool for the comprehensive characterization of hydrate-bearing sediments is guided by the critical parameters needed for the analysis of hydrate reservoirs and the design of gas production strategies (listed in Table 2.1). Accordingly, Table 3.1 summarizes the key design component of the borehole tool in this project to address some of these needs.

Table 3.1 Key physical properties of hydrate-bearing sediments and the corresponding capabilities of the borehole tool in this project.

\begin{tabular}{l|l|l}
\hline \multicolumn{1}{c|}{ Physical properties } & \multicolumn{1}{c}{ Note } \\
\hline & In-situ temperature - pressure & Direct measurement \\
& In-situ stresses & PD * \\
Index Properties & Porosity - Hydrate saturation & NM \\
and Reservoir & Grain size distribution - Fines content, mineralogy & Sampling \\
Characteristics & Stratigraphy / hydrate morphology & Sampling, video \\
& Formation history & Sampling \\
& Salinity & Sampling \\
& Pore water geochemistry & Sampling, PD \\
\hline Thermal Proper- & Thermal conductivity & Direct measurement \\
ties & Specific heat and latent heat & NM \\
\hline \multirow{2}{*}{ Hydraulic Prop- } & Water retention curve - Relative k & NM \\
erties & Hydraulic conductivity & Indirect measurement \\
& Potential migration pathways & NM \\
\hline \multirow{3}{*}{$\begin{array}{l}\text { Mechanical } \\
\text { Properties }\end{array}$} & Lateral stress coefficient & NM \\
& Soil Stiffness: shear and bulk stiffness & PD \\
\hline
\end{tabular}

${ }^{*} \mathrm{PD}$ : has potential to be equipped with this device; ${ }^{+} \mathrm{NM}=$ not measured by this device

The borehole tool developed in this project is essentially a penetrometer. Penetrometers for offshore cone penetration tests (CPT) to obtain fundamental physical, hydraulic, and geomechanical properties of marine sediments have been developed for decades. They vary in penetration mechanisms, dimensions, and mostly for shallow soil depth characterization (Table 3.2). None of these is specifically for the characterization of hydrate deposits. 
Table 3.2 Offshore CPT development (updated from [Lunne, 2012])

\begin{tabular}{|c|c|c|c|}
\hline $\begin{array}{l}\text { Penetration } \\
\text { mechanism }\end{array}$ & Date & Equipment & Features \\
\hline \multirow{4}{*}{$\begin{array}{l}\text { Discontinuous } \\
\text { push }\end{array}$} & 1972 & Dead weight, platform & Max 4m penetration \\
\hline & 1972 & Seacalf & Max $25 m$ penetration \\
\hline & 1976 & Diving bell & $60 \mathrm{~m}$ penetration achieved \\
\hline & 1991 & SCOPE & Self-leveling \\
\hline \multirow{4}{*}{$\begin{array}{l}\text { Continuous } \\
\text { push }\end{array}$} & 1983 & ROSON & Roller wheels \\
\hline & 1984 & Modified BORROS rig & Synoptical hydraulic cylinders \\
\hline & 1984 & Wheeldrive Seacalf & Roller wheels \\
\hline & 2010 & DeepCPT & Suction anchor; 10 and $15 \mathrm{~cm}^{2}$ cones \\
\hline Coiled Rod & 2000 & Penfeld & $\begin{array}{l}\text { Self-powered by lead batteries. Can penetrate to } \\
30 \mathrm{~m}\end{array}$ \\
\hline Seabed drilling & 2001 & PROD & Rods stored in carousel on sea bottom \\
\hline \multirow[t]{2}{*}{ Combined rig } & 1997 & Searobin & $10 \mathrm{~cm}^{2}$ cone \\
\hline & 2001 & Geoceptor & $10 \mathrm{~cm}^{2}$ cone \\
\hline \multirow[t]{3}{*}{ Mini-rigs } & 1992 & Seascout & Coiled rod, $1 \mathrm{~cm}^{2}$ cone \\
\hline & 2000 & Neptun & $\begin{array}{l}\text { Coiled rod; } 5 \text { and } 10 \mathrm{~cm}^{2} \text { cones; } 20 \mathrm{~m} \text { penetra- } \\
\text { tion }\end{array}$ \\
\hline & 1999 & MiniCPT & Coiled rod; $2 \mathrm{~cm}^{2}$ cone; up to $12 \mathrm{~m}$ penetration \\
\hline \multirow[t]{2}{*}{ ROV mounted } & 1983 & Mini Wison & $1 \mathrm{~m}$ stroke, $5 \mathrm{~cm}^{2}$ cone penetrometer \\
\hline & 2014 & GOST & $5 \mathrm{~cm}^{2}$ cone; to $4000 \mathrm{~m}$ water depth \\
\hline \multirow{2}{*}{$\begin{array}{l}\text { Hydraulic/mud } \\
\text { pressure }\end{array}$} & 1972- & WINSON (XP, EP) & 3m stroke, memory unit \\
\hline & 1984 & Dolphin & Memory unit \\
\hline \multirow{2}{*}{$\begin{array}{l}\text { Coupled with } \\
\text { drilling }\end{array}$} & 2001 & CPTWD & Memory unit \\
\hline & 2016 & This project & $\begin{array}{l}\text { Comprehensive physical properties, memory } \\
\text { unit }\end{array}$ \\
\hline
\end{tabular}

General Characteristics. The tool is designed as a stackable-type modular penetration system with a simple but versatile architecture. Measurements are made ahead of the borehole during and after penetration. The tool is made of stainless steel 316 for high stress- and chemical-resistance. All modules are $36.5 \mathrm{~mm}$ in diameter (an area $10 \mathrm{~cm}^{2}$ ). The device consists of the body, the modular probe system, and electronics (Figure 3.1). 


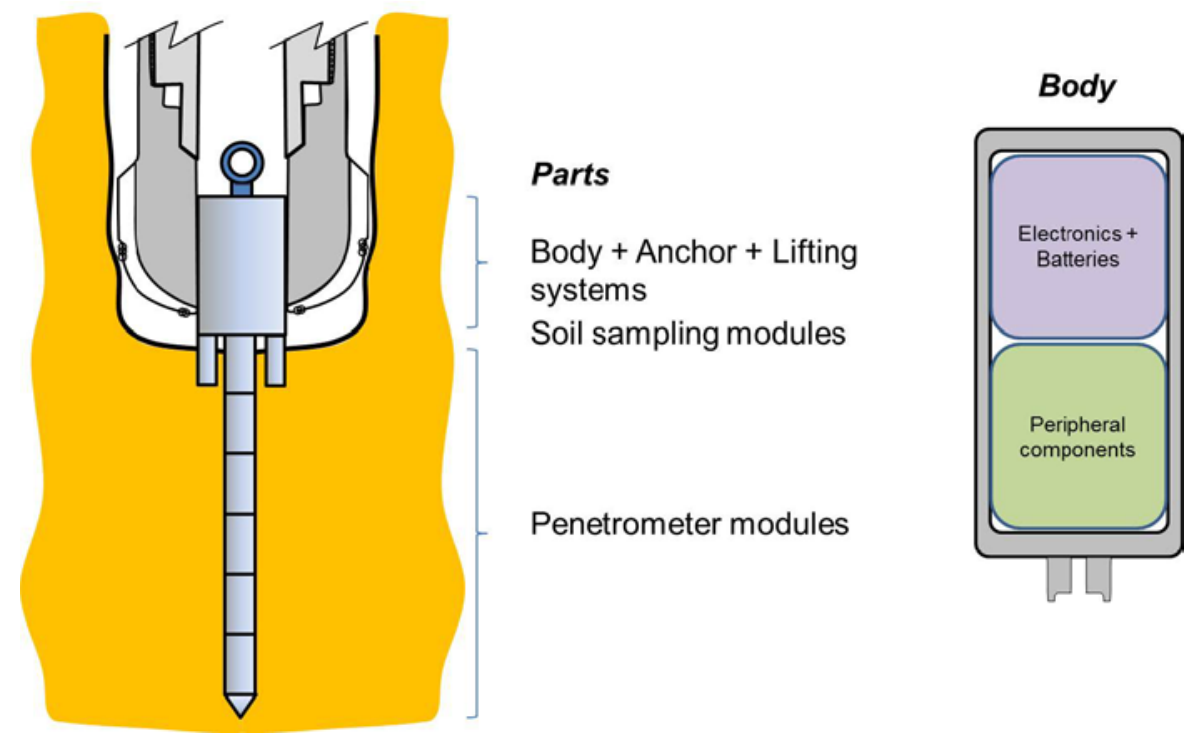

Figure 3.1 In-situ characterization tool: General view.

Body. The body is a cylindrical cavity (OD = $100 \mathrm{~mm}$; SS316) with two rigid end caps. The body supports the modular penetrometer and sampling tubes houses the electronics including the fishing and lifting system, and the anchor to the drill bit Bottom Hole Assembly BHA (details in Session 5.1). The anchor system couples the tool to the drilling string to use the weight of the drill bit to advance the penetration device. The geometry of the body depends on the drill string available at the site.

Modular Probe. The maximum penetration force is computed for a hydrate-bearing sediment with an undrained shear strength $S_{u}=10 \mathrm{MPa}$ (hydrate saturation $S_{h}=100 \%$ [Waite et al., 2009]). The maximum force needed to penetrate a $10 \mathrm{~cm}^{2}$ probe into this formation is about 90kN. The maximum tool length to avoid buckling is computed from Euler's equation. Results show that the maximum length is $L_{\max }=1.20 \mathrm{~m}$ for the case of both ends hinged (Figure 3.2). The load cell at the tip of the modular probe has a capacity of 200MPa and measures a combination of water pressure and penetration resistance (Figure 3.2). The tool can be internally pressurized prior to deployment to pre-stress the load cell to extend the depth range of the probe. 

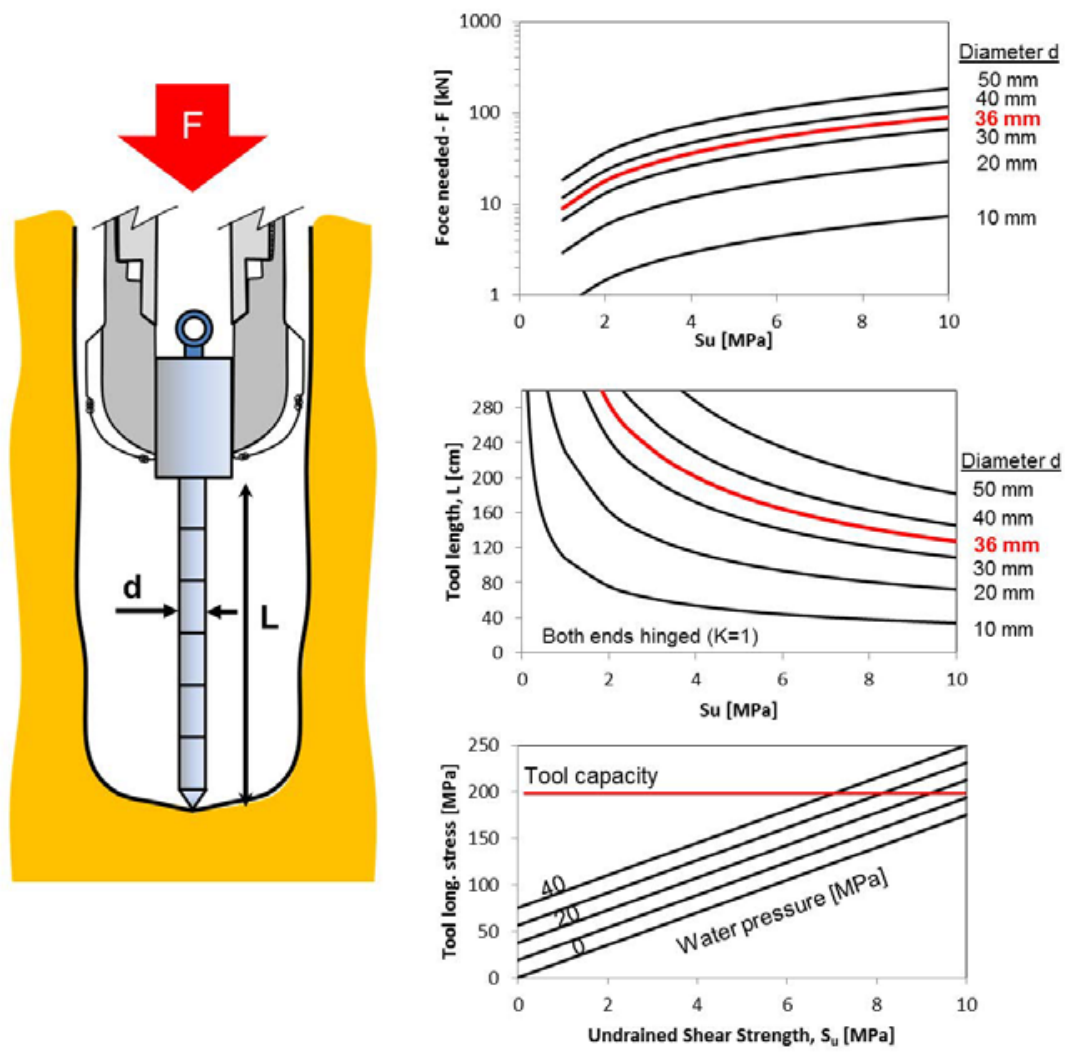

Figure 3.2 Overall mechanical design. (a) Maximum needed force. (b) Maximum tool length to satisfy buckling restrictions. (c) Tool longitudinal stress dependence between water pressure and undrained shear strength.

\subsection{Tip (force) module}

Design. The tip module consists of the tip itself, the sleeve and the porous filter (Figure 3.3). The sleeve houses and protects the instrumentation. The nucleus is instrumented with a full bridge strain gage (to cancel bending and temperature effects) and two thermocouples. Details of the two thermocouples in the cone tip will be introduced in the 3.6 Thermal module. The porous filter ring is made of stainless steel 316.

Mechanical Verification. The tip module is designed to sustain the expected penetration forces and water pressure. Analytical solutions and a FEM numerical model are used to assess internal stress concentrations, the collapsibility of the sleeve and buckling of the tool. Figure 3.4 shows the stress field for the tip module facing $90 \mathrm{kN}$ penetration force and $10 \mathrm{MPa}$ water pressure. Results show adequate mechanical performance under these extreme conditions. 


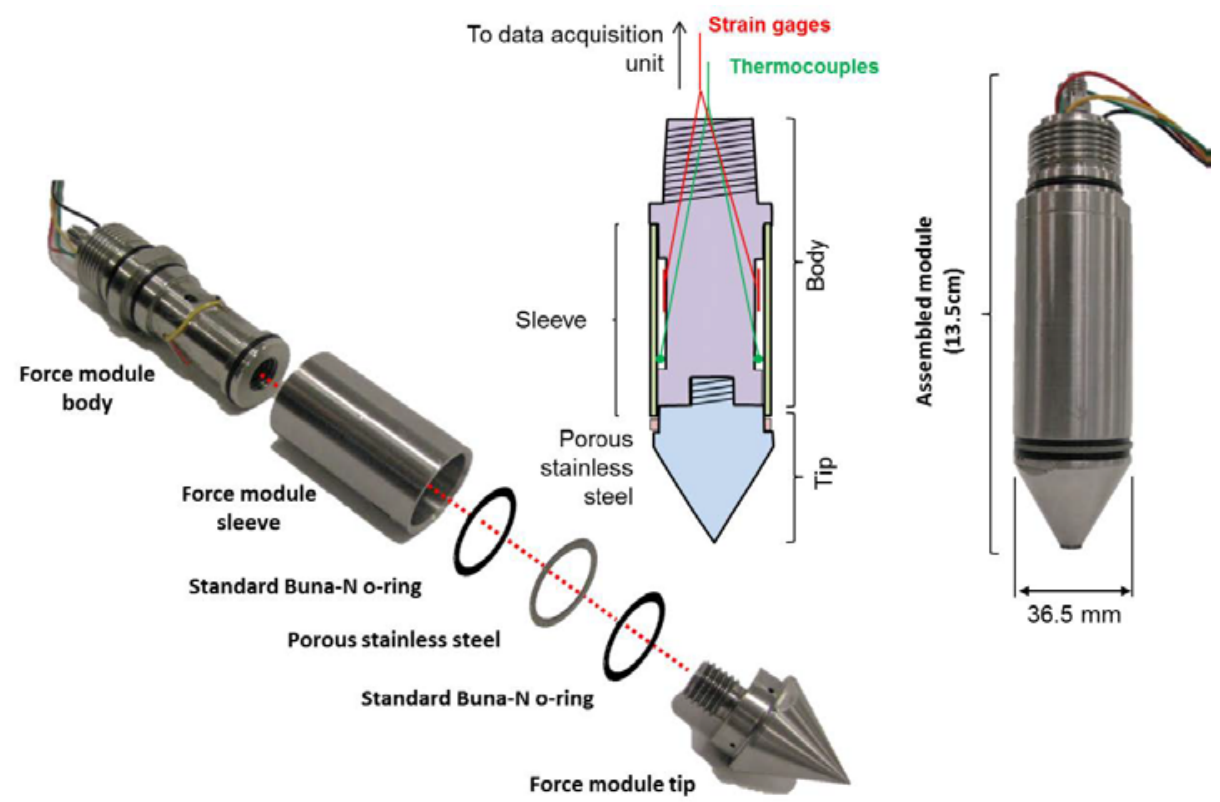

Figure 3.3 Tip module: parts, elements, and wiring.
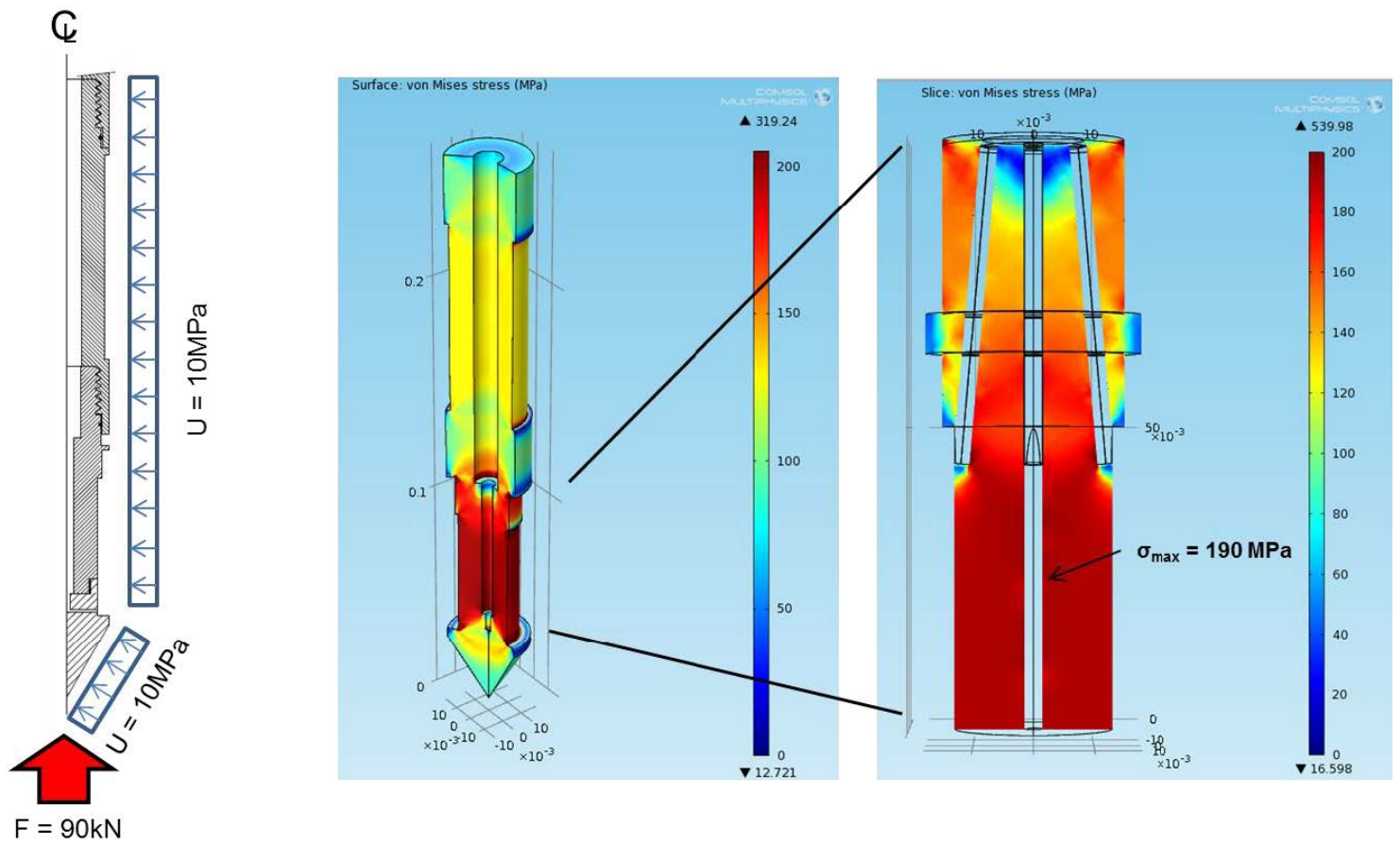

Figure 3.4 Tip module mechanical verification: Yield stress for SS316 is 200MPa.

Calibration. A chamber and coupler are designed to calibrate the tool. It consists of a $1.20 \mathrm{~m}$ long SS316 tube with a cap to couple with the tool to the pressure chamber (Figure 3.5). All cables exit from the top; the tool response is logged using a standard computer- 
based data logger. The tip was successfully tested to 25MPa of water pressure. The tool pore pressure response (generally called $u_{2}$ ) and insertion forces $\underline{q}_{t}$ correlate well with the applied fluid pressure in the chamber ( $2 \%$ error). The tip resistance determined with the strain gauges fixed to the core is corrected for tip-to-core area ratio and the pore pressure effect on the shoulder.
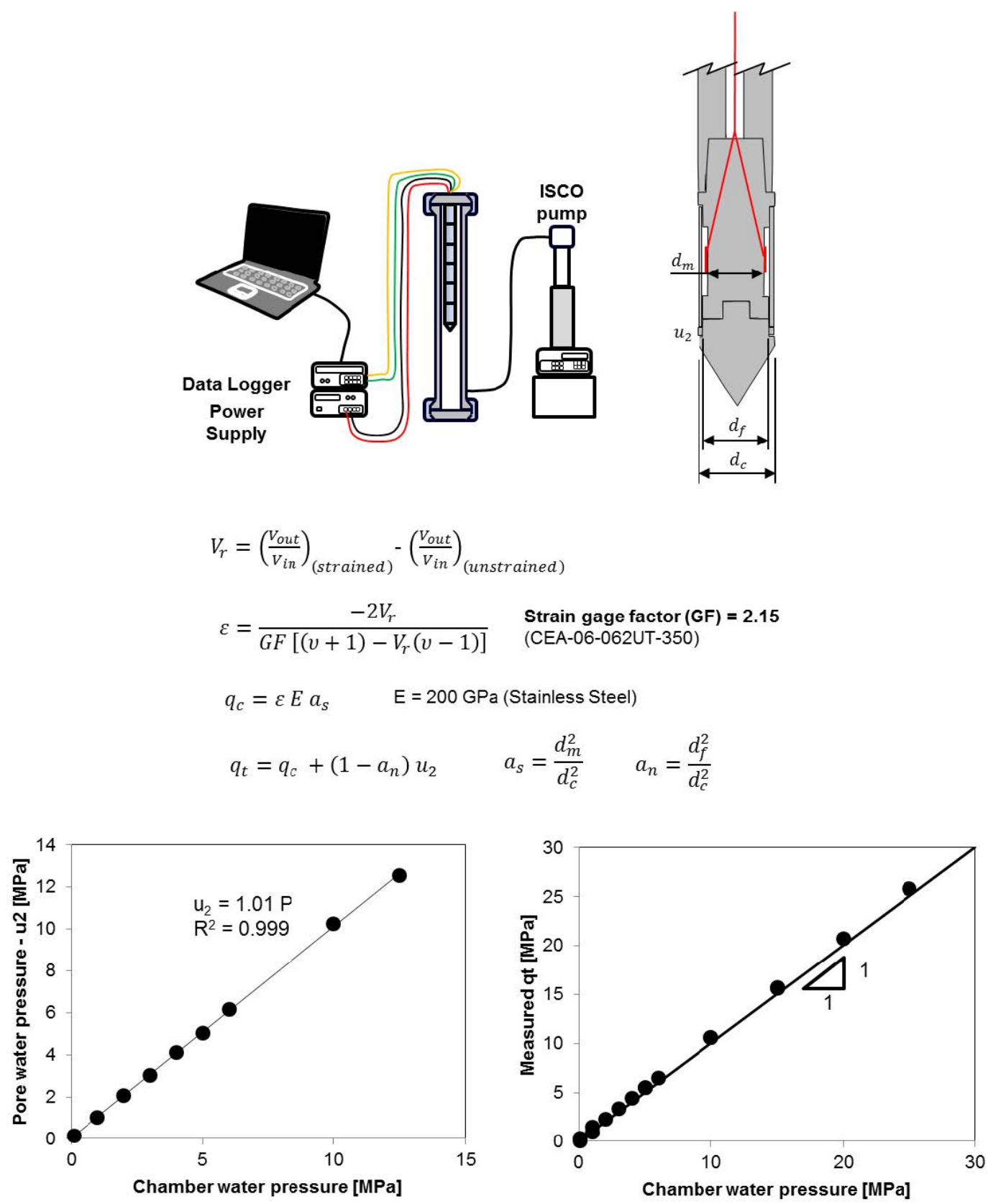

Figure 3.5 Tip module calibration. Measured pressure using strain gauges vs. chamber water pressure. 


\subsection{Hydraulic module}

Design. Hydraulic conductivity is measured using a system of valves and pressure transducers to determine the flow rate and pressure gradient (Figure 3.6). The water extraction inlet at the tip of the force module is connected to the storage tank through a solenoid valve and a check valve to prevent reversed flow after sampling. The pressure transducer in the tank measures the pressure evolution in the gas in order to compute flow rate using Boyle's law.

a)

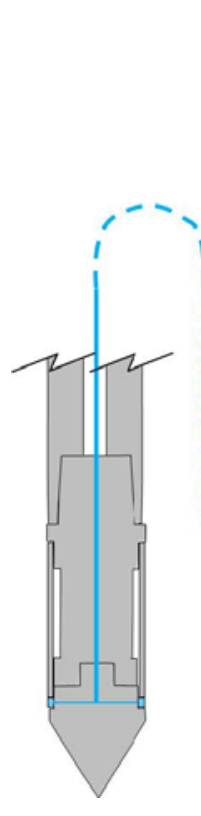

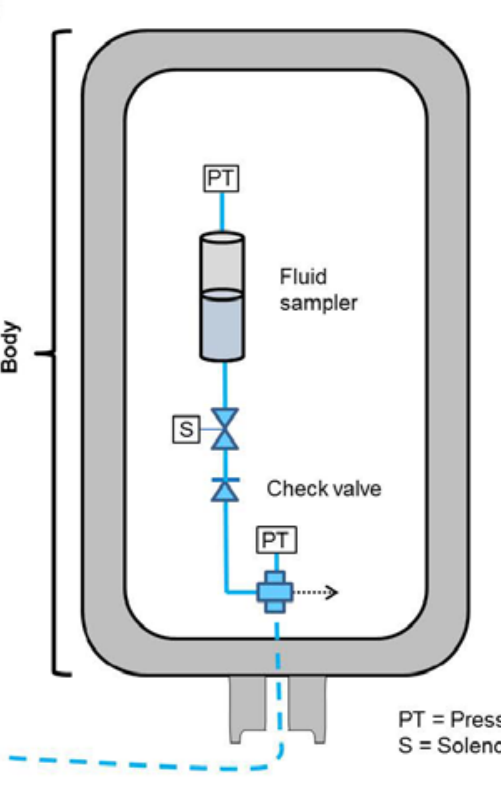

b)

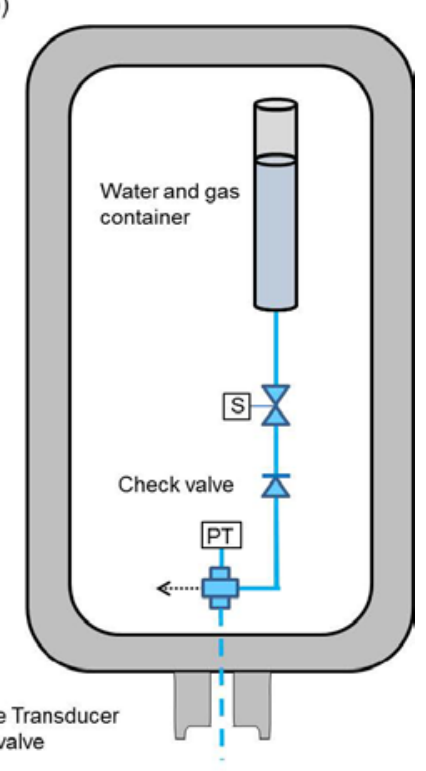

Figure 3.6 Hydraulic dual-system components: (a) Hydraulic conductivity measurement system. (b) Mini-production test

The governing equation

$$
q=F k\left(u_{0}-p_{0}\right),
$$

shows the flow rate $q$ as a function of the hydraulic conductivity $k$, the initial reservoir pressure $u_{o}$, the initial pressure in the container $p_{o}$, and a shape factor $F$ which accounts for boundary conditions. Pore water can be sampled without dissociation by pre-pressurizing the container to an initial pressure $u_{o}$ higher than the dissociation pressure. Water permeability k can be estimated as [Torstensson, 1984]:

$$
k=\frac{p_{0} v_{0}}{F t}\left\{\frac{1}{p_{0} u_{0}}-\frac{1}{p_{t} u_{0}}+\frac{1}{u_{0}^{2}}\left[\ln \left(\frac{p_{0}-u_{0}}{p_{0}} \frac{p_{t}}{p_{t}-u_{0}}\right)\right]\right\},
$$


where $v_{o}$ the initial volume of gas in the container, and $p_{t}$ is the pressure in the container at time $t$. The test duration is highly dependent on the permeability. A passive test can be implemented with this probe as well by measuring the dissipation of the excess of pore pressure generated during penetration [Burns and Mayne, 1998; 1999]. A parallel hydraulic system allows for a mini-production test. A solenoid valve opens a tank kept at a pressure $p_{o}$ below the dissociation pressure, thus water and gas can be extracted and sampled (Figure 3.7a).

Verification. The shape factor $F$ for this probe is determined using numerical simulations. The computed value is $F=2 D$ (Figure 3.7b) and corresponds well with published analyses [Chirlin, 1989; Hvorslev, 1951; Mathias and Butler, 2006]. Given the location of the water inlet, flow conditions resemble spherical flow. The numerical and analytical solutions for a spherical flow are compared in Figure 3.8. The chart shown in Figure 3.8c facilitates the estimation of the hydraulic conductivity using this probe from the measured flow rates and differential pressure changes. Additionally, Reynold's number should be $\operatorname{Re}<10$ everywhere in the soil mass to satisfy laminar flow, i.e. Darcy's condition.

a)
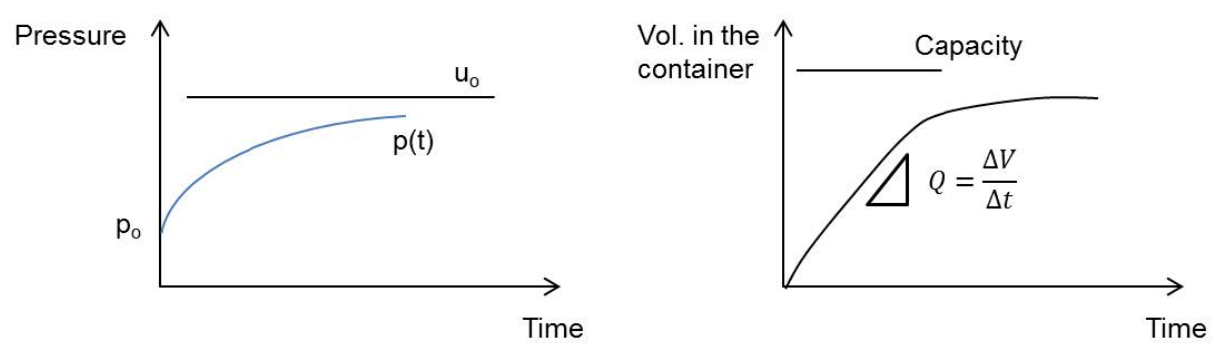

b)
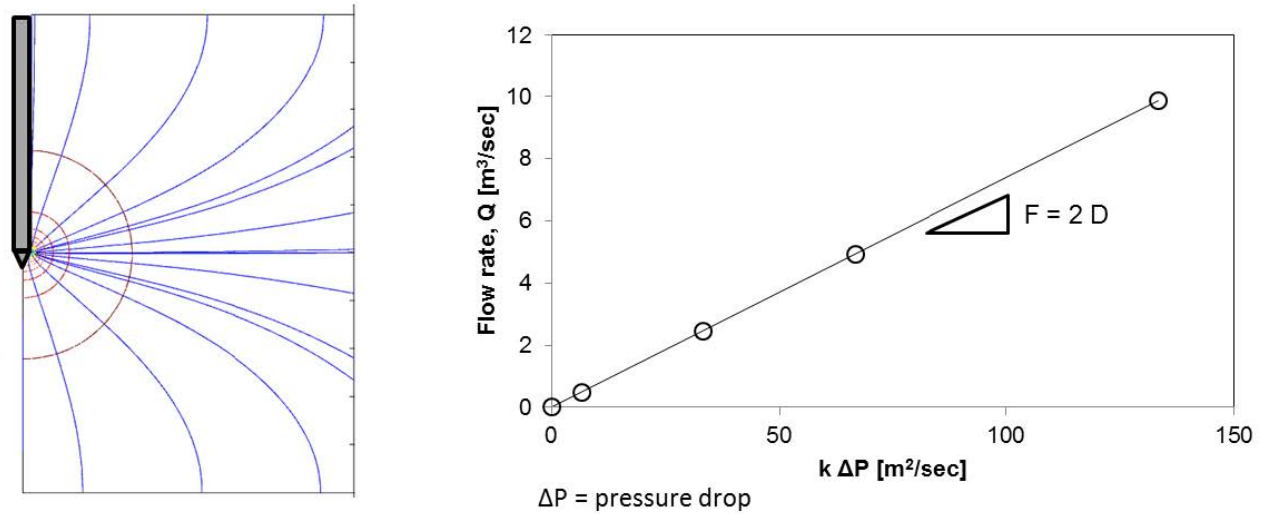

Figure 3.7 Hydraulic conductivity measurement system. (a) Pressure and volume versus time. (b) Shape factor from numerical simulations. Note: $u_{o}$ is the reservoir water pressure and $p_{o}$ the initial water pressure in the container. 
a)

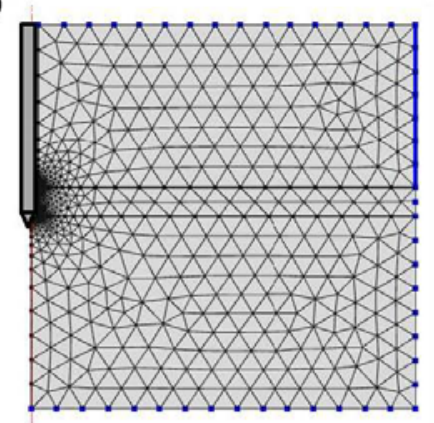

b)

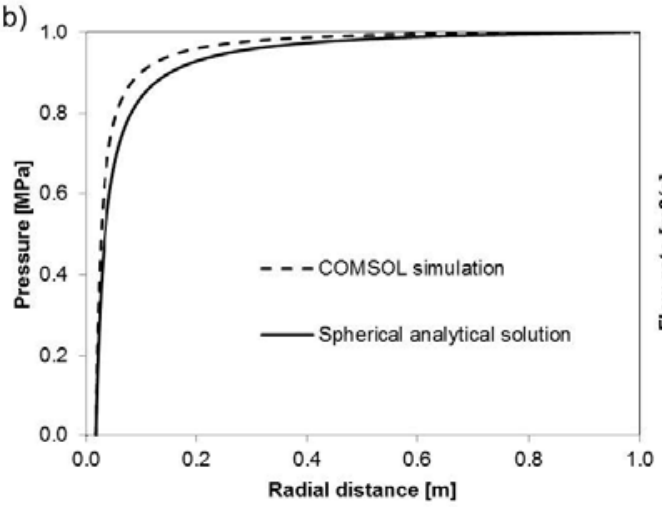

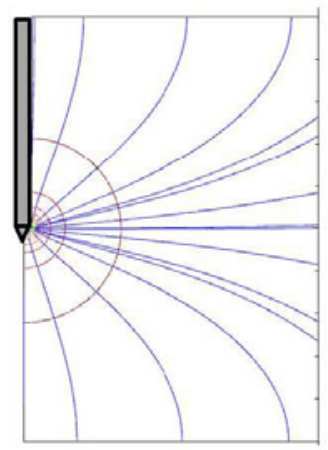

c) 10

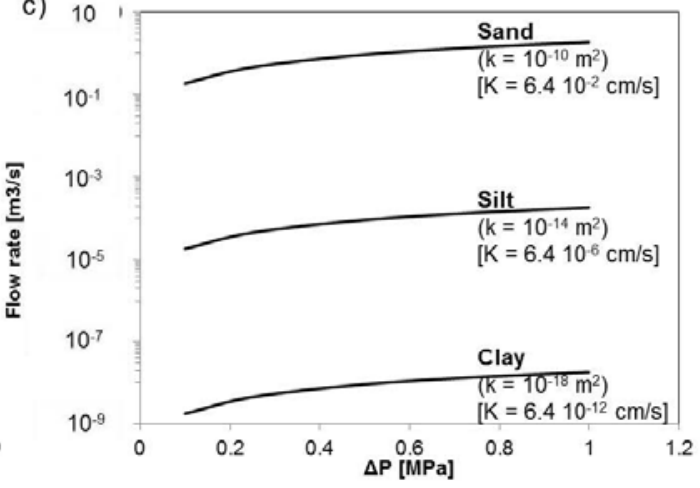

Figure 3.8 Hydraulic conductivity system verification. (a) Numerical model in COMSOL. (b) Comparison of the numerical model and the ideal spherical case. (c) Solution chart for a measured flow rate and water pressure change.

Calibration. Four porous filters are calibrated under flow-control (low flow rate) and pressure-control (high flow rate; set-up in Figure 3.9). The filters include a standard CPT plastic filter and three filters made of stainless steel 316 with different pore sizes. Results are compared with numerical simulations to match the pressure drop $\Delta p$; all filters exhibit high conductivity $\left(>10^{-3} \mathrm{~cm} / \mathrm{s}\right)$.

Fluid sampling tests are shown in Figure 3.10 and result for $\Delta p=u_{o}-p_{o}=0.33 \mathrm{MPa}$, for different filter types. Measurement must fall on the right-hand side of plots to disregard measurement errors. 

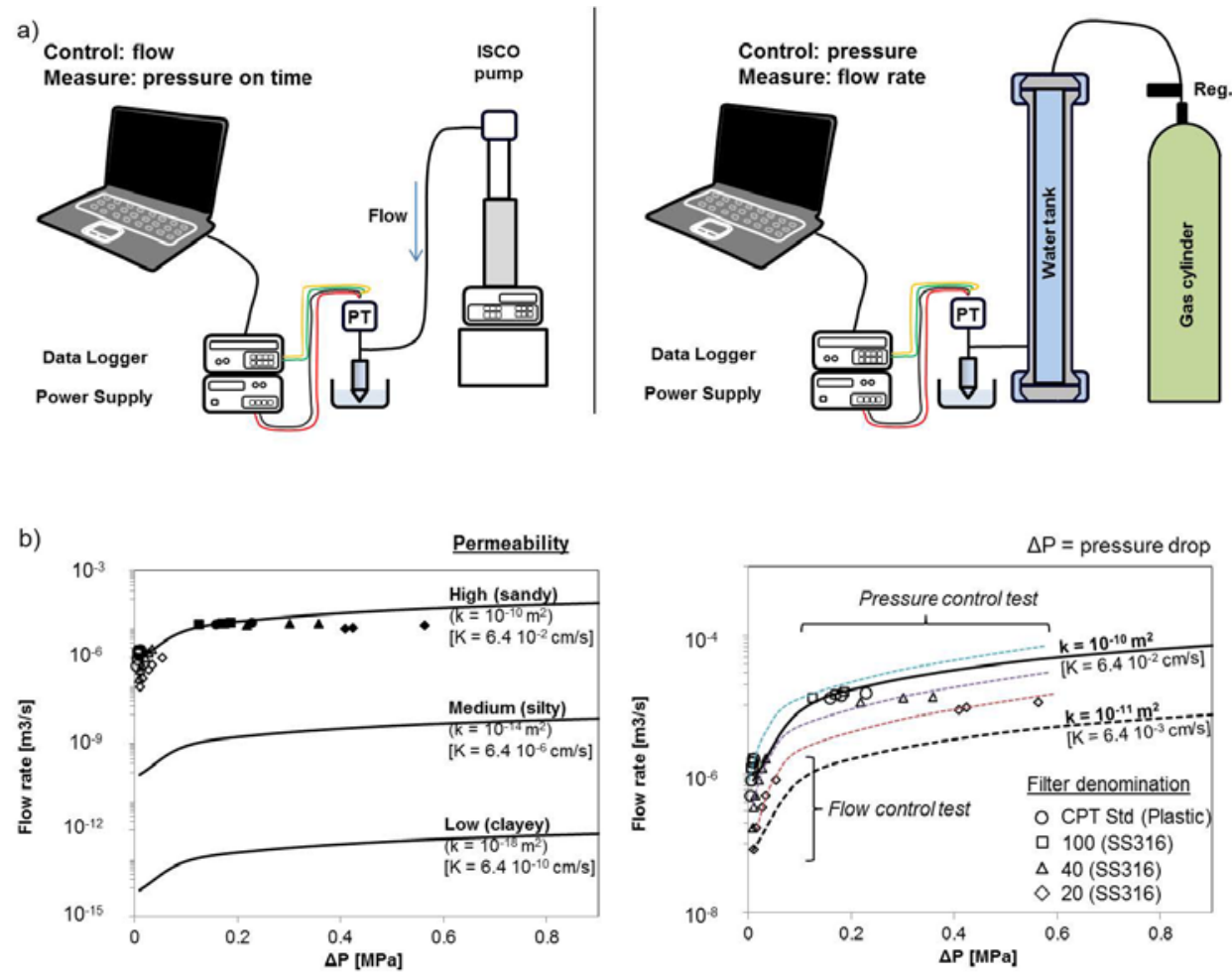

Figure 3.9 Porous filter calibration: (a) Setup of the two types of control tests: flow control and pressure control-based test. (b) Results for the different porous filter. Lines represent results from numerical simulations and discrete points show measured values.

a)
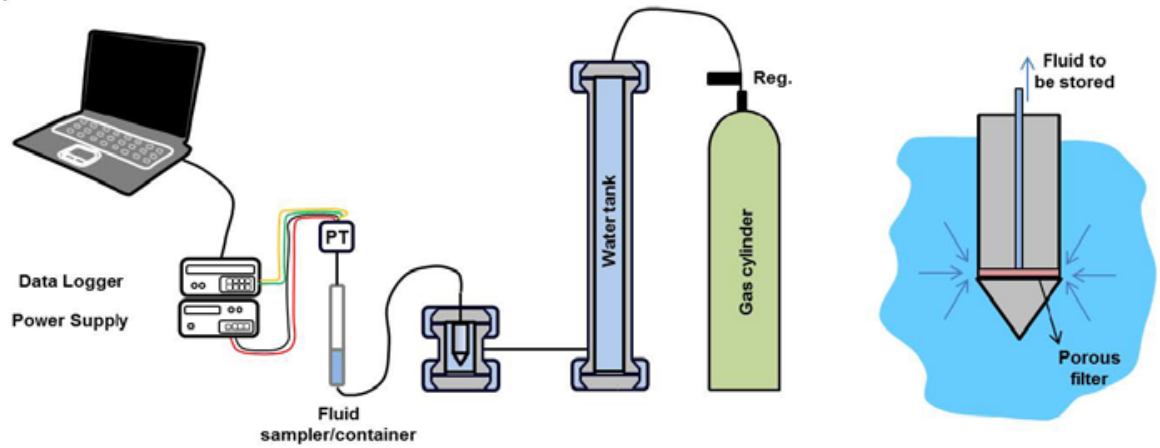

b)
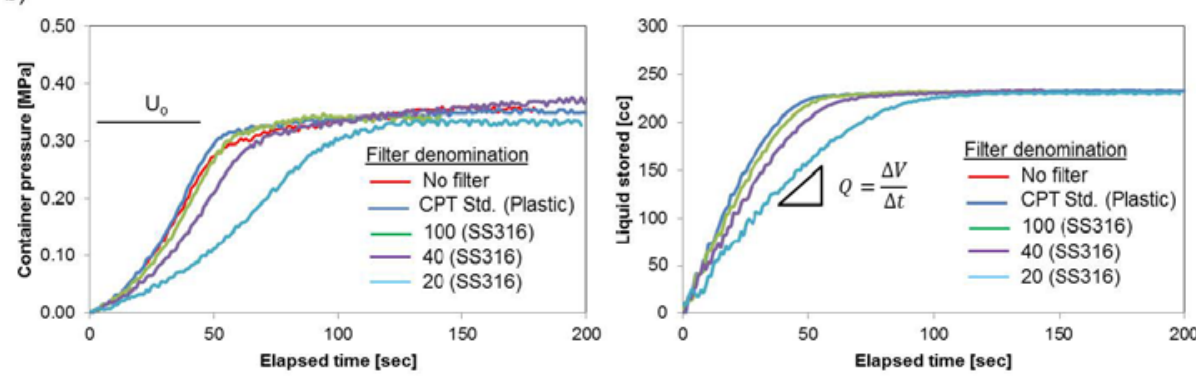

Figure 3.10 Complete hydraulic/fluid sampling test: (a) Setup. (b) Results for different porous filters. 


\subsection{Electrical module}

Design. The local electrical resistivity is measured using a button-type electrode pair. A small PEEK plastic screw (OD $=9.4 \mathrm{~mm}$ ) is used for electrical insulation. The steel module works as the ground and the central electrode in the button is the active electrode. The button-type electrode pair can be deployed in any module of the penetrometer (Figure 5.20). The peripheral electronics involves an AC source with a frequency $f=100 \mathrm{kHz}$ and two voltmeters [Cho et al., 2004].
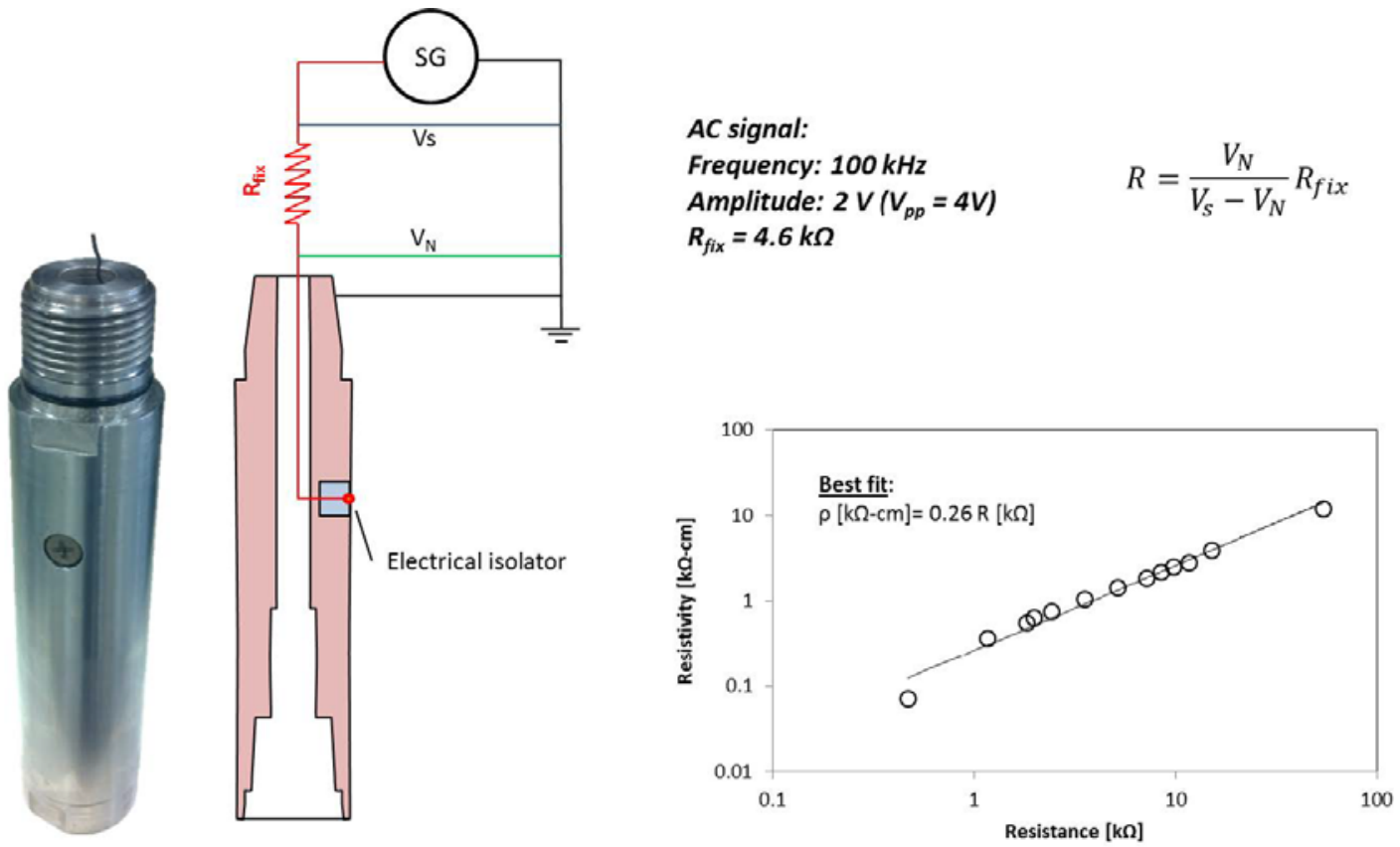

Figure 3.11 Electrical resistivity module and calibration.

Calibration. The button-type electrode pair is calibrated for different values of electrical resistivity. Figure 3.11 shows the setup and calibration results. These results allow for the direct comparison of voltage drop ratio onto electrical resistivity, that is the inherently account for the shape factor associated with the 3D electric field.

A direct comparison of the impedance analyzer chip was performed. With a $10 \mathrm{k} \Omega$ comparison resistor, it was possible to measure impedances from approximately $6 \mathrm{k} \Omega$ to 200 $\mathrm{k} \Omega$ with an error less than 5\%. Below $6 \mathrm{k} \Omega$ the error increases dramatically (amplifier in the chip reaching its maximum output). Above $200 \mathrm{k} \Omega$ the error increases linearly (Figure 
3.12). Errors below $6 \mathrm{k} \Omega$ (not shown in the figure) increase quickly: $300 \%$ at $1 \Omega, 800 \%$ at $500 \Omega$.
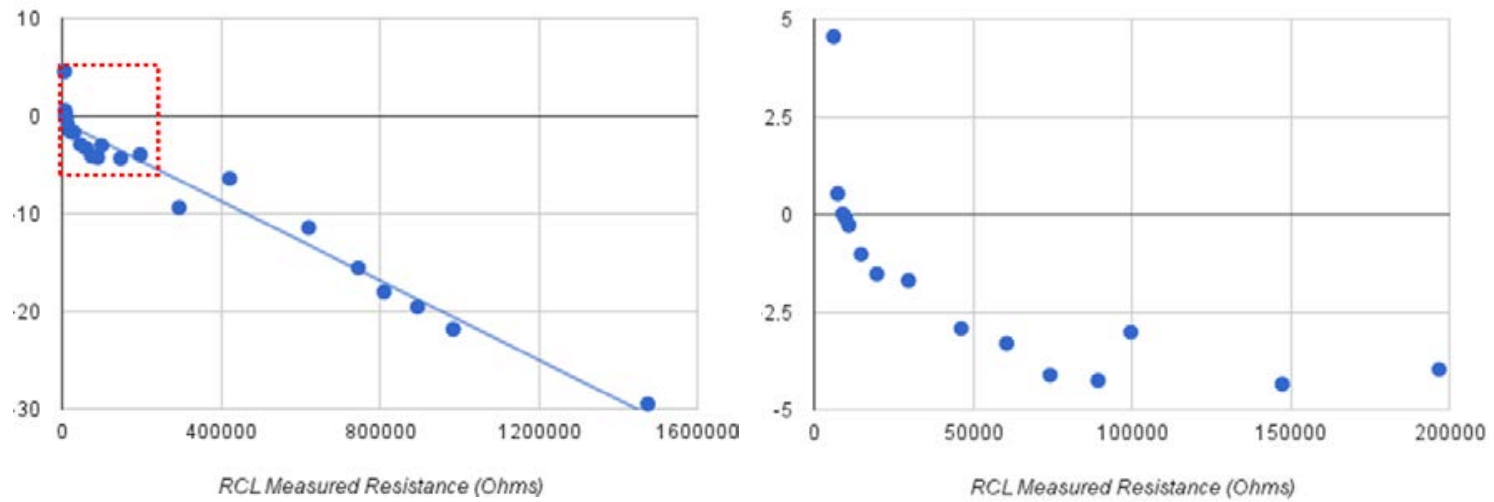

Figure 3.12 Impedance analyzer comparison test: Error respect to measured resistance.

\subsection{Sampling module}

Design. Small tube samplers are attached to the tool body to recover disturbed samples (Figure 3.13). The samplers consist of a cutting shoe, sampler tube, and catcher. The cutting shoe is designed with a taper angle of 10 degrees and an internal step to lock the catcher against the sampler. The sampler tube houses the recovered sediment kept in place by the catcher. The tube is threaded at the top to mount the sampler to the body of the tool. An extrusion device is designed to push sediments out of the tube sampler (Figure 3.13e).

Field Verification. The tests documented in Section 5 and 6 confirmed the good performance of the sampler for coarse and fine-grained soils. 
a)

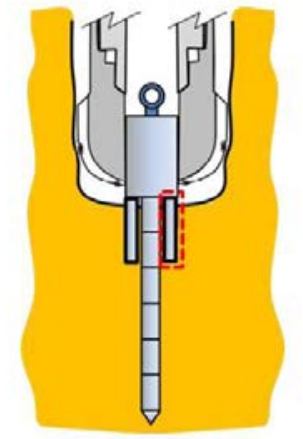

d)

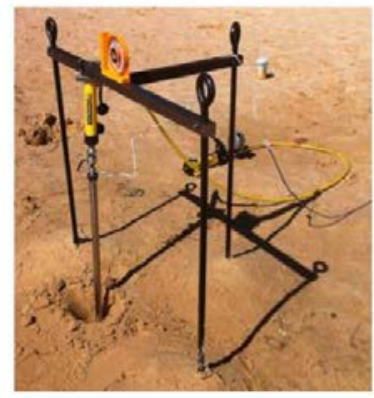

b)

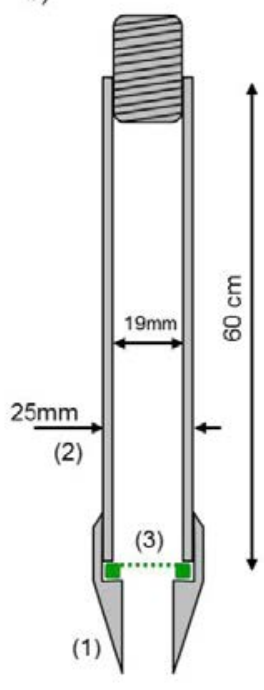

e) c)

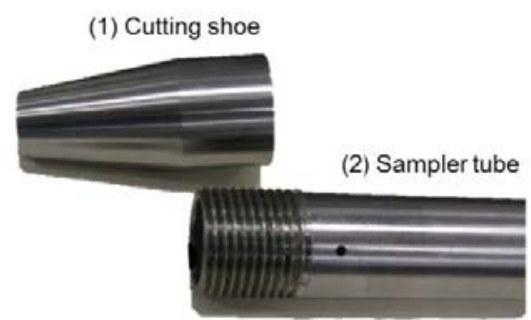

(3) Catcher

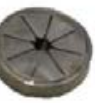

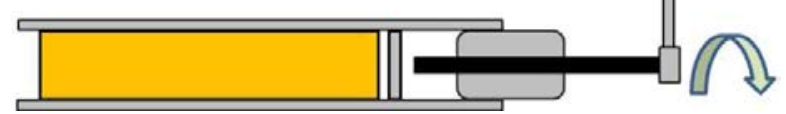

Figure 3.13 Sediment piston sampler. (a) Position in the tool. (b) Drawings. (c) Photographs. (d) Field test. e) Extrusion devise.

\subsection{Thermal module}

The thermal module consists two major components: one is for in situ temperature measurement using the two thermal couples housed in the tip module (data can be used for the inversion of thermal conductivity) and the other one using transient plane heat source [Dai et al., 2015] to measure temperature and thermal conductivity.

Thermocouples in the tip module. The thermocouples in the force module are located inside the protecting sleeve. Thermal effects are partially compensated: they cancel in the full bridge but strains in the core remain. A 30 degrees Celsius change in temperature produces a $0.12 \mathrm{mV}$ bridge response for a $10 \mathrm{~V}$ bridge excitation (Figure 3.14). The tool thermal response was measured by subjecting it to cooling and heating cycles in an environmental chamber. The response delay is 10sec during cooling, and 8sec during heating (Figure 3.15). 


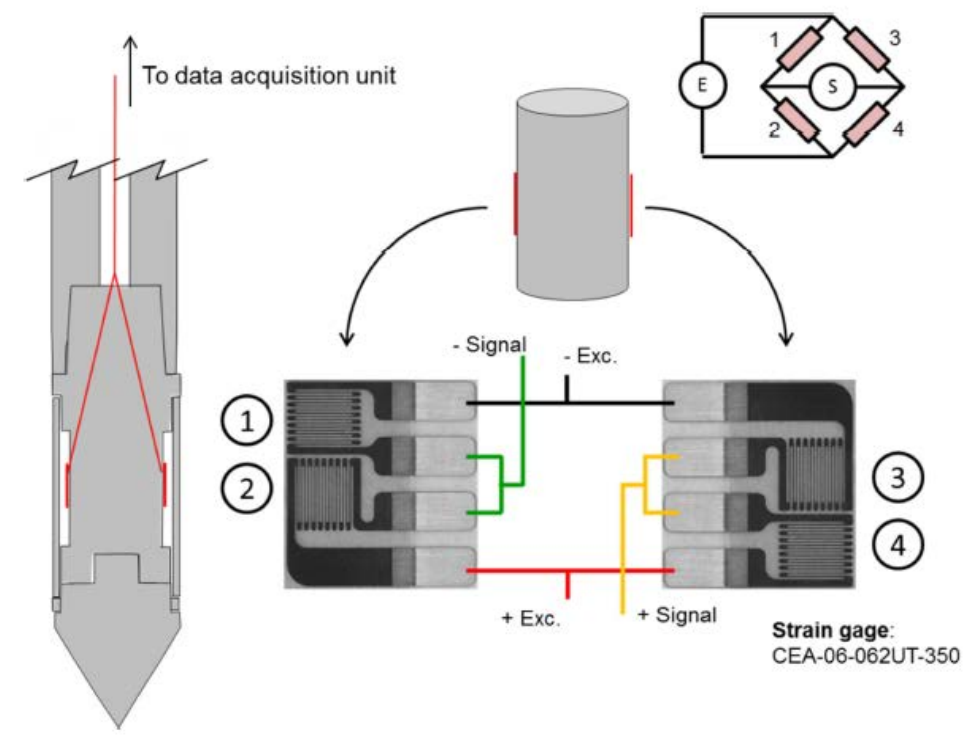

Figure 3.14 Strain gauge installation and configuration.

a)

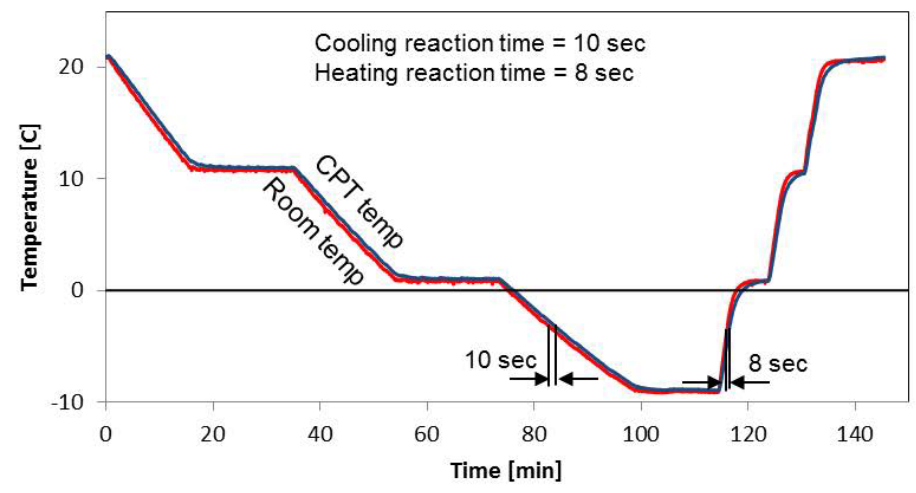

b)

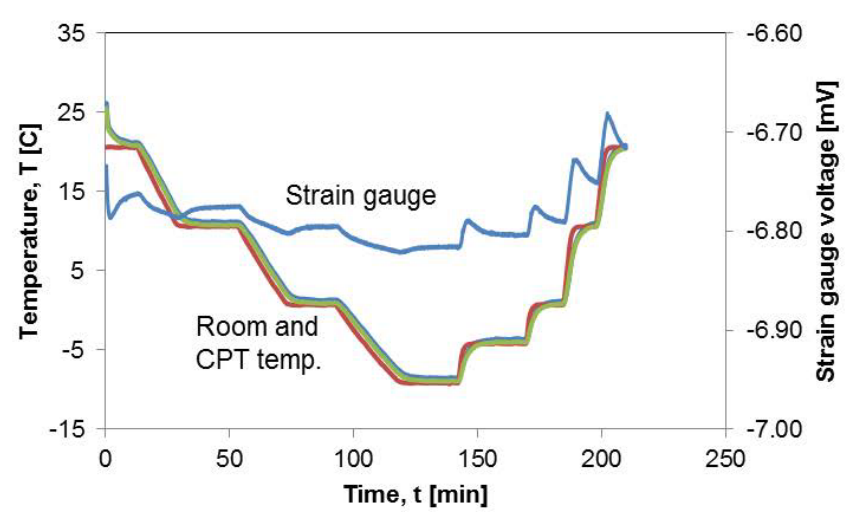

Figure 3.15 Tip module: temperature effect. (a) Thermocouples response time. (b) Strain gage response to temperature change. 
Thermal conductivity measurement. Thermal conductivity and diffusivity can be determined in active mode with a known heat source (either during heating or after shut off) and a thermocouple that is used to record the temperature change in time [Cortes et al., 2009; Waite et al., 2002]. A passive method can be implemented as well using the heat generated during probe penetration into the sediment (the typical increase in temperature is low $\Delta \mathrm{T}<1^{\circ} \mathrm{C}$ ). The passive method has been successfully used to characterize marine sediments [Von Herzen and Maxwell, 1959].

Thermal properties measurement using the single-sided transient plane heat source (TPS) technique has also been developed and laboratory tested. NETL has measured the thermal conductivity of pure hydrate crystals using the single-side TPS technique [Rosenbaum et al., 2007], which basically glued a TPS sensor on a PVC substrate to measure the thermal properties of the specimen laid on top of the substrate. So this becomes a problem of a plane heat source dissipating into two media, with thermal properties known for the substrate but to be determined for the tested specimen. Reasonably accurate thermal conductivity data of hydrate-bearing sediments can be achieved after simplification assumptions [Dai et al., 2015].
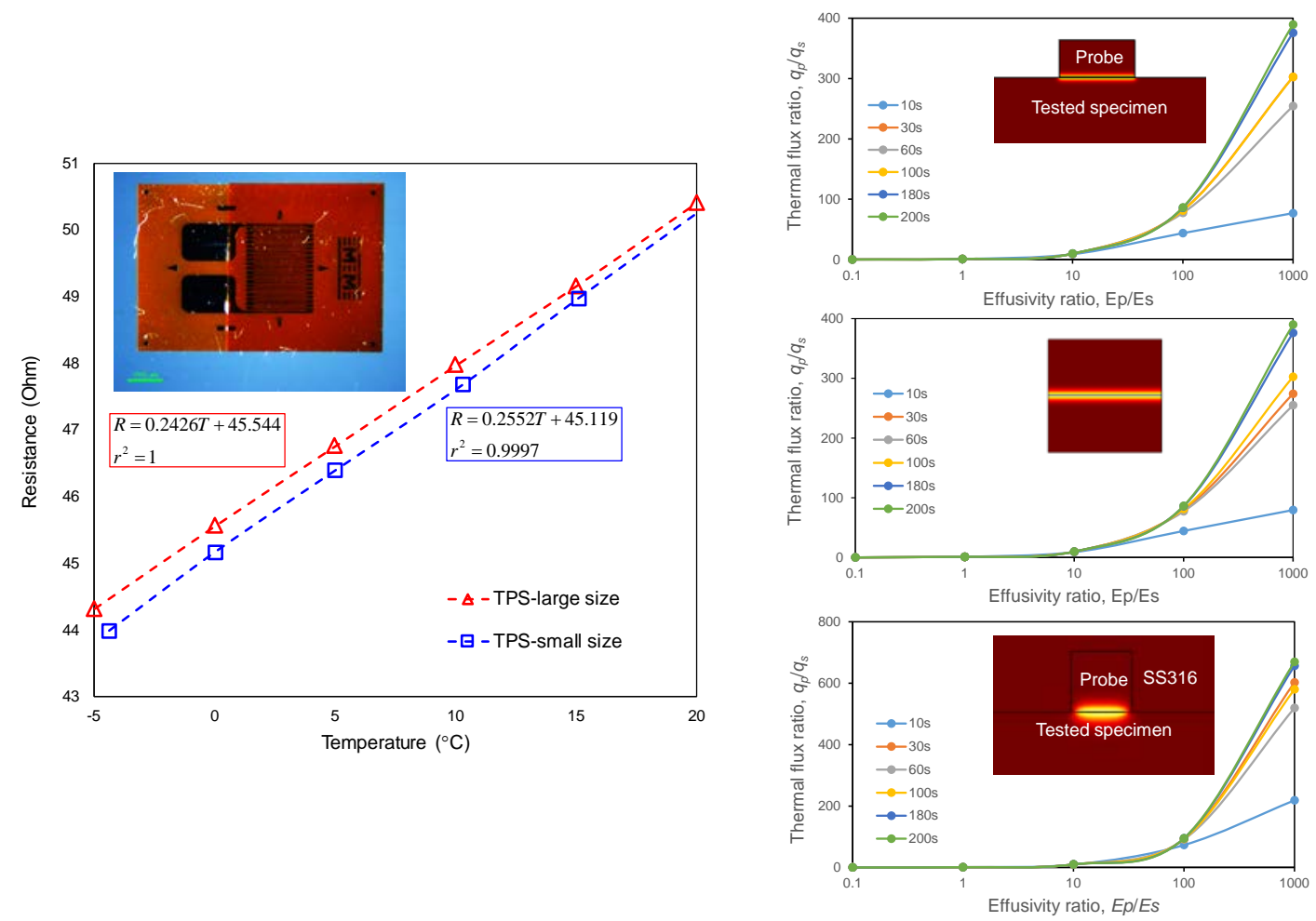

Figure 3.16 Left: Sensor calibration. Right: Impacts of the S-TPS probe configuration on measured thermal properties of the specimens. The $x$-axis reflects the effusivity (density $x$ thermal conductivity $x$ thermal diffusivity) ratio between the thermal probe and the tested specimen; the $y$ axis reflects the thermal flux ratio between the probe and the tested specimen. Scenarios of 
different duration of current injection have also been considered (from 10s to 200s) in order to identify optimum measurement duration.

\subsection{Visual module}

A module with visual capability has been prototyped and tested in the laboratory. The approach resembles video-cone developments by Hryciw and co-workers [RD Hryciw et al., 1998; Roman Hryciw and Raschke, 1996; Raschke and Hryciw, 1997]. Figure 3.17 shows the new video module and assembly to the tool. This module consists of an expanded body with the ability to hold an off-the-shelf high-pressure window (shown in the figure). The camera will be housed in this window. The system includes LED lights for illumination. This module is based on a standard Arduino friendly camera installed behind a sapphire window. Images of grains obtained in preliminary tests using this technology are shown in Figure 3.18.

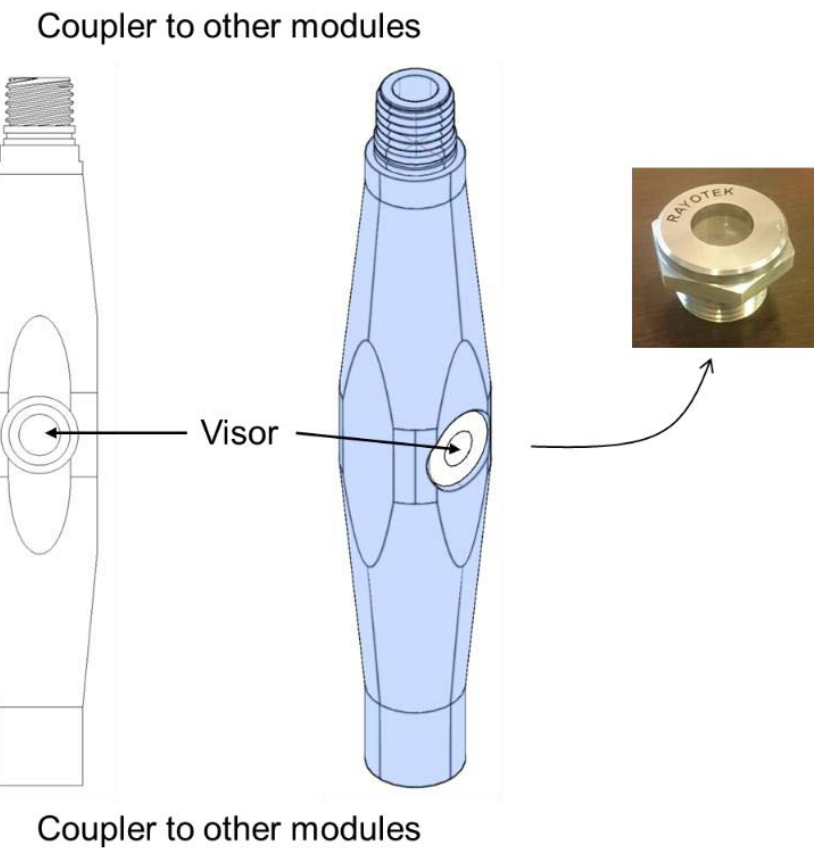

Figure 3.17 Video module. The visor consists of a high-pressure window. 


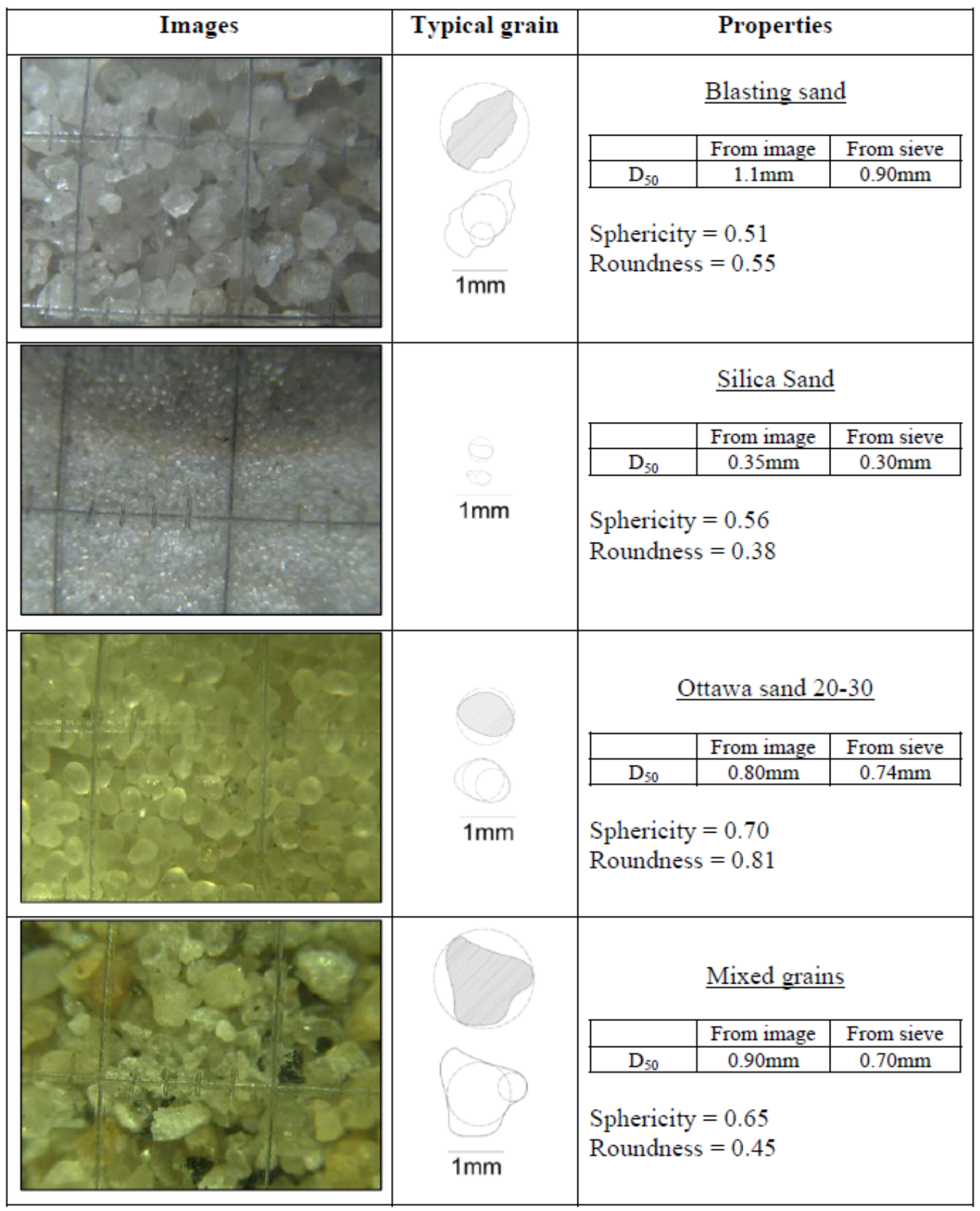

Figure 3.18 Video capability prototype test. Image analysis of typical grain compares well with sieving analysis in coarse grains. Sphericity = area of particle projection/area of the circle with diameter equal to the longest length of the projection. Roundness= average radius of curvature of surface features/radius of the maximum sphere that can be inscribed. 


\section{Borehole tool design - Instrumentation}

\subsection{Electronics - general configuration}

Collected data using this borehole tool can either transmitted to the surface vessel in real time or stored in the memory disks of the tool. Transmission requires a communication cartridge and a communication modem (weatherford.com). Data storage within the tool is possible using off-the-shelf microprocessors powered by standard batteries. This is the approach selected for this borehole tool. The chosen microprocessor is an Arduino UNO (www.arduino.cc) due to its intuitive architecture for sensor development, low power consumption, small dimensions and a large online library of projects and peripherals. Figure 4.1 shows the device ready to store data in an SD card, and its technical specifications.

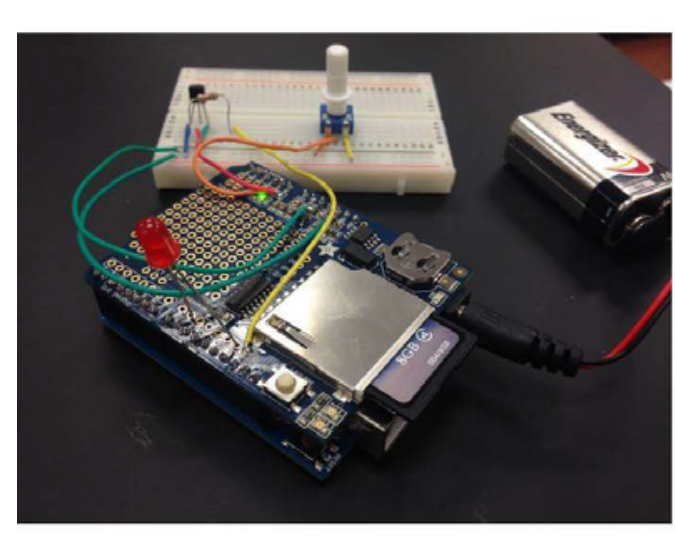

\begin{tabular}{|l|l}
\hline CPU & $16 \mathrm{MHz}$ ATmega328 \\
\hline Pins In/Out & $14 \mathrm{l} / \mathrm{O}$ \\
\hline Sampling frequency & $1 \mathrm{~ms}$ \\
\hline Memory flash & $32 \mathrm{~K}$ \\
\hline Size & $2.7 \mathrm{in} \times 2.1 \mathrm{in}$ \\
\hline Software & Arduino IDE (Java based) \\
\hline Power & Batteries / USB / AC-to-DC adapter \\
\hline Pc connection & USB port \\
\hline Voltage (limits) & $6-20 \mathrm{~V}$ \\
\hline Voltage (recomm.) & $7-12 \mathrm{~V}$ \\
\hline Operation voltage & $5 \mathrm{~V}$ \\
\hline Resolution & 10 bits \\
\hline Memory storage & Peripheral / SD card \\
\hline Price & $\sim \$ 30$ \\
\hline
\end{tabular}

Figure 4.1 Data storage unit: Arduino UNO (arduino.cc)..

The analog-to-digital converter ADC available on the microprocessor's on board is a 10 bits unit (expandable to 16 bits). This allows a resolution of $0.01^{\circ} \mathrm{C}$ for thermocouples and $0.01 \mathrm{mV}$ for load cells and strain gauges (Figure 4.2a, b, and c). Measured power consumption is plotted in Figure 4.2d for the Arduino, Secure Digital SD card writer, thermocouples, load cells, strain gauges and impedance analyzer (electrical resistivity measurements). Most of the power is consumed by the microprocessor and the data storage components. The maximum amount of time a single $9 \mathrm{~V}$ battery can last varies from 1 to $3 \mathrm{hrs}$.

The microprocessor, board, and circuitry have been tested to improve accuracy and resolution of the various strain gages used in the tool. The force module integrated with the new command board were tested within a high-pressure chamber (maximum pressure = 35MPa) under two power supply voltage levels: 5 and 10V. Figure 4.3 shows the results 
of this test. The $5 \mathrm{~V}$ board delivered lower resolution data (0.5MPa to $1.8 \mathrm{MPa}$ jumps). On the other hand, the $10 \mathrm{~V}$ supply delivered data with $0.18 \mathrm{MPa}$ resolution. The final tool assembly involves three battery packs for power supply: strain gages, microprocessor and solenoid valves.
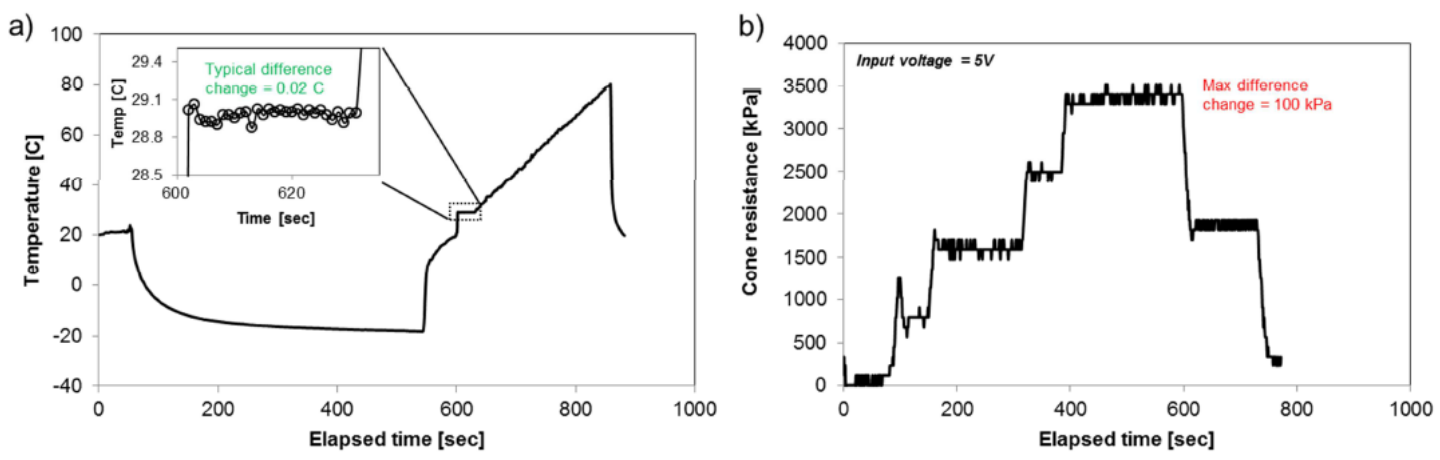

c)

d)
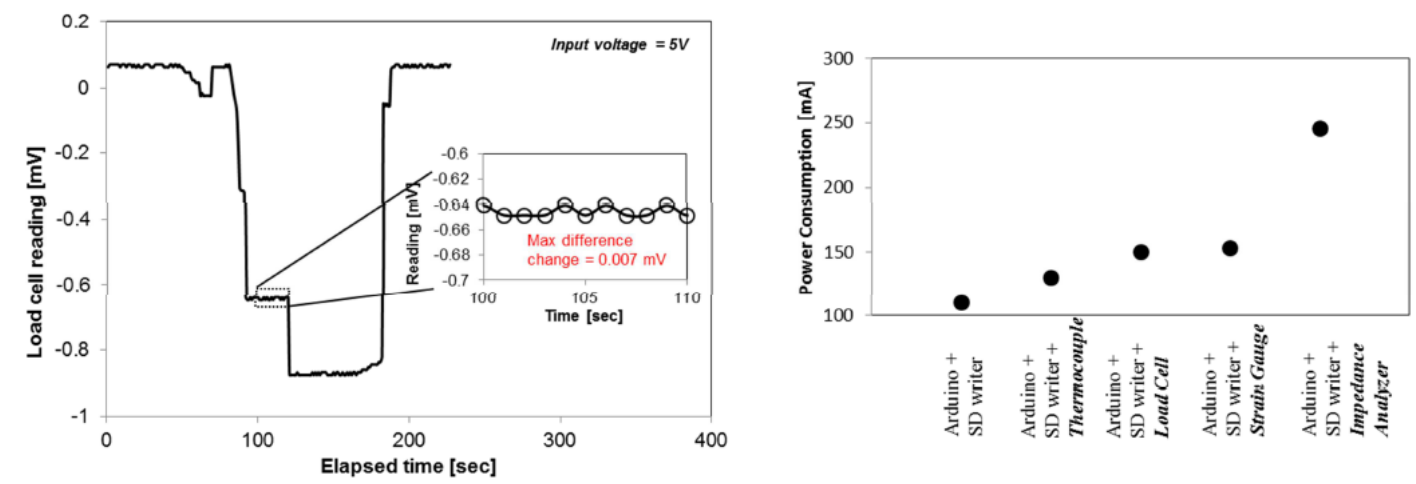

Figure 4.2 Data storage unit: Resolution (a) Thermocouples. (b) Strain gauge. (c) Standard load cell. (d) Power consumption.
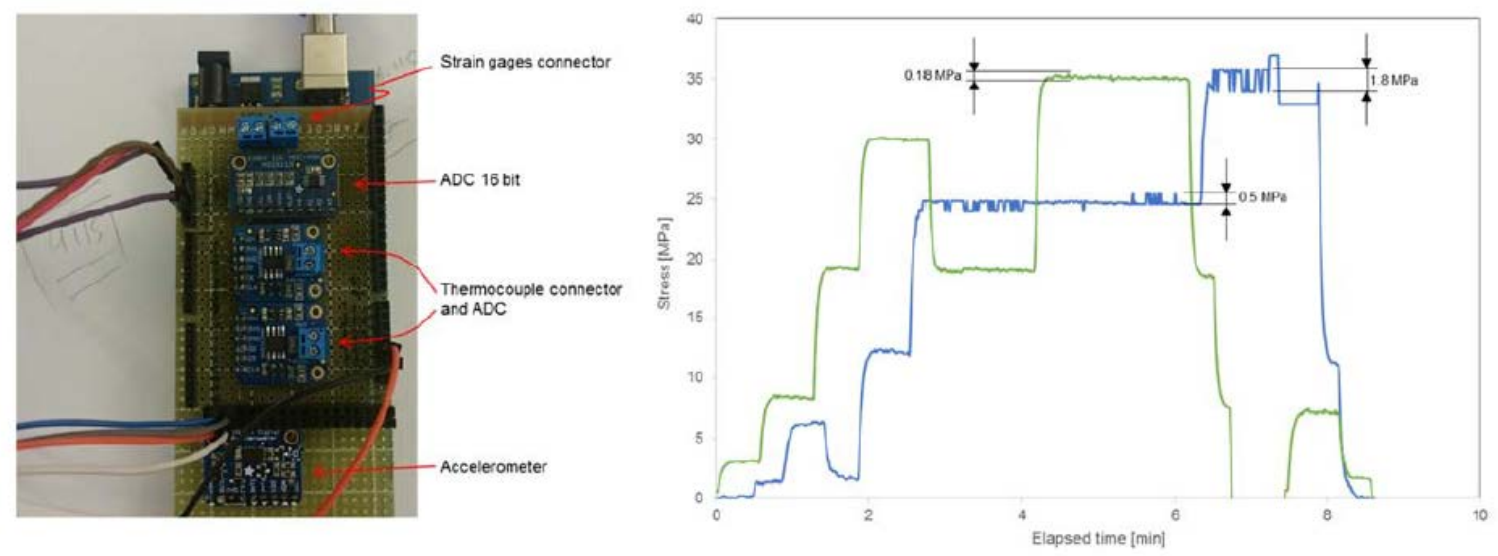

Figure 4.3 Electronics: Enhanced resolution attained with the new board, microprocessor and circuitry. 
The final design for the board (PCB; Figure 4.4) and circuitry have been finalized (Figure 4.5). The current design brings significantly enhanced flexibility for new sensors, as needed in the near future. This new PCB consists of a Raspberry Pi master controller and an Arduino Mega as a slave. The master commands the Arduino, indicates when to run tests and operating conditions, and is in charge of data storage. At the same time, the Raspberry Pi gathers data from the three pressure transducers.

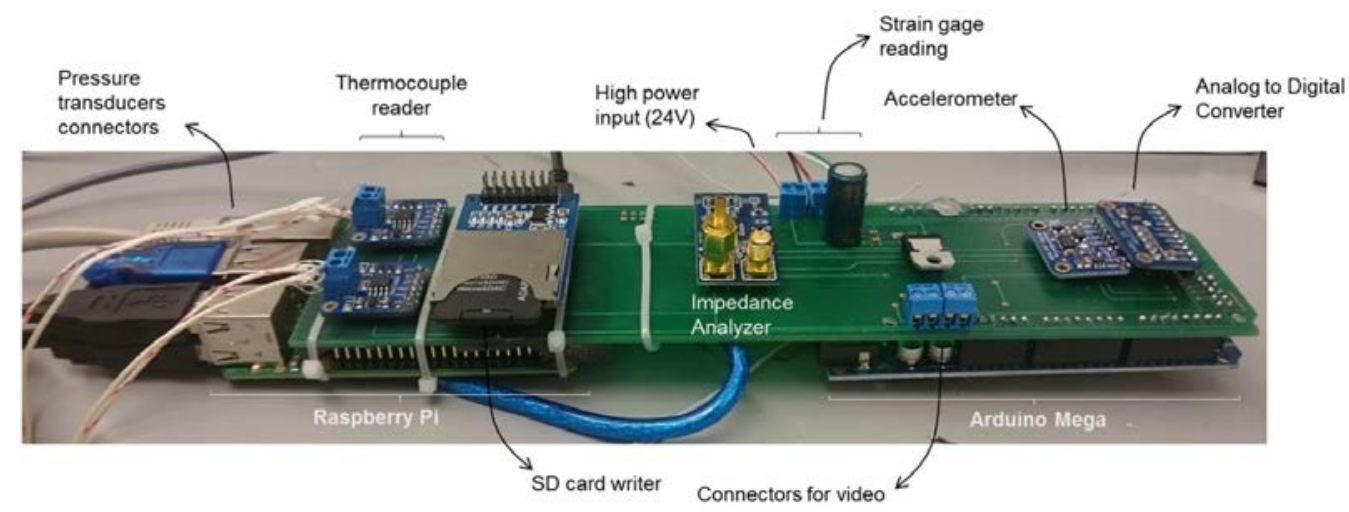

Figure 4.4 Electronics: new PCB configuration.

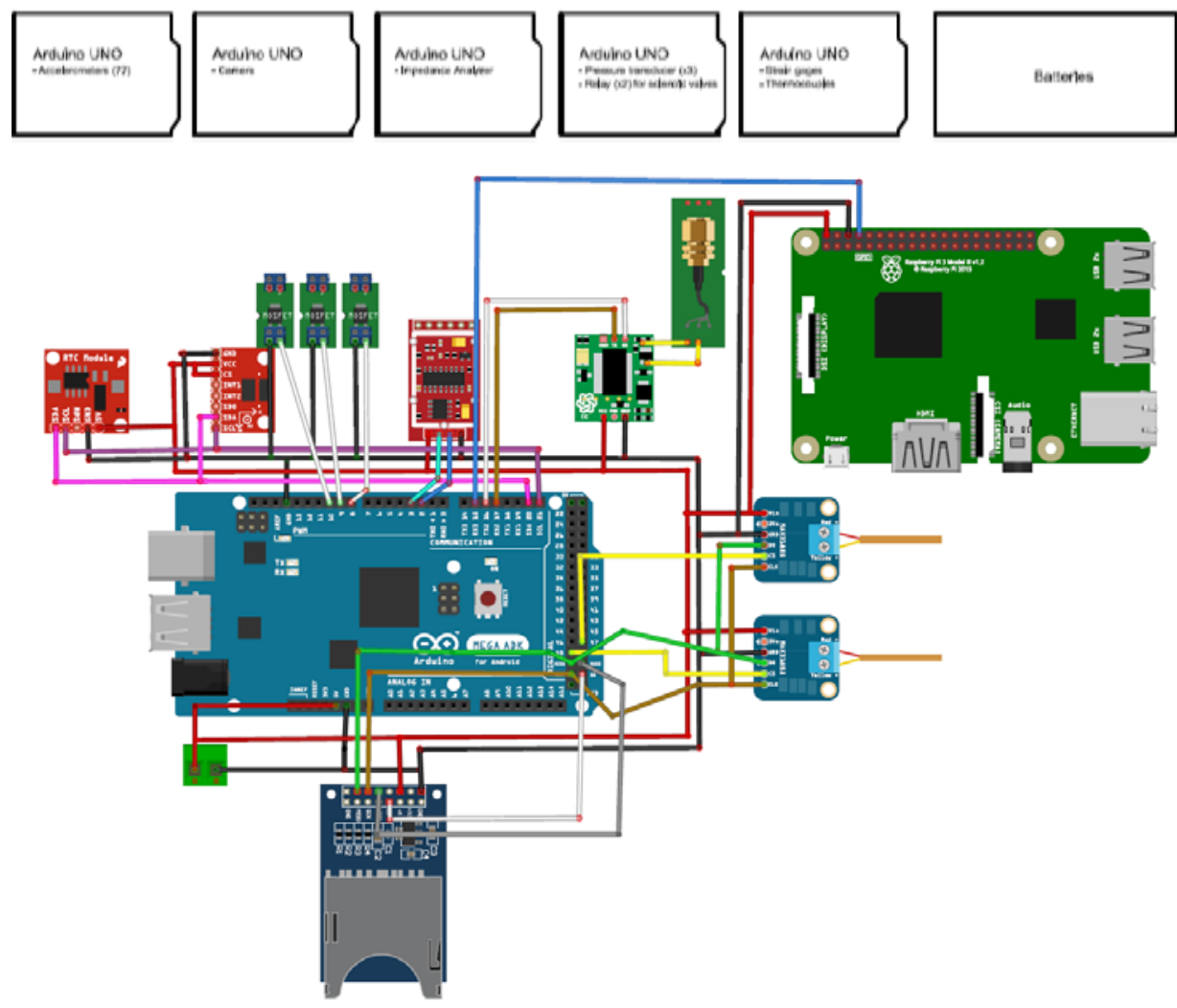

Figure 4.5 Latest version of electronics configuration (updated after field deployment). Arduino Mega with peripheral data amplifiers. 


\subsection{Moduli configuration}

Figure 4.6 presents the detailed design of the board, circuitry, and key component of each testing module in the borehole tool developed in this project.

Force measurement

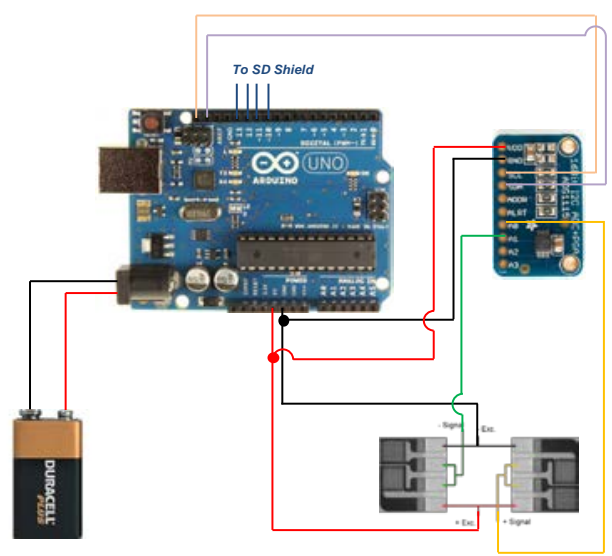

Pressure

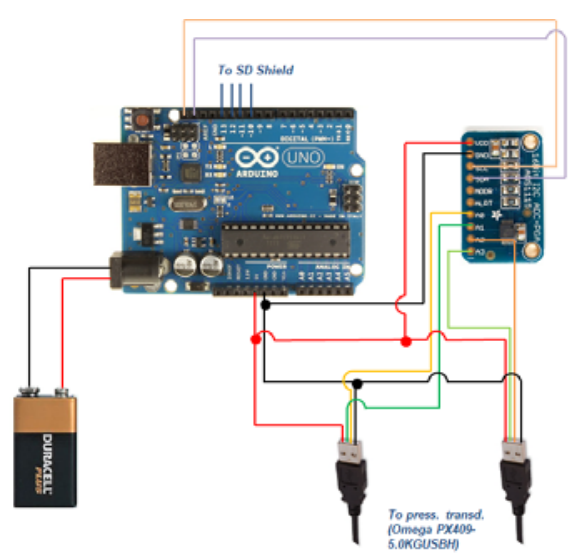

Electrical conductivity

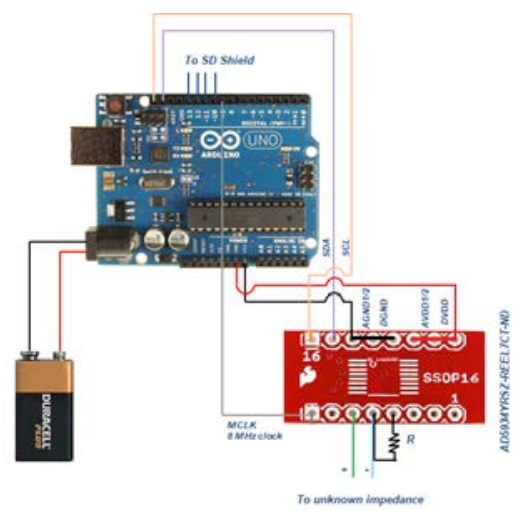

Thermal

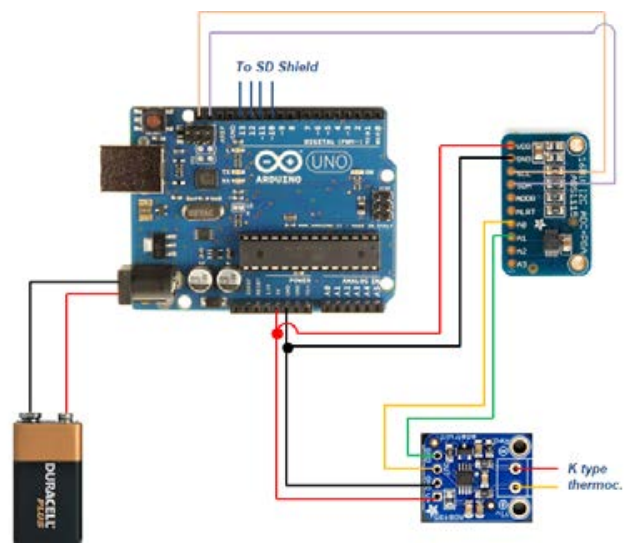

Sampling and hydraulic conductivity

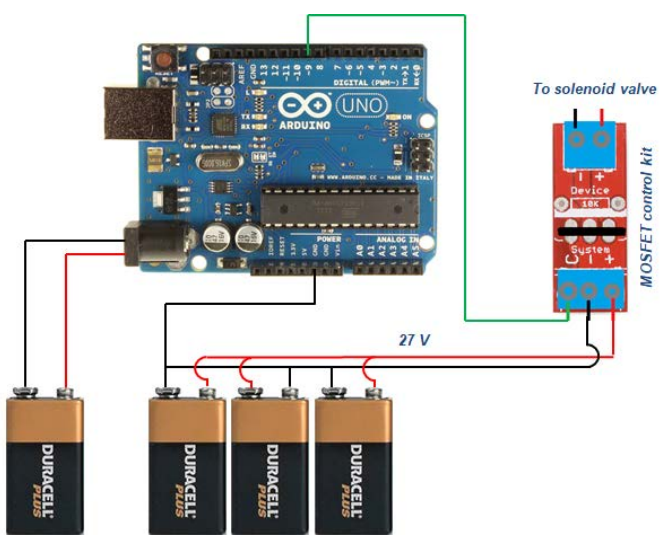

Video

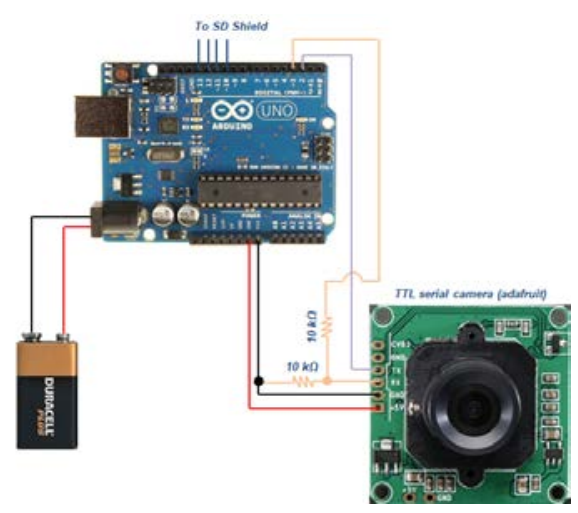

Figure 4.6 Details of the components and circuitry design of each testing module. 


\section{Laboratory full-scale prototype assessment}

\subsection{Tool fabrication and assembly}

Major components of the borehole tool in this project include the body, the testing module, the tip (force) module, the coupling with BHA, and electronics. Detailed dimensions of each machined piece are presented in Figures 5.1-5.4.
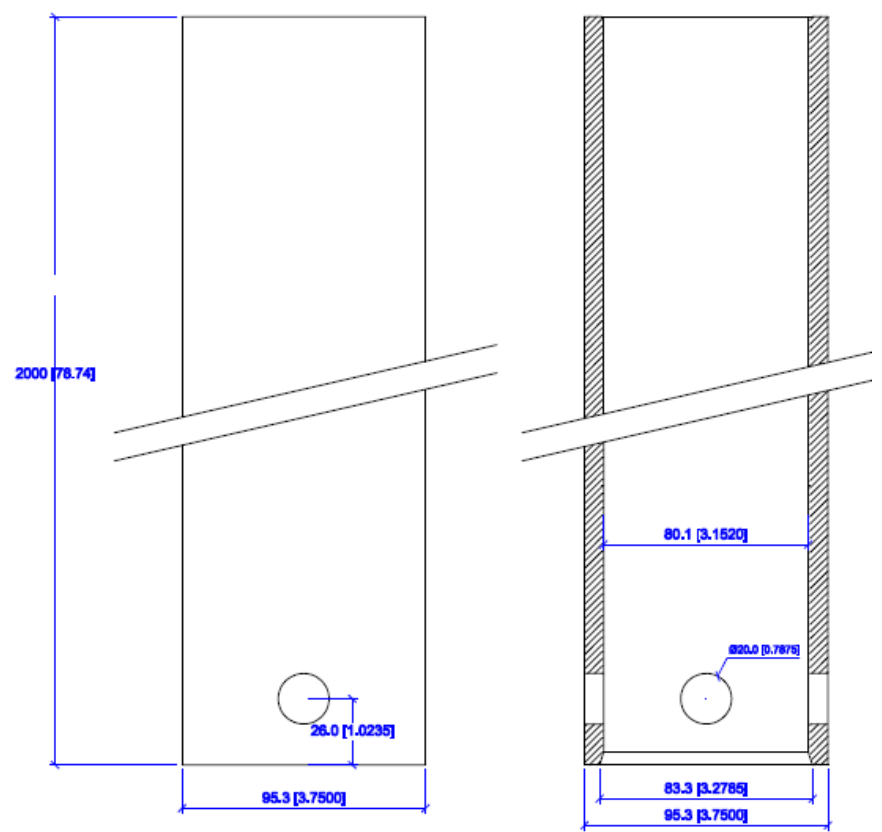

Figure 5.1 The detailed dimension of the tool body (to house electronics, valves, cables, and memory disks).
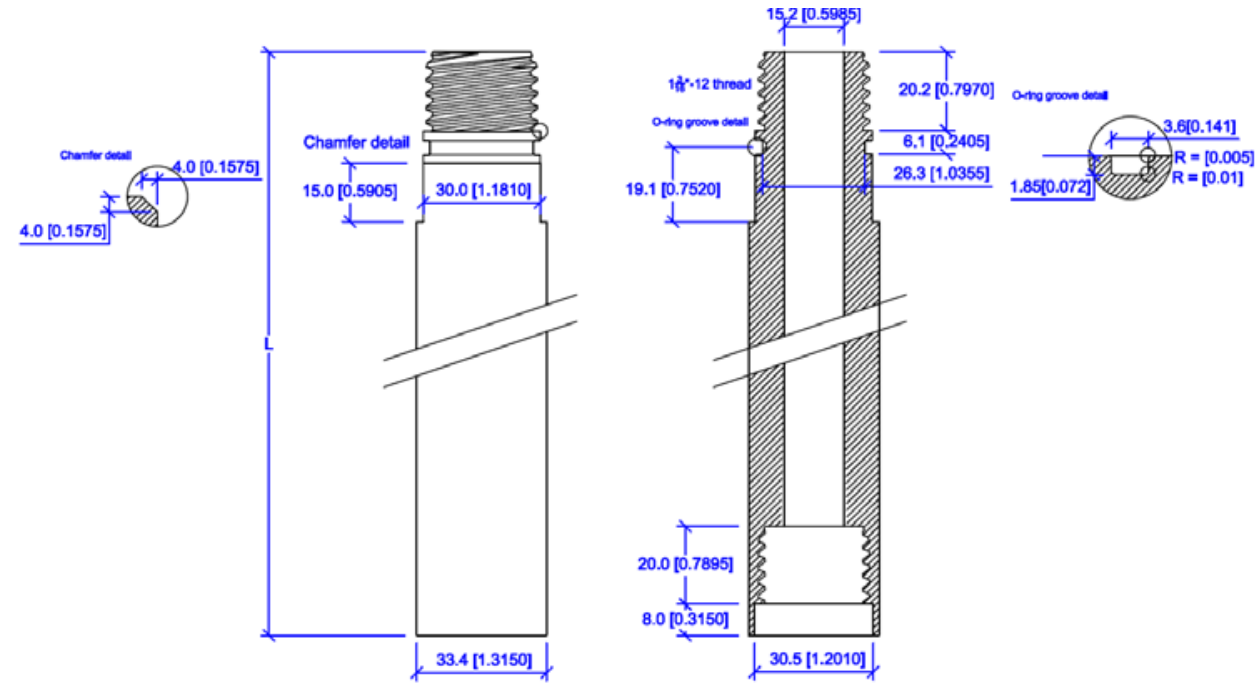

Figure 5.2 The detailed dimension of the testing module. The length of each testing module varies 
from $0.15 \mathrm{~m}$ to $1 \mathrm{~m}$ depending on the nature of the measurement properties and methods.

(a)
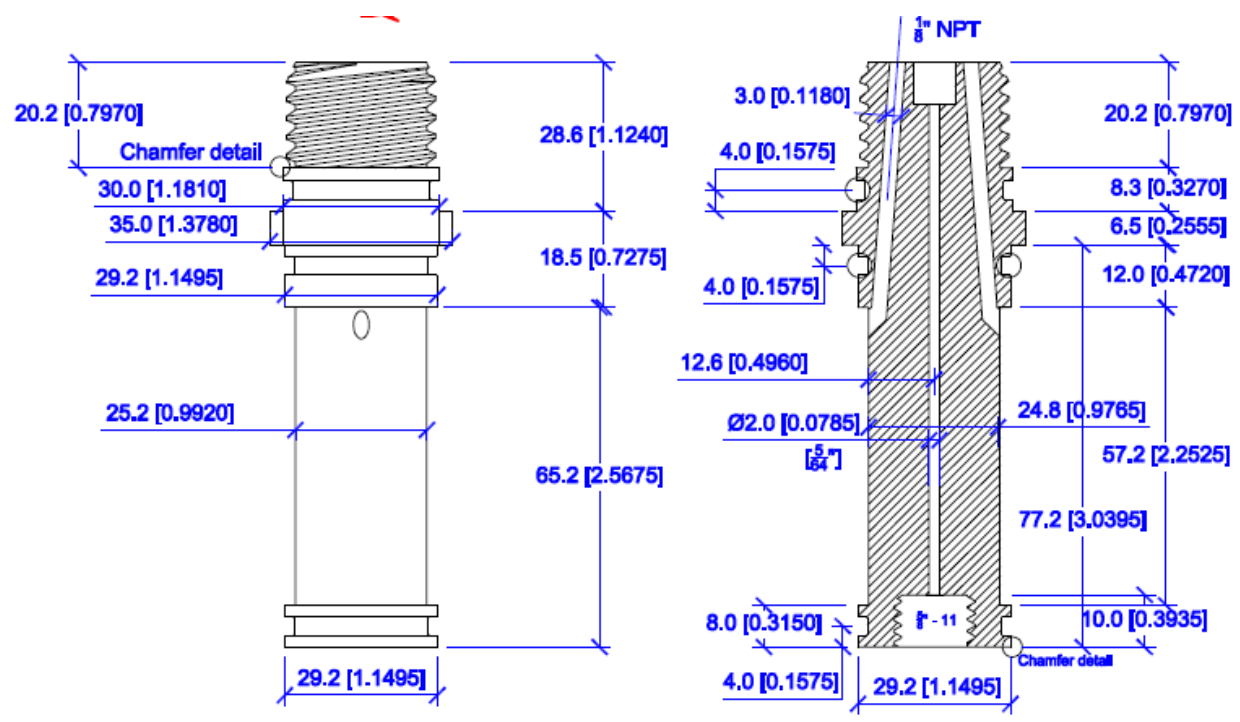

(b)

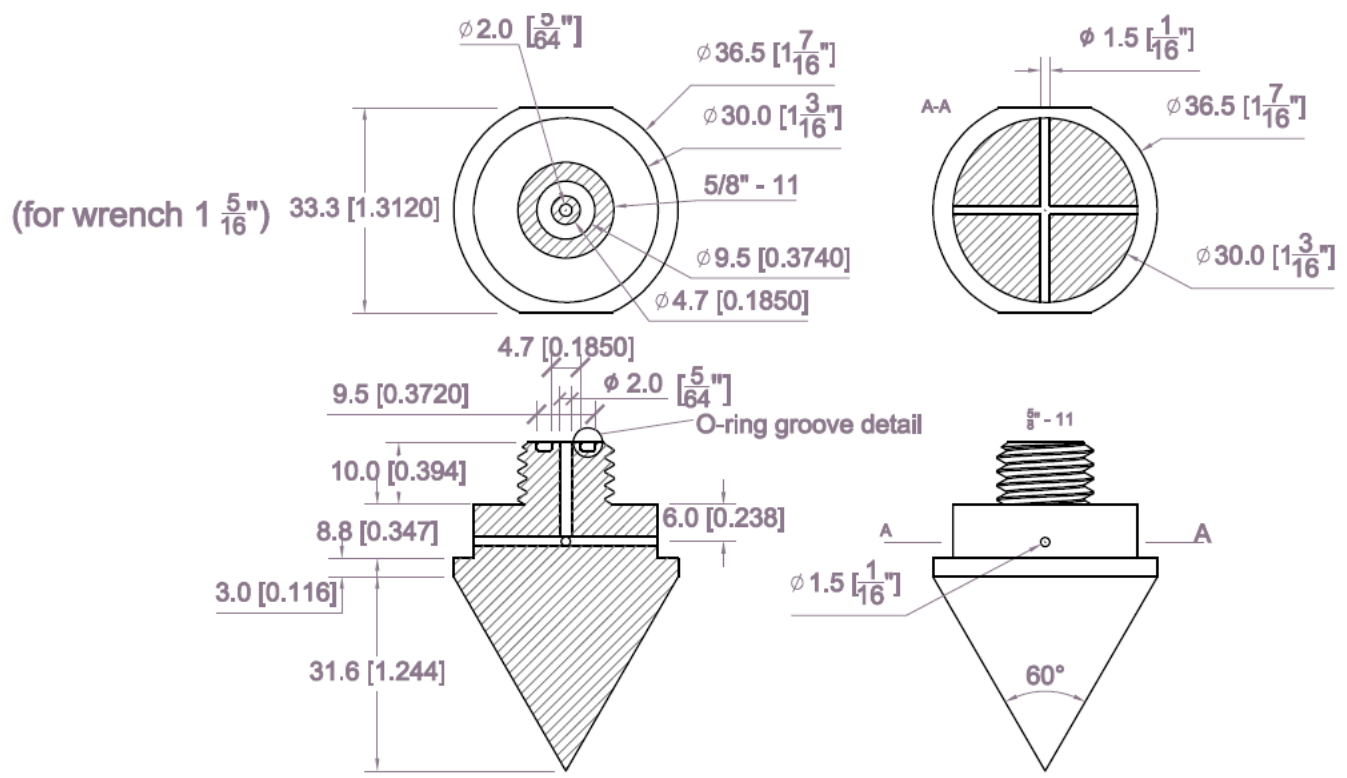

Figure 5.3 The detailed dimension of the tip (force) module. (a) The inner stem of the force module to house strain-gauges for strength measurement and two thermocouples for temperature measurement. (b) The tip of the force module for penetrating into hydrate formations and pore water sampling. Note that the force module has identical end connection as that in the testing modules. 

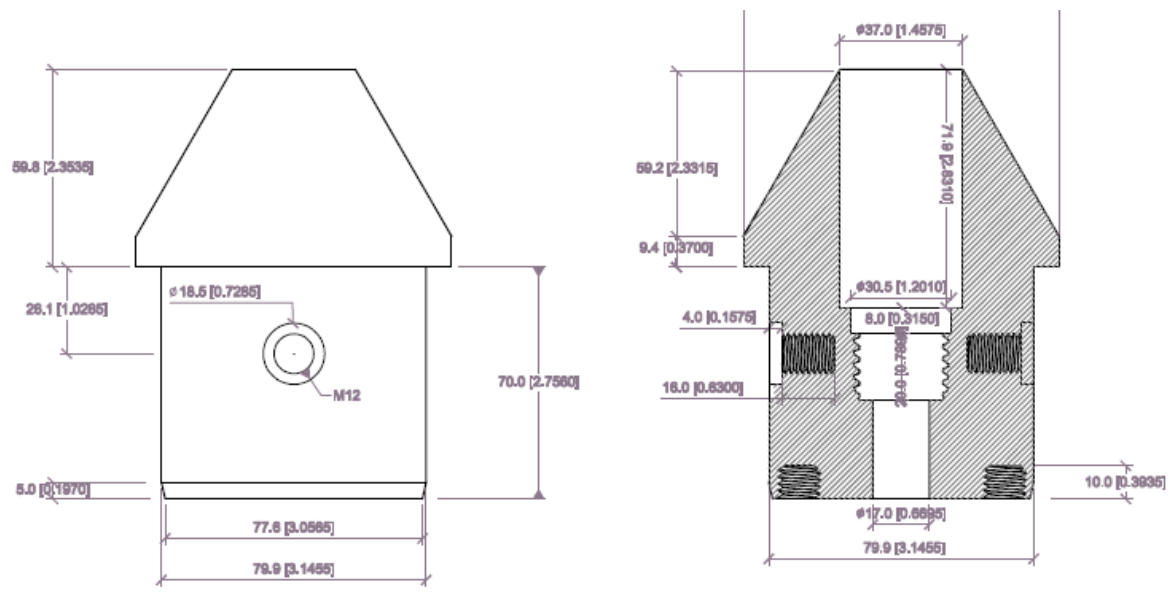

Figure 5.4 The detailed dimension of the bottom cap to couple the testing modules with the main body.

Figures 5.5-5.8 show the assembly of the major machined pieces, electronics and peripherals housed in the tool body, and the overall geometry after assembly of them.

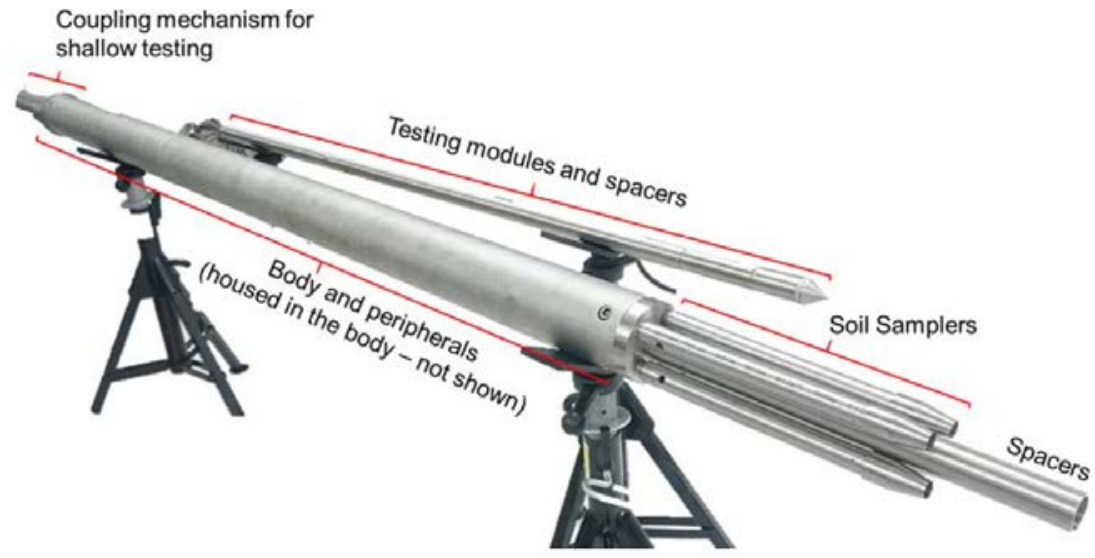

Figure 5.5 Major machined pieces of the borehole tool.

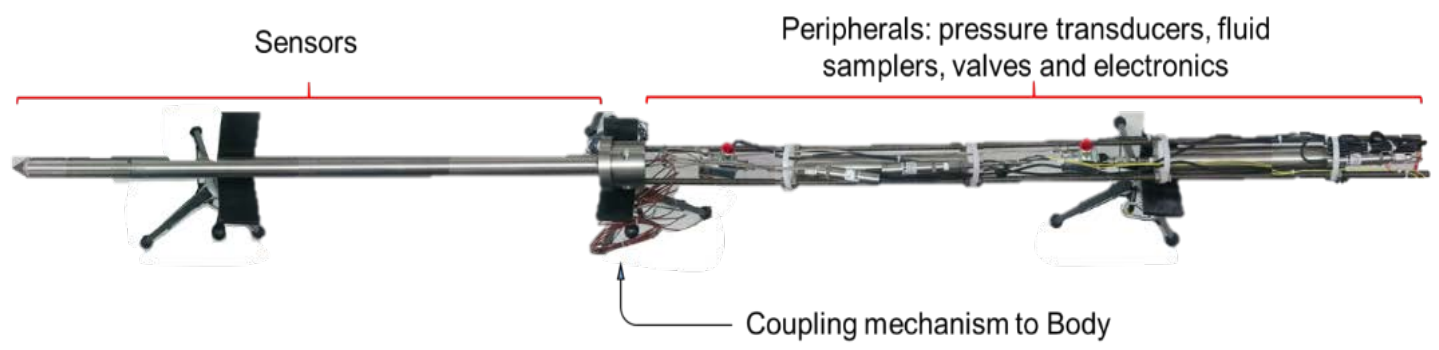

Figure 5.6 Sensors and peripheral components housed within the tool body. 


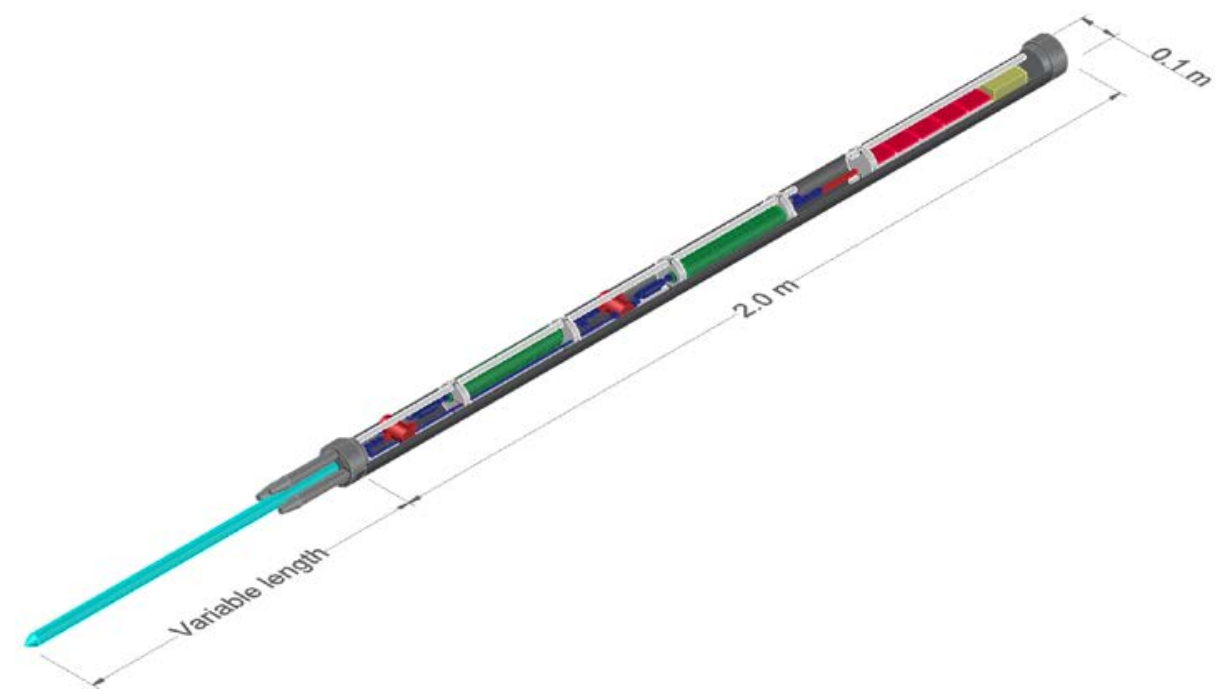

Figure 5.7 Overall dimension of the assembly borehole tool.
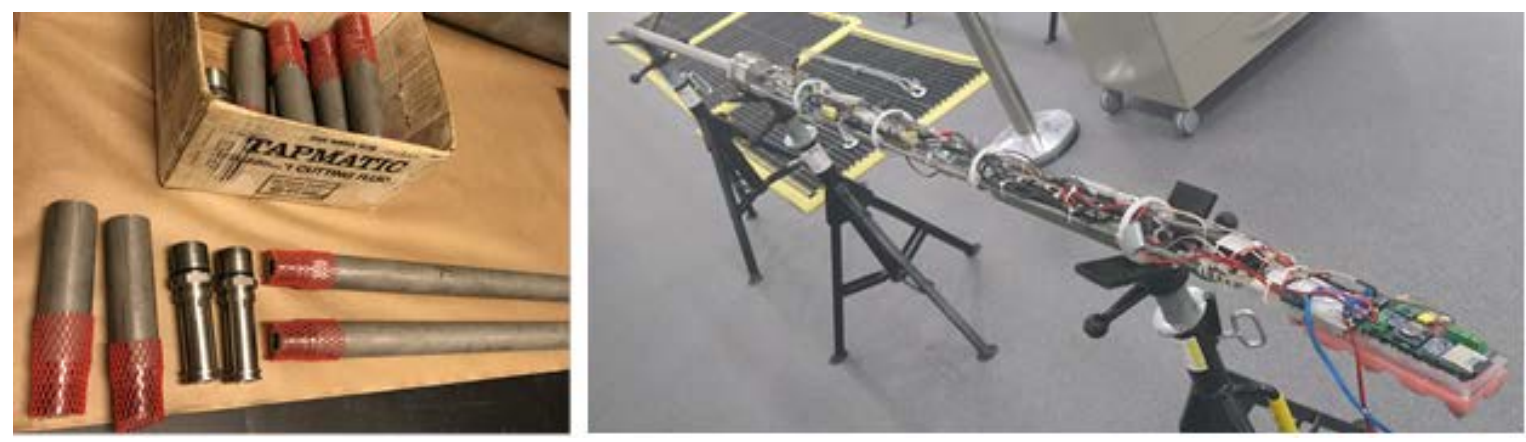

Figure 5.8 Left: machined testing modules and the tip module. Right: assembled borehole tool. The body houses the peripheral components of the tool including the piping, pressure transducers, fluid samplers, valves, and electronics.

\subsection{Borehole tool coupling with PCTB BHA}

The force module has a $10 \mathrm{~cm}^{2}$ cone area and a $130 \mathrm{~mm}^{2}$ sleeve area. No any crosssectional diameter of the tool exceeds 3-3/4 inches, so that it can go through the seal bore drill collar and the landing seat. A CDS type coupler was designed by Pettigrew Engineering to couple the borehole tool in the project with PCTB bottom hole assembly (BHA) and APC/XCB BHA.

The CDS can drive the probe into the formation $1.8 \mathrm{~m}$ and provide for \pm 2 meters heave compensation. The maximum designed load is 9,000 lbs. If exceeded, the overload collet will release to allow the probe be retracted inside the BHA. The designed CDS is compatible with both the PCTB BHA and the APC/XCB BHA. Figure 5.9 illustrates the coupler 
and major components of the coupler design.

(a)
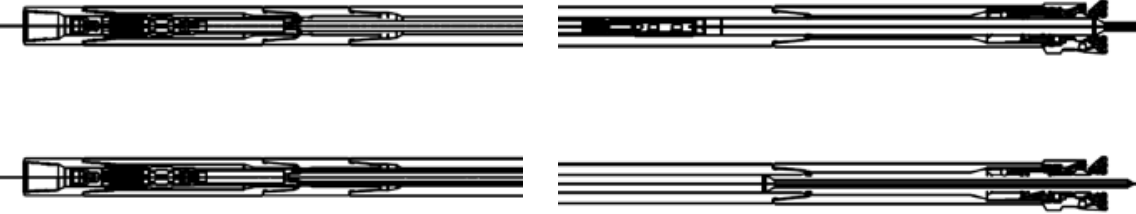

(b)
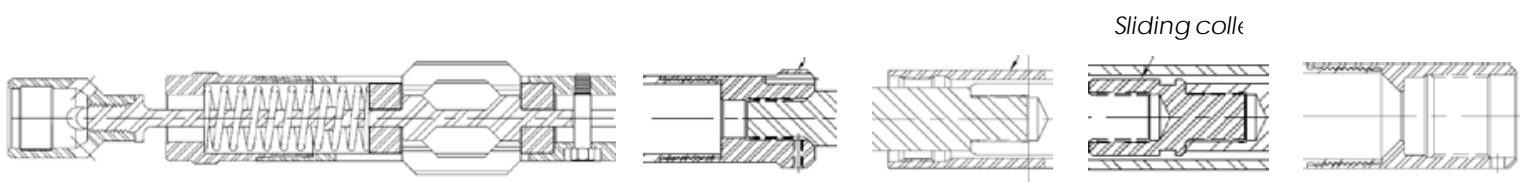

Figure 5.9 Coupler design. (a) Illustration of the borehole tool in run in and collet release status with PCTB BHA. (b) Major parts and assembly the CDS-type coupler of the tool with PCTB BHA.

\subsection{Prototype test}

The prototype tests include a mechanical test at Lake Acworth, Georgia and a highpressure test at the Coastal Marine Resources Core Laboratory at the King Abdullah University of Science and Technology (KAUST).

Mechanical tests. The near surface sampling tests to validate the expected recoverable length in un-cemented soil using a small radius sampler were conducted on Lake Acworth, Georgia (coarse-grained soils) and in a fill at Georgia Tech (fine-grained soils). Two driving conditions were tested. The first one consists of driving two different samplers into the sand with a hammer (dynamic penetration). The second test uses a continuous push. This system implies a reaction frame, with three ground anchors, an Enerpac hydraulic cylinder, and a load cell to record penetration forces (Figure 5.10). The water table is 5cm below the surface.

Two samplers were tested using both penetration methods. Sampler one is a $25 \mathrm{~mm}$ open ended pipe; hence its inside clearance $C_{i}$ is zero. Sampler two is a specially designed sampler for the recovery of disturbed samples from hydrate-bearing sediments. It has a cutting shoe with $\alpha=10^{\circ}$ angle and a reduction of the internal diameter so that the inside clearance ratio is $C_{i}=3.7 \%$. No catcher was used with either sampler. 


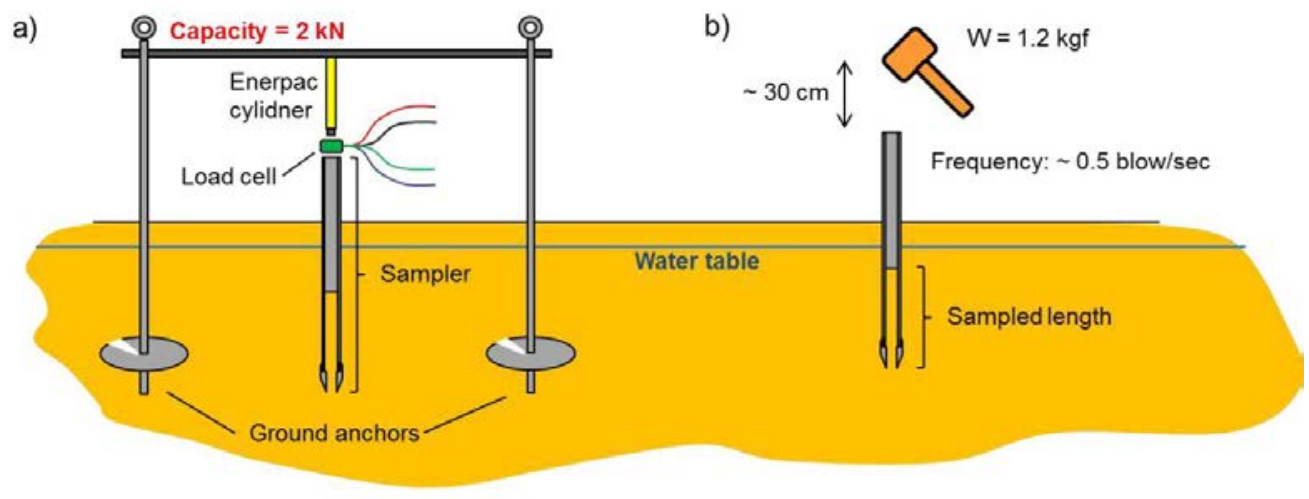

c)

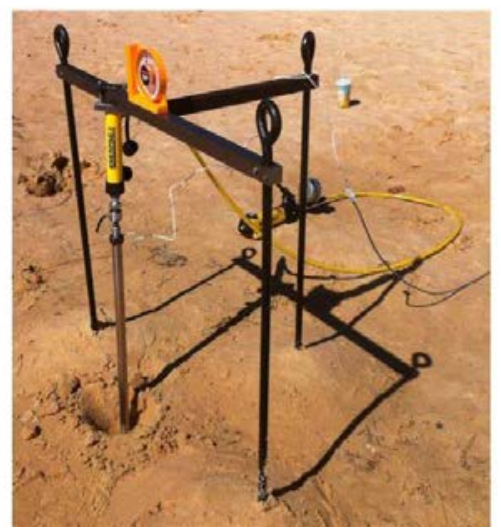

d)

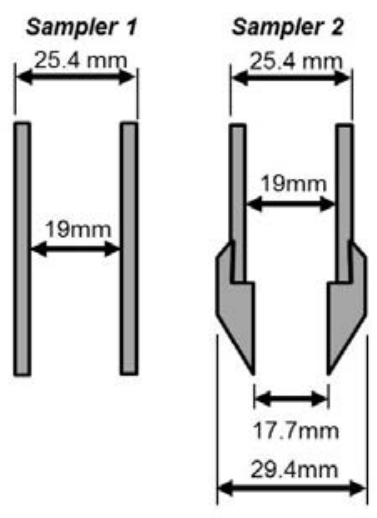

Figure 5.10 Core recovery with small sampler - Field study: (a) Continuous push schematics. (b) Dynamic driving. (c) The picture at the site. (d) Samplers dimensions.

Figure 5.11 shows the lengths of the recovered two types of soil samples using the two driving methods of both samplers. Each test was repeated 5 times. The box represents the median, $25^{\text {th }}$ and $75^{\text {th }}$ percentile of test results, while the segments run from the maximum and the minimum recorded values.

The results confirm the benefits of dynamic driving over pushing to gather longer samples. Sampler two, with a sharp cutting shoe and an internal clearance, delays frictional build up and leads to longer samples in both static and dynamic modes. The internal clearance facilitated the extrusion of the sample after testing in the case of fine-grained soils. The expected plug length is also shown here for the cases of friction angles of $\varphi=20^{\circ}$ and $\varphi=35^{\circ}$. They agree well, particularly with data gathered with sampler one, i.e., a pipe without a cutting shoe.

The penetration force was recorded to the maximum load cell capacity $2 \mathrm{kN}$ (Figure 5.11b). The penetration forces increase quasi-linearly with depth, as expected for frictional materials, and there is no evident difference between the penetration resistances exhibited 
on both samplers with different cutting shoes.

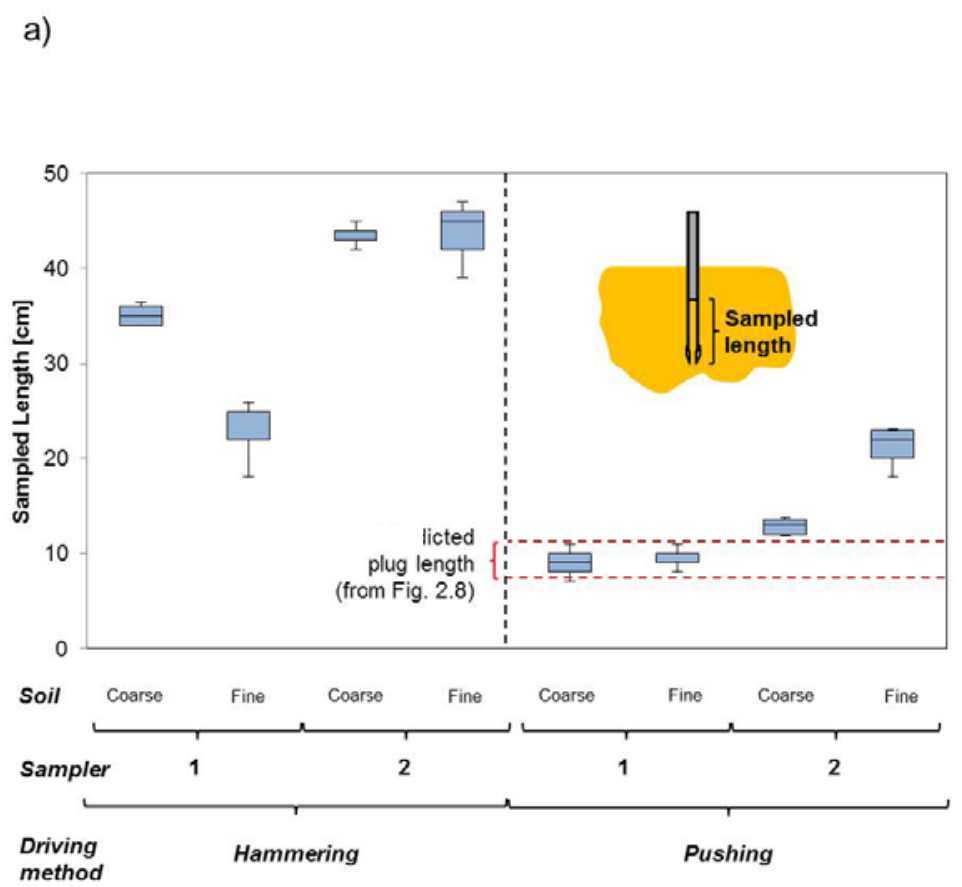

b)

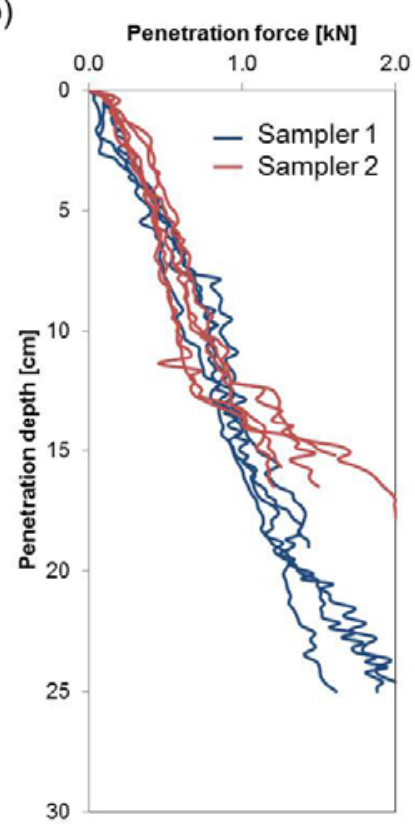

Figure 5.11 Core recovery with the small sampler. (a) Sampled length (distance measured before removing the sampler from the ground). (b) Penetration force vs. depth. There is no clear evidence of significant differences between the two samplers.

Pressure testing. The borehole tool was subjected to a pressure test within the highpressure vessel at the Coastal Marine Resources Core Laboratory at KAUST. The highpressure vessel has a $0.5 \mathrm{~m}$ internal diameter, a $2.5 \mathrm{~m}$ internal depth, and is able to sustain up to $100 \mathrm{MPa}$ internal pressure at temperatures ranging from 0 to $100^{\circ} \mathrm{C}$. Figure 5.12 shows the borehole tool about to be tested in the high-pressure vessel, the pressure history imposed during the test including pressure steps at 1, 5, 10, 20 and 35MPa, and the highpressure vessel with the testing tool. The borehole tool sustained the 35MPa (350 bars) water pressure without any leakage.

Figure 5.13 shows the data gathered with three pressure transducers, two thermocouples, and a three-axis accelerometer. One pressure transducer captures the three penetration events (others are for flow tests and remain inactive). The accelerometer signature shows spikes and plateaus reflecting different stages during tool manipulation. 

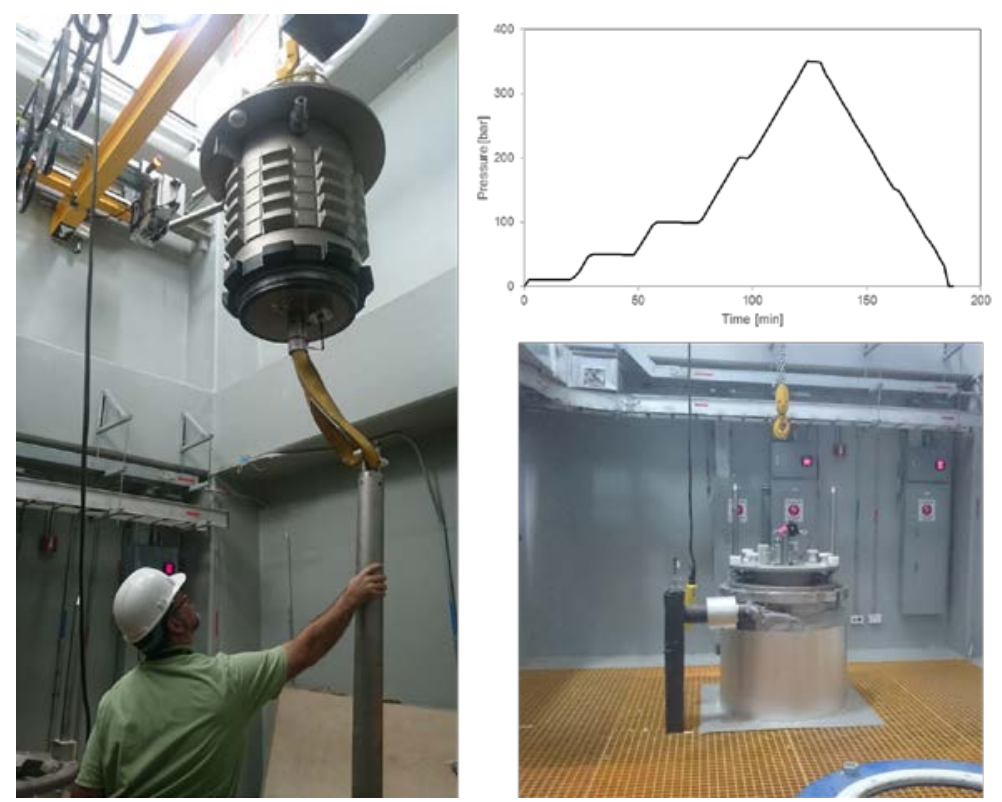

Figure 5.12 High pressure vessel and pressure test.

a)

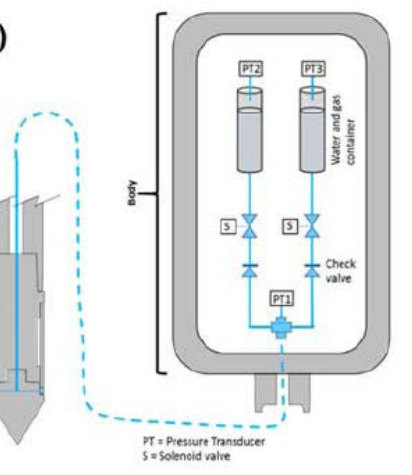

e)

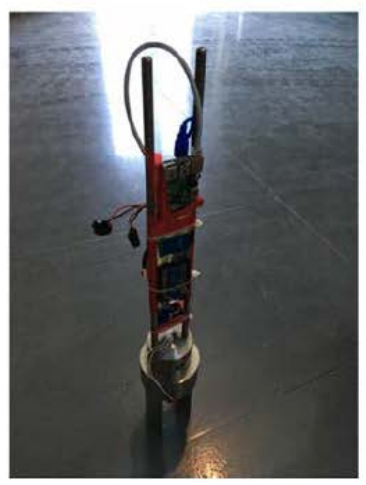

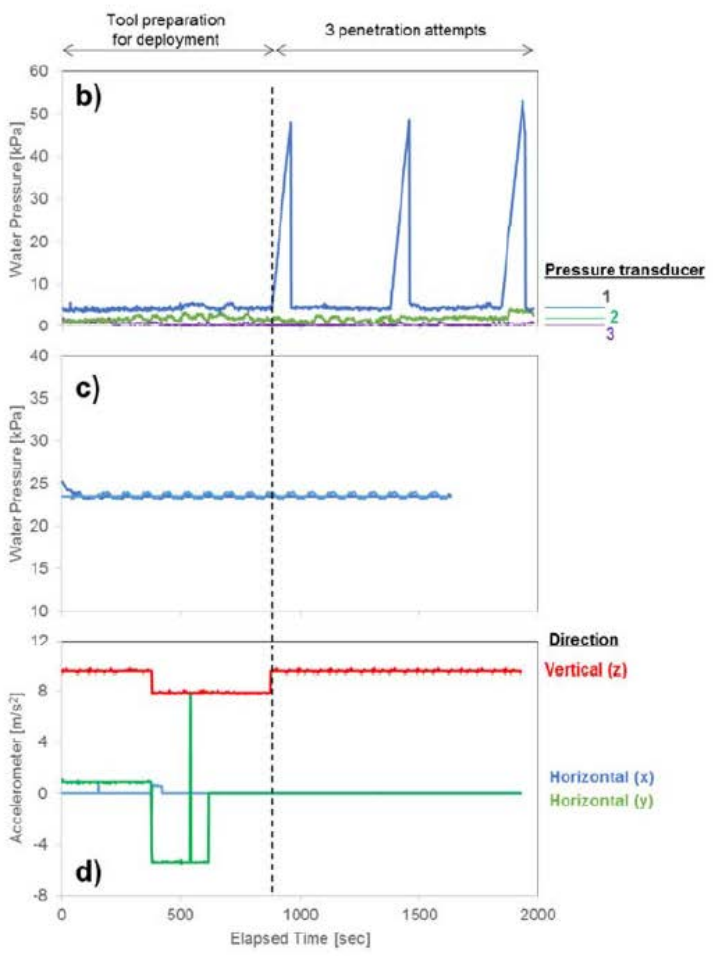

Figure 5.13 High-pressure vessel testing - sensor readings. (a) Pressure transducers location. (b) Pressure transducers readings showing the three tool insertions. (c) Temperature readings at the tip. (d) Accelerations for the three principal directions. (e) Assembly of electronics in the rack ready to be connected and inserted into the tool body. 


\section{Field deployment}

\subsection{Offshore deployment}

Offshore deployment of the borehole tool has been performed twice on the near coast of KAUST. The location for this test is at about $12 \mathrm{~km}$ from the shore (as shown in Figure 6.1). The test site was advised by the Coastal and Marine Operations Resources of KAUST and agreed together with the Coast Guard. The water depth at this site is 20.6 meters.

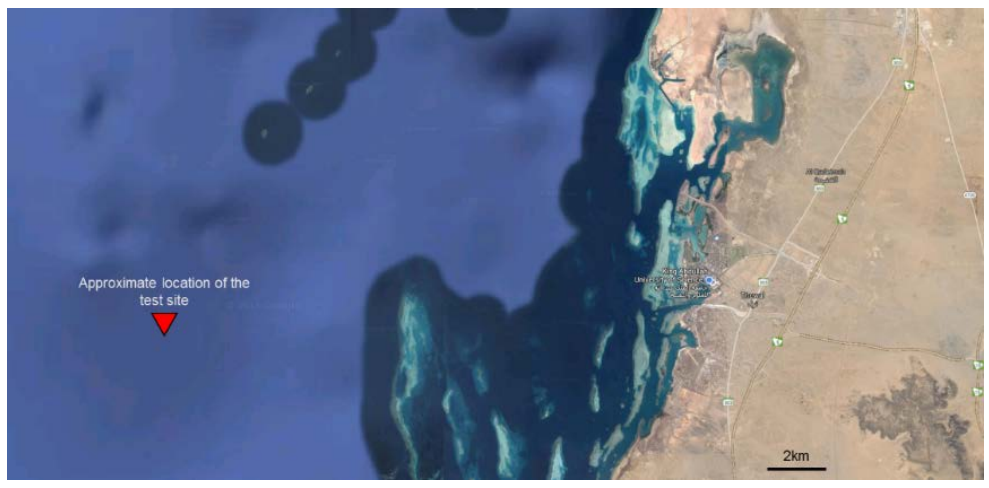

Figure 6.1 Test site of the tool field deployment: 12 km offshore KAUST.

The two deployments were able to determine penetration resistances, water pressures, thermal properties, and obtain soil and water samples. For both of the tool deployment, the in-situ tool was assembled as shown in Figure 6.2.

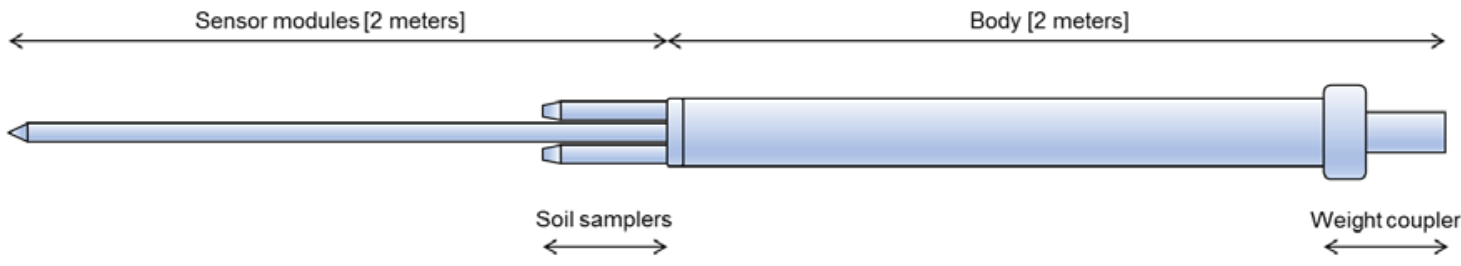

Figure 6.2 General schematics of the tool assembly and the dimensions.

Complete testing procedures are following:

- Arrival at the testing site;

- Lower the tool up to 5 meters for stabilization and final check for electronics and sensors; 
- Sediment testing: cone penetration at a rate of $2 \mathrm{~m} / \mathrm{min}$;

- Controlled water sampling;

- Tool recovery.

Figure 6.3 summarizes the key steps of the two fieldwork.
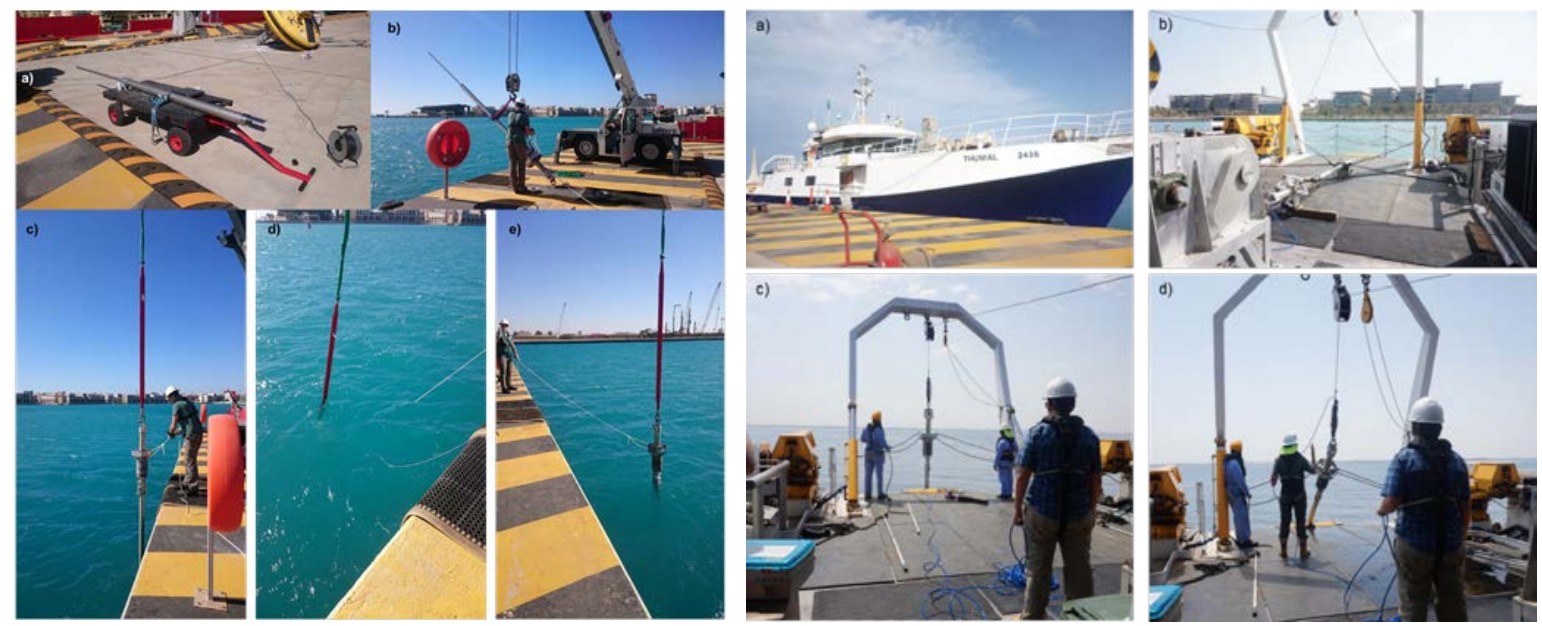

Figure 6.3 Key steps of the tool deployment. Left $-1^{\text {st }}$ tool deployment: (a) Tool waiting to be coupled. (b) Lifting and approach to the water. (c) Decoupling to the hoist. (d) Lowering the tool to start the test. (e) Retrieving the tool. Right $-2^{\text {nd }}$ tool deployment: (a) Research Vessel Thuwal R/V. (b) Departing from KAUST. (c) Tool ready to be lowered. (d) Tool recovery.

Figure 6.4 shows the measured water pressure and the penetration rates recorded by a built-in accelerometer. Key sequential events of the tool testing (marked in Figure 6.4 as well) can be summarized as:

1. Setting the tool vertical;

2. A first approach up to 5 meters water depth;

3. Stabilization at 5 meters depth and general check of electronics/sensors;

4. Descent to a maximum water depth of 20 meters at a rate of $2 \mathrm{~m} / \mathrm{min}$;

5. First touch to the sediment, tool stabilization, and electronics final check;

6. Sediment penetration (note: slight tilting of the tool was observed, as shown by the accelerations in $\mathrm{X}$ and $\mathrm{Y}$ directions);

7. Internal valve opened for fluid sampling (note the internal water pressure drop); 
8. Valve closed and tool recovery;

9. Travel through the water column;

10. Setting the tool horizontally on the deck.
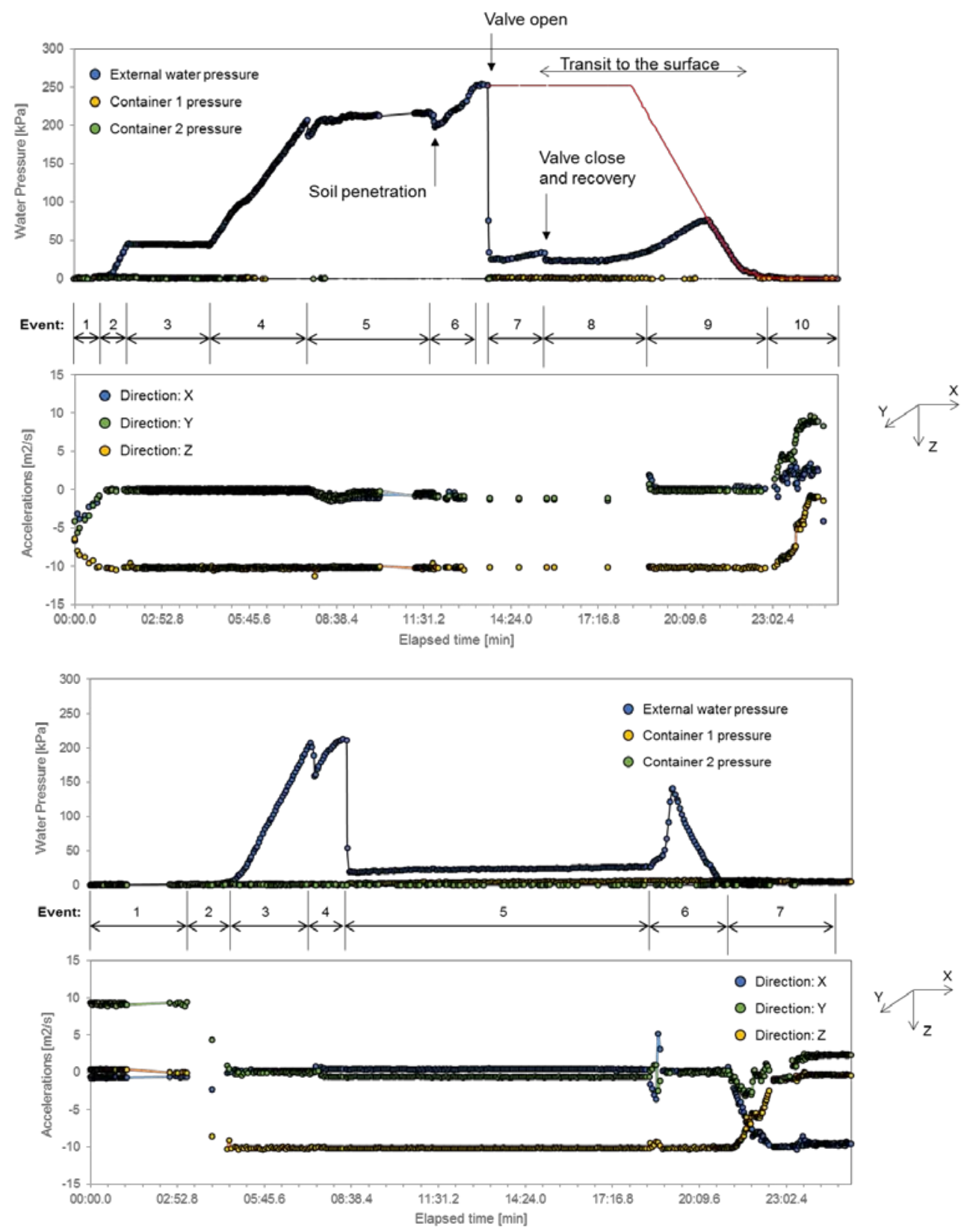

Figure 6.4 Measured water pressure and the 3-axis accelerator data during the two deployments.

\subsection{Deployment results, analyses, and tool improvement}


Penetration resistance. During the deployments, it was possible to obtain the penetration resistance up to 3.5 meters in the sediment. Figure 6.5 shows the obtained pressure reading and tip resistance signatures for this deployment. Results show a low penetration resistance of about $150 \mathrm{kPa}$ which can be expected for a non-dense material.

The pore water pressure decreases in the first meter of the sediments but tends to increase approaching the hydrostatic water pressure. This implies the sediments in the first meter may be fine-grained and subsequently followed by the sandy material to allow pore pressure recovery.

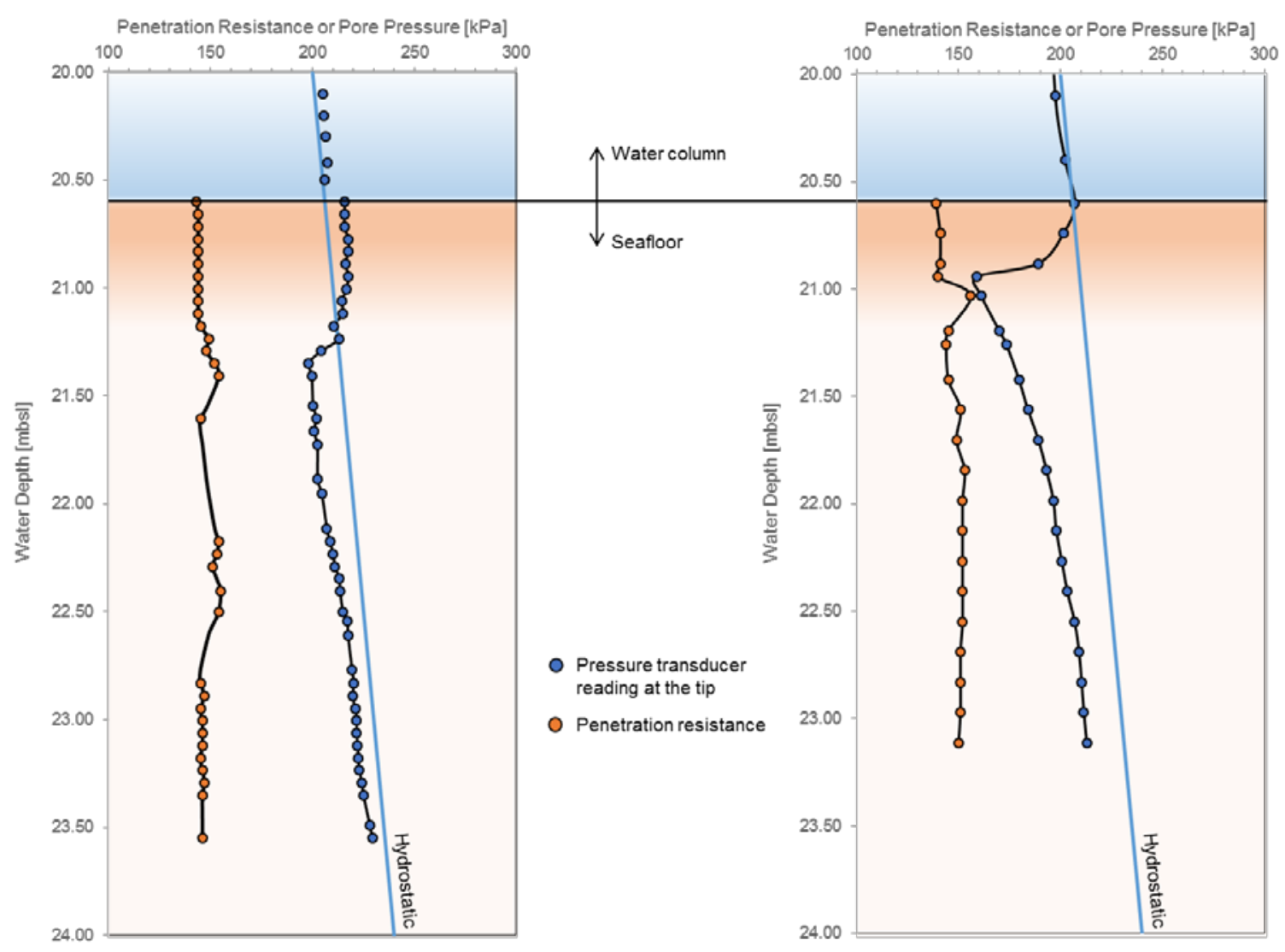

Figure 6.5 Penetration resistance obtained from the tool deployment.

Thermal properties. On the second deployment, two thermocouples located at the tip of the tool were continuously reading the temperature. Due to the high temperature at the ship's deck, the tool was able to reach a constant $34^{\circ} \mathrm{C}$ on the surface. After penetrating into the sediment, the tool liberated that heat to the sediment. Because of the high complexity of this system, a numerical simulation was performed to match those computed values with the ones measured. Figure 6.6 shows the COMSOL transient 
simulation at the initial condition, considering the properties of the tool (i.e., stainless steel) and iterating the sediment properties to match the recorded temperature.

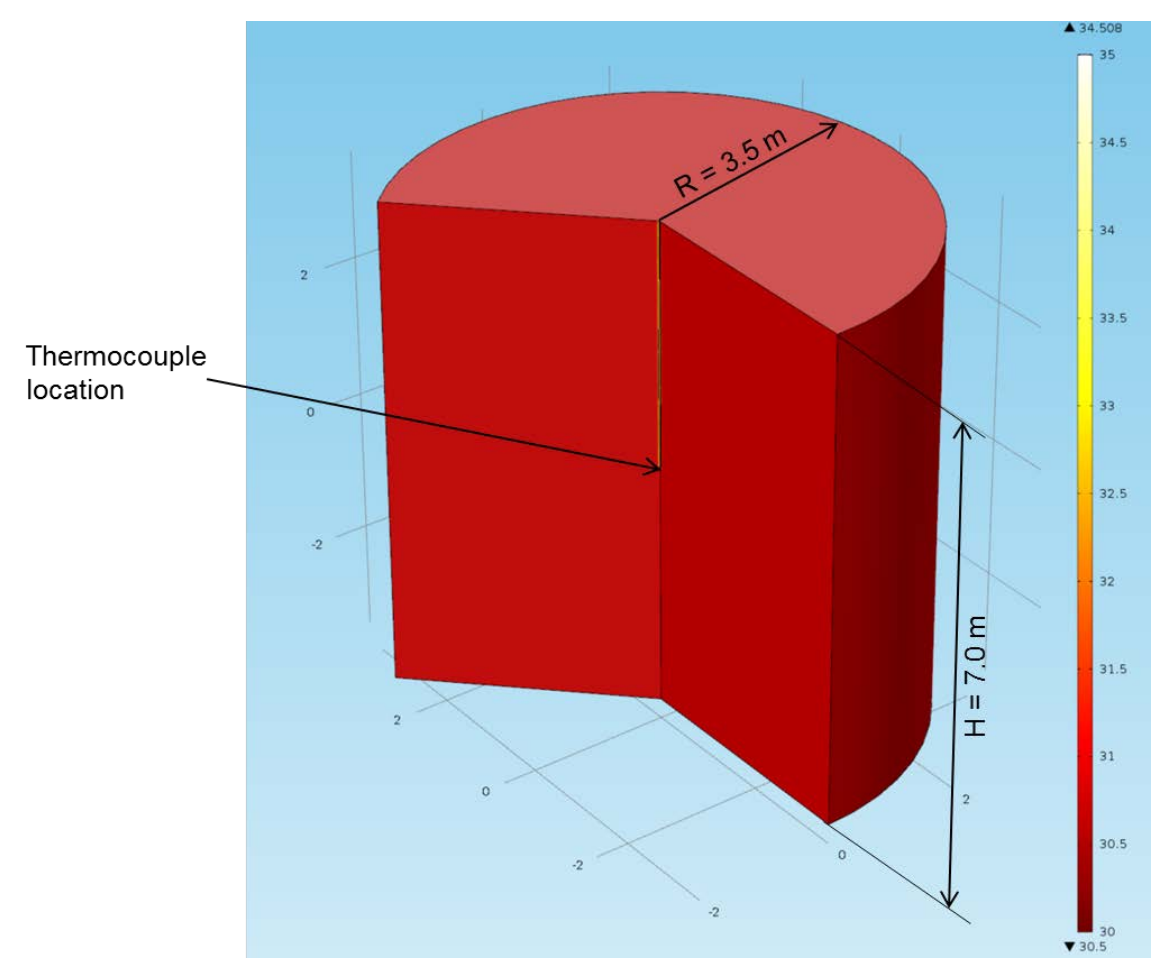

Figure 6.6 COMSOL numerical simulation of inverse sediments thermal properties. Dimensions of this model are shown here along with the initial conditions (i.e., tool at $33.75^{\circ} \mathrm{C}$ and sediment temperature at $30.5^{\circ} \mathrm{C}$ ) and the thermocouple location.

The thermal properties of any material can be described by its thermal conductivity $k$, specific heat capacity $c_{p}$ and density $\rho$. These parameters can be combined in the thermal diffusivity, defined as:

$$
\alpha=\frac{k}{\rho c_{p}}\left[\frac{m^{2}}{s}\right]
$$

Figure 6.7 shows the measured values from the two thermocouples and the simulation results using different assumed values of thermal diffusivity. Results show that the thermal diffusivity that best fits the measured data is approximately $10^{-6} \mathrm{~m}^{2} / \mathrm{s}$. Assuming a saturated loose soil with a density of $1500 \mathrm{~kg} / \mathrm{m}^{3}$ and a heat capacity of $1500 \mathrm{~J} / \mathrm{kg} / \mathrm{K}$, the thermal conductivity is then about $2.2 \mathrm{~W} / \mathrm{m} / \mathrm{K}$, which compares well with literature values of saturated soils. 


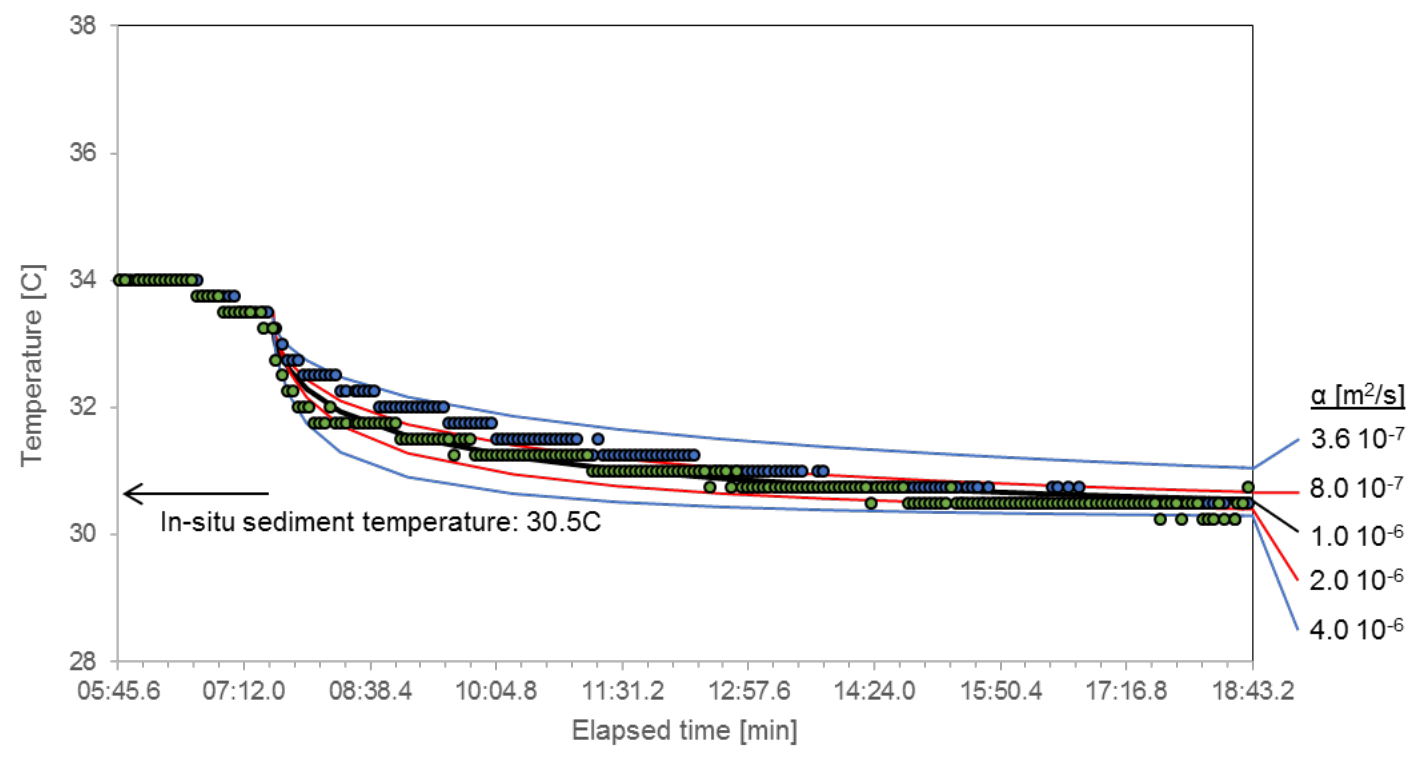

Figure 6.7 Thermal diffusivity of the Red Sea sediments on the selected test site. Blue and green dots represent the measured values, while the continuous lines are results of COMSOL simulations for this particular case with differently assumed diffusivities.

Fluid sampling and hydraulic conductivity. While the tool was positioned on the seafloor during the second deployment, an internal solenoid valve controlled by Arduino was opened for about 15 minutes to sample in situ pore fluids of about $20 \mathrm{ml}$ (Figure 6.8a). The valve was then closed. Further laboratory measurement of the sampled pore fluids shows a $\mathrm{pH}$ value of 7.5.

The pore fluids were sampled at a rate of $\sim 1.72 \mathrm{ml} / \mathrm{min}$. This system was simulated on a COMSOL model for determining the hydraulic conductivity of the tested sediments (Figure 6.8b). Figure 6.8c shows an interpretation chart based on numerical simulation results with assumed hydraulic conductivities for the three typical types of soils. Measured data is placed on this interpretation chart and the results suggest that the material tested behaves as a silty-clayey sediment. 


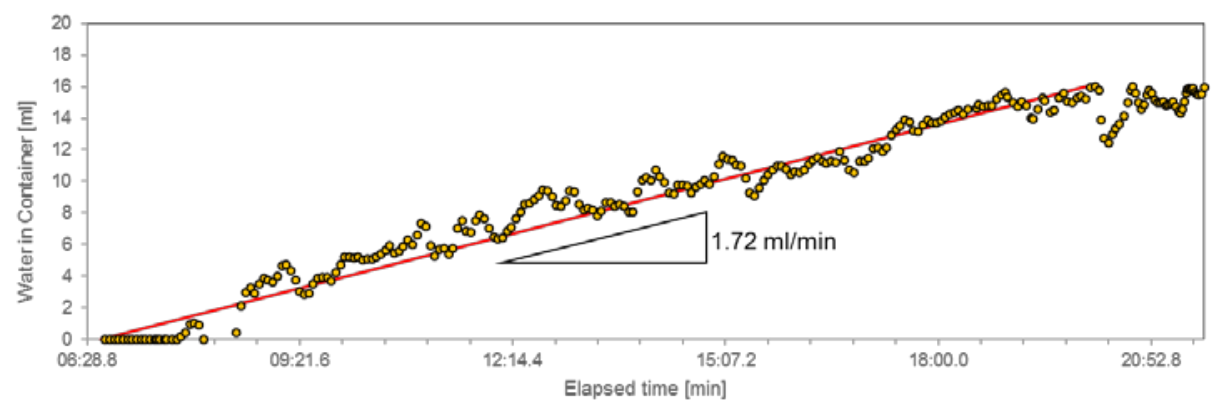

b)

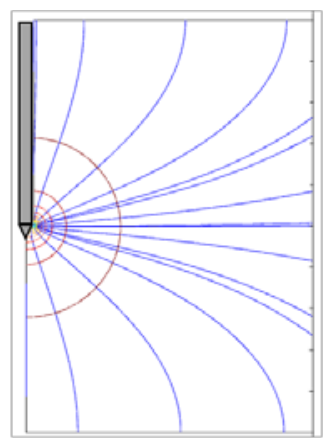

c)

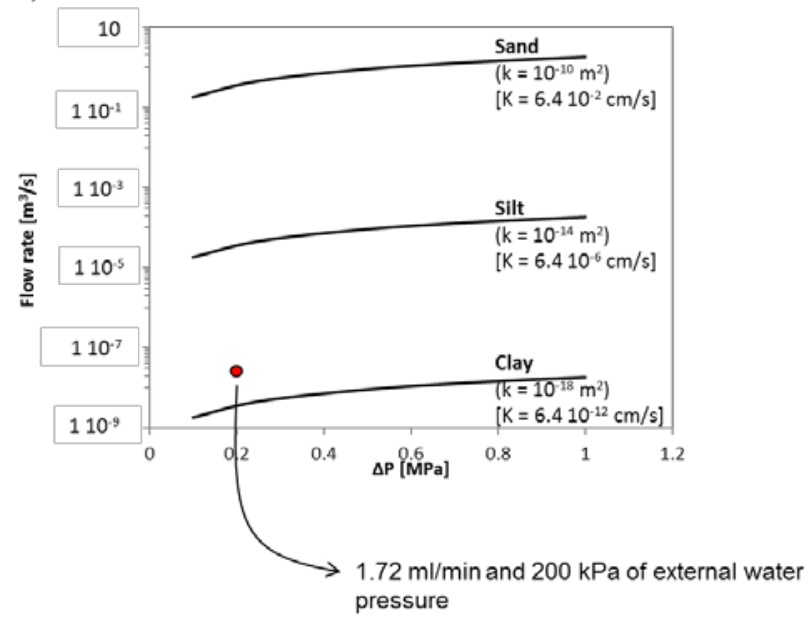

Figure 6.8 Hydraulic conductivity test. (a) Water volume in the container during sampling. (b) Numerical simulation on COMSOL. (c) Data interpretation.

Sediment sampling. The sediments are collected using the soil samplers. Two types of soil catchers were tested. The first type (red in Figure 6.9) is a 3D printed version with a stiff and brittle plastic, and the second type (white in Figure 6.9) is a machined soil catcher made of nylon. The second type showed slightly better elasticity performance. A total of 4 soil samples were recovered with volumes of $68,79,70$ and $65 \mathrm{~cm}^{3}$ respectively. The recovery factors (sampled soil volume over the inner volume of soil samplers) are 75, 88, 78 and $72 \%$, indicating good performance for both designs of soil catchers.

After the recovery, the tubes were stored in sealed plastic containers for extra tests to be performed in the laboratory. Grain size distribution (Figure 6.10) shows a fine sandy material with a high amount of silt and clay ( 20\%). A closer look at the particles, they seem to be very angular and a mean particle diameter similar to the one obtained from grain size distribution. Residuals of marine life were also present (Figure 6.10 inset). The specific surface was obtained using the methylene blue method and showed a value of $20.2 \mathrm{~m}^{2} / \mathrm{g}$, consistent with the grain size distribution. 


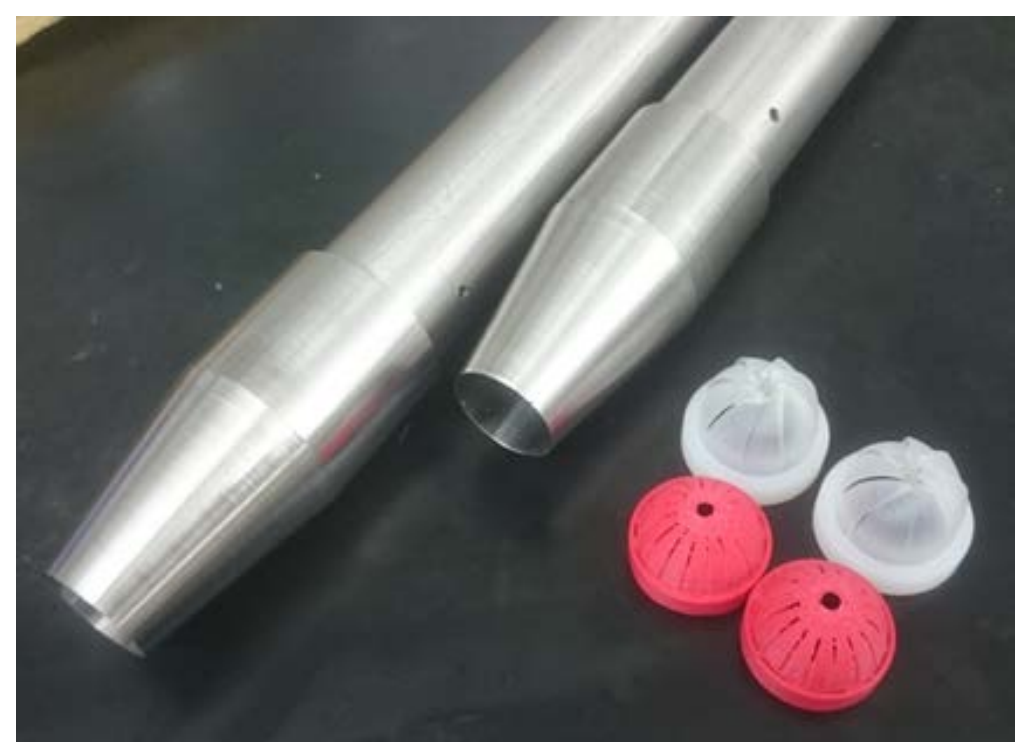

Figure 6.9 Soil samplers and soil catchers tested during the offshore field deployments.

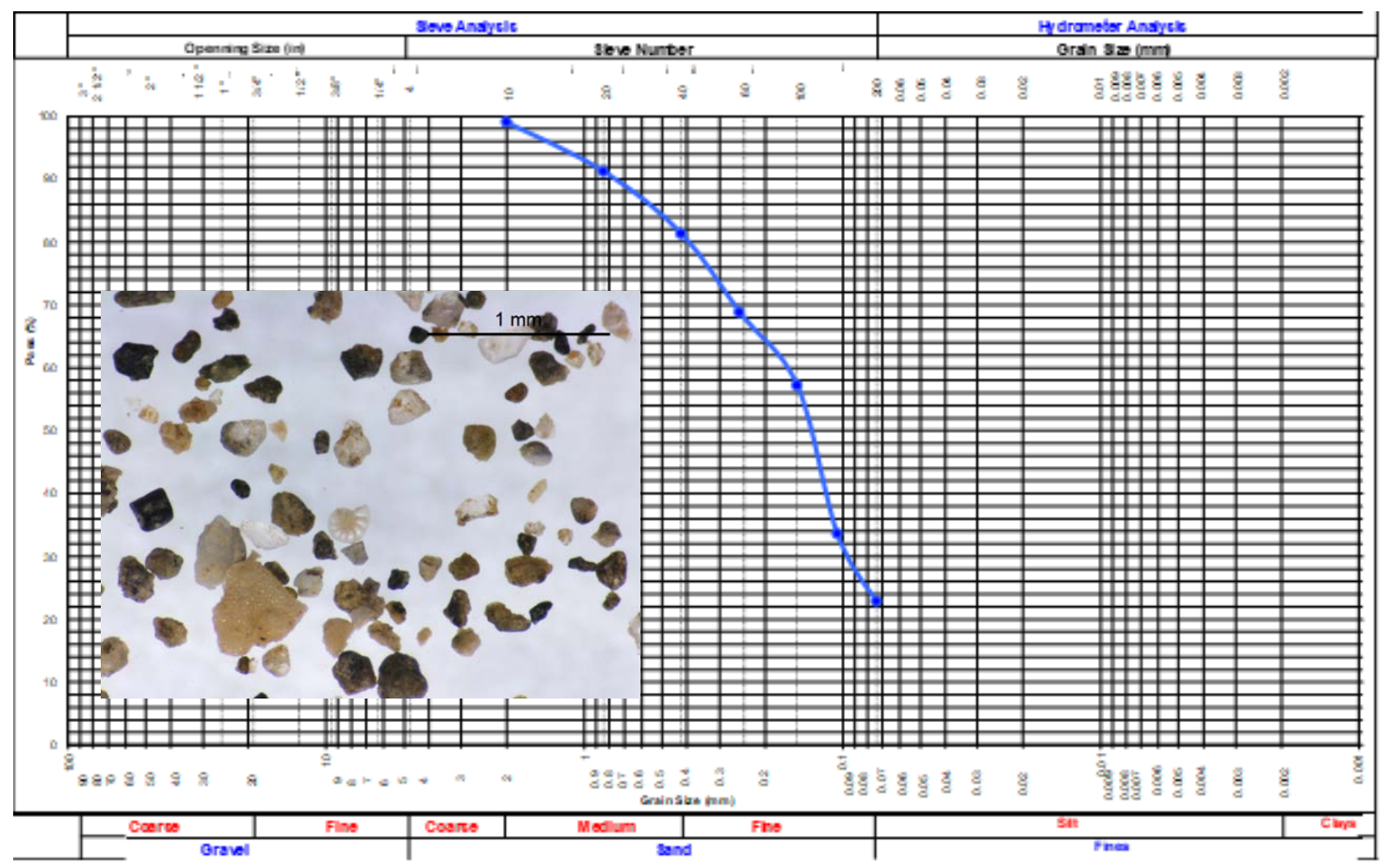

Figure 6.10 Grain size distribution of collected soil samples. The inset image shows the microscopic photo of collected sandy sediments. The particles are angular with mean grain size $\mathrm{d}_{50}$ $=\sim 0.15 \mathrm{~mm}$ in accordance with the grain size distribution. 


\section{Summary and conclusions}

This project analyzed the sampling disturbances to natural hydrate-bearing sediments and consequent alternations to their fundamental properties. All devices and equipment for the coring, storage, transfer, subsampling, and testing of natural hydrate-bearing sediments should acknowledge these underlying physics.

This project reviewed and updated the database of fundamental properties of hydratebearing sediments. Robust correlations with index parameters have been developed and incorporated into an elegant IT tool that uses limited input information to predict various physical properties of hydrate-bearing sediments with uncertainty analyses to provide optimal field characterization and input parameters for reservoir simulators.

This project developed a cone-based borehole tool to characterize hydrate-bearing sediments at in situ. The current testing capabilities of this tool include a force (or strength) module, a hydraulic module, an electrical module, a thermal module, a video module, and a sampling module. All moduli are designed with identical cross-sectional geometry, connection method, and built-in electronics, so that future development of new testing capabilities can easily add to this existing tool.

This borehole tool has been machined, assembled, and tested in the laboratory and the field. A coupler to connect this tool with bottom hole assembly was also developed to allow the characterization of marine sediments at a much greater depth than conventional offshore CTP characterization which is typically limited within the top 50 meters of seafloor sediments.

Some highlights from this research are listed as follows:

- Sampling disturbance is inevitable for natural sediments and the presence of hydrate exacerbate this situation;

- An IT knowledge database has been developed to predict fundamental physical, geomechanical, thermal, and hydraulic properties of hydrate-bearing sediments with uncertainty analyses;

- A CTP-based borehole tool for comprehensive characterization of natural hydrate deposits has been developed, with capabilities of measuring in situ pressure, temperature, pore fluids sampling and analyses, thermal conductivity, hydraulic conductivity, strength, and sediments sampling for later laboratory analyses of grain size distribution, fines content, mineralogy, and stress-strain responses. 


\section{Related activities}

\subsection{Training of highly qualified personnel}

- Dr. Terzariol, Marco (2015). Thesis: Laboratory and field characterization of hydrate-bearing sediments. Now a research scientist at KAUST.

- M.S. Yang, Fan (2017). Thermal conductivity module development. Now at ADP.

- Mr. Sun, Zhonghao, Ph.D. in progress

- Mr. Kim, Jongchan, Ph.D. in progress

- Mr. Go, Jinwoo, M.S. in progress

\subsection{Publications}

- Dai, S. and Santamarina, J.C., (2014). Sampling disturbance in hydrate-bearing sediment pressure cores: NGHP-01 expedition, Krishna-Godavari Basin example. Marine and Petroleum Geology, 58, pp.178-186.

- Dai, S., Lee, J. Y., Santamarina, J. C. (2014). Hydrate nucleation in quiescent and dynamic conditions. Fluid Phase Equilibria, 378, 107-112.

- Jang, J. and Santamarina, J. C. (2015). Fines Classification Based on Sensitivity to Pore-Fluid Chemistry. Journal of Geotechnical and Geoenvironmental Engineering, 142(4), 06015018.

- Terzariol, M. and Santamarina, J.C. (2016). Characterization and physical properties of hydrate-bearing sediments. AGU Fall Meeting Abstracts.

- Dai, S., and Santamarina, J.C., (2017). Stiffness evolution in frozen sands subjected to stress changes. Journal of Geotechnical and Geoenvironmental Engineering 143(9), 04017042.

- Yang, F. and Dai, S. (2017). Thermal properties measurements for hydrate-bearing sediments using a single-sided heat source. 9th International Conference on Gas Hydrates, June 25-30, 2017, Denver, CO.

- Dai, S., Boswell, R., Waite, W.F., Jang, J., Lee, J.Y., and Seol, Y. (2017). What has been learned from pressure cores. 9th International Conference on Gas Hydrates, Jun 25-30, 2017, Denver, CO.

- Terzariol, M., Goldsztein, G. and Santamarina, J.C., (2017). Maximum recoverable gas from hydrate-bearing sediments by depressurization. Energy, 141, pp.16221628.

- Santamarina, J.C. and Sun, Z. (2017). Mixed fluid conditions: capillary phenomena. Poromechanics VI, 70-89.

- Yang, F., Cortes, D., Dai, S. (2017) Thermal properties measurement using singlesided transient plane source method. Applied Physics Letters (in preparation). 


\section{Reference}

Buonaccorsi, J. P. (1995), Prediction in the presence of measurement error: general discussion and an example predicting defoliation, Biometrics, 1562-1569.

Burns, S., and P. Mayne (1998), Monotonic and dilatory pore-pressure decay during piezocone tests in clay, Canadian Geotechnical Journal, 35(6), 1063-1073.

Burns, S., and P. Mayne (1999), Pore Pressure Dissipation Behavior Surrounding Driven Piles and Cone Penetrometers, Transportation Research Record: Journal of the Transportation Research Board, 1675(-1), 17-23.

Chirlin, G. R. (1989), A critique of the Hvorslev method for slug test analysis: The fully penetrating well, Groundwater Monitoring \& Remediation, 9(2), 130-138.

Cho, G., J. Lee, and J. Santamarina (2004), Spatial Variability in Soils: High Resolution Assessment with Electrical Needle Probe, Journal of Geotechnical and Geoenvironmental Engineering, 130(8), 843-850, doi:doi:10.1061/(ASCE)10900241(2004)130:8(843).

Coleman, H. W., and W. G. Steele (2009), Experimentation, validation, and uncertainty analysis for engineers, John Wiley \& Sons.

Collett, T. S., M. W. Lee, M. V. Zyrianova, S. A. Mrozewski, G. Guerin, A. E. Cook, and D. S. Goldberg (2012), Gulf of Mexico Gas Hydrate Joint Industry Project Leg II logging-while-drilling data acquisition and analysis, Marine and Petroleum Geology, 34(1), 41-61.

Cook, R. D., and S. Weisberg (1999), Graphs in statistical analysis: Is the medium the message?, The American Statistician, 53(1), 29-37.

Cortes, D. D., A. I. Martin, T. S. Yun, F. M. Francisca, J. C. Santamarina, and C. Ruppel (2009), Thermal conductivity of hydrate-bearing sediments, J. Geophys. Res., 114(B11), B11103, doi:10.1029/2008jb006235.

Dai, S., R. Boswell, W. F. Waite, J. Jang, J. Y. Lee, and Y. Seol (2017), What Has Been Learned From Pressure Cores, paper presented at Proceedings, 9th International Conference on Gas Hydrates.

Dai, S., J. H. Cha, E. J. Rosenbaum, W. Zhang, and Y. Seol (2015), Thermal conductivity measurements in unsaturated hydrate-bearing sediments, Geophysical Research Letters, 42(15), 6295-6305.

Dai, S., and J. C. Santamarina (2014), Sampling disturbance in hydrate-bearing sediment pressure cores: NGHP-01 expedition, Krishna-Godavari Basin example, Marine and Petroleum Geology, 58, 178-186.

Hryciw, R., A. Ghalib, and S. Raschke (1998), In situ soil characterization using Vision Cone Penetrometer (VisCPT), Proc. 1st IC on Site Characterization, Atlanta, 2, 10811086.

Hryciw, R., and S. Raschke (1996), Development of computer vision technique for in situ soil characterization, Transportation Research Record: Journal of the Transportation Research Board(1526), 86-97.

Hvorslev, M. J. (1951), Time lag and soil permeability in ground-water observations.

Jefferies, M., L. J* onsson, and K. Been (1987), Experience with measurement of horizontal geostatic stress in sand during cone penetration test profiling, Géotechnique, 37(4), 483-498. 
Lee, M. W., and T. S. Collett (2011), In-situ gas hydrate hydrate saturation estimated from various well logs at the Mount Elbert Gas Hydrate Stratigraphic Test Well, Alaska North Slope, Marine and Petroleum Geology, 28(2), 439-449.

Lunne, T. (2012), The Fourth James K. Mitchell Lecture: The CPT in offshore soil investigations-a historic perspective, Geomechanics and Geoengineering, 7(2), 75101.

Lunne, T., K. H. Andersen, H. E. Low, M. F. Randolph, and M. Sjursen (2011), Guidelines for offshore in situ testing and interpretation in deepwater soft clays, Canadian geotechnical journal, 48(4), 543-556.

Mathias, S., and A. Butler (2006), Linearized Richards' equation approach to pumping test analysis in compressible aquifers, Water resources research, 42(6).

McBratney, A. B., B. Minasny, S. R. Cattle, and R. W. Vervoort (2002), From pedotransfer functions to soil inference systems, Geoderma, 109(1), 41-73.

Miyazaki, K., A. Masui, Y. Sakamoto, K. Aoki, N. Tenma, and T. Yamaguchi (2011), Triaxial compressive properties of artificial methane-hydrate-bearing sediment, Journal of Geophysical Research: Solid Earth (1978-2012), 116(B6).

Miyazaki, K., N. Tenma, K. Aoki, and T. Yamaguchi (2012), A nonlinear elastic model for triaxial compressive properties of artificial methane-hydrate-bearing sediment samples, Energies, 5(10), 4057-4075.

Moridis, G., T. S. Collett, M. Pooladi-Darvish, S. H. Hancock, C. Santamarina, R. Boswell, T. J. Kneafsey, J. Rutqvist, M. B. Kowalsky, and M. T. Reagan (2011), Challenges Uncertainties and Issues Facing Gas Production From Gas-Hydrate Deposits, SPE Reservoir Evaluation \& Engineering, 14(01), 76-112.

Priest, J. A., E. V. L. Rees, and C. R. I. Clayton (2009), Influence of gas hydrate morphology on the seismic velocities of sands, J. Geophys. Res., 114(B11), B11205, doi:10.1029/2009jb006284.

Randolph, M., and S. Gourvenec (2011), Offshore geotechnical engineering, CRC Press.

Raschke, S. A., and R. D. Hryciw (1997), Vision cone penetrometer for direct subsurface soil observation, Journal of geotechnical and geoenvironmental engineering, 123(11), 1074-1076.

Rawlings, J. B., and D. Q. Mayne (2009), Model predictive control: Theory and design, Nob Hill Pub.

Rosenbaum, E. J., N. J. English, J. K. Johnson, D. W. Shaw, and R. P. Warzinski (2007), Thermal Conductivity of Methane Hydrate from Experiment and Molecular Simulation, The Journal of Physical Chemistry B, 111(46), 13194-13205, doi:10.1021/jp074419o.

Santamarina, J. C., S. Dai, J. Jang, and M. Terzariol (2012), Pressure Core Characterization Tools for Hydrate-Bearing Sediments, Scientific Drilling, 14, 44-48, doi:10.2204/iodp.sd.2214.2206.2012, doi:10.2204/iodp.sd.14.06.2012.

Santamarina, J. C., and C. Ruppel (2008), The impact of hydrate saturation on the mechanical, electrical, and thermal properties of hydrate-bearing sand, silts, and clay, paper presented at the 6th International Conference on Gas Hydrate, Vancouver, British Columbia, Canada, July 6-10.

Schultheiss, P. J., et al. (2006), Pressure coring, logging and subsampling with the HYACINTH system, Geological Society, London, Special Publications, 267(1), 151163, doi:10.1144/gsl.sp.2006.267.01.11. 
Sloan, E. D., and C. A. Koh (2008), Clathrate hydrates of natural gases, 3rd ed., CRC Press, Boca Raton.

Steiner, A., J.-S. L'Heureux, A. Kopf, M. Vanneste, O. Longva, M. Lange, and H. Haflidason (2012), An in-situ free-fall piezocone penetrometer for characterizing soft and sensitive clays at Finneidfjord (Northern Norway), in Submarine mass movements and their consequences, edited, pp. 99-109, Springer.

Sun, Y., D. Goldberg, T. Collett, and R. Hunter (2011), High-resolution well-log derived dielectric properties of gas-hydrate-bearing sediments, Mount Elbert Gas Hydrate Stratigraphic Test Well, Alaska North Slope, Marine and Petroleum Geology, 28(2), 450-459.

Torstensson, B.-A. (1984), Device for taking ground water samples in soil and rock, edited, Google Patents.

Von Herzen, R., and A. Maxwell (1959), The measurement of thermal conductivity of deep-sea sediments by a needle-probe method, Journal of Geophysical Research, 64(10), 1557-1563.

Waite, W. F., B. deMartin, S. Kirby, J. Pinkston, and C. Ruppel (2002), Thermal conductivity measurements in porous mixtures of methane hydrate and quartz sand, Geophysical Research Letters, 29(24), 82-81-82-84.

Waite, W. F., et al. (2009), Physical properties of hydrate-bearing sediments, Rev. Geophys., 47(4), RG4003, doi:10.1029/2008rg000279.

Yoneda, J., A. Masui, N. Tenma, and J. Nagao (2013), Triaxial testing system for pressure core analysis using image processing technique, Review of Scientific Instruments, 84(11), 114503. 


\section{National Energy Technology Laboratory}

626 Cochrans Mill Road

P.O. Box 10940

Pittsburgh, PA 15236-0940

3610 Collins Femy Road

P.O. Box 880

Morgantown, WV 26507-0880

13131 Dairy Ashford Road, Suite 225

Suga r Land, TX 77478

1450 Queen Avenue SW

Albany, OR 97321-2198

Arc tic Energy Office

420 L Street, Suite 305

Anchorage, AK 99501

Visit the NERL website at:

www.netl.doe.gov

Customer Service Line:

1-800-553-7681 